\title{
Imaging of cerebrovascular pathology in animal models of Alzheimer's disease
}

\author{
Jan Klohs ${ }^{1,2}$, Markus Rudin ${ }^{1,2,3}$, Derya R. Shimshek ${ }^{4}$ and Nicolau Beckmann ${ }^{5 *}$ \\ Institute for Biomedical Engineering, University of Zurich and ETH Zurich, Zurich, Switzerland \\ ${ }^{2}$ Neuroscience Center Zurich, University of Zurich and ETH Zurich, Zurich, Switzerland \\ ${ }^{3}$ Institute of Pharmacology and Toxicology, University of Zurich, Zurich, Switzerland \\ ${ }^{4}$ Autoimmunity, Transplantation and Inflammation/Neuroinflammation Department, Novartis Institutes for BioMedical Research, Basel, Switzerland \\ ${ }^{5}$ Analytical Sciences and Imaging, Novartis Institutes for BioMedical Research, Basel, Switzerland
}

\section{Edited by:}

Paula I. Moreira, University of

Coimbra, Portugal

\section{Reviewed by:}

Marc Dhenain, Commissariat à

I'Énergie Atomique, France

Sylvia Villeneuve, University of

California, Berkeley, USA

*Correspondence:

Nicolau Beckmann, Analytical

Sciences and Imaging, Novartis

Institutes for BioMedical Research,

Forum 1, Novartis Campus,

WSJ-386.2.09, CH-4056 Basel,

Switzerland

e-mail:nicolau.beckmann@

novartis.com
In Alzheimer's disease (AD), vascular pathology may interact with neurodegeneration and thus aggravate cognitive decline. As the relationship between these two processes is poorly understood, research has been increasingly focused on understanding the link between cerebrovascular alterations and $A D$. This has at last been spurred by the engineering of transgenic animals, which display pathological features of $A D$ and develop cerebral amyloid angiopathy to various degrees. Transgenic models are versatile for investigating the role of amyloid deposition and vascular dysfunction, and for evaluating novel therapeutic concepts. In addition, research has benefited from the development of novel imaging techniques, which are capable of characterizing vascular pathology in vivo. They provide vascular structural read-outs and have the ability to assess the functional consequences of vascular dysfunction as well as to visualize and monitor the molecular processes underlying these pathological alterations. This article focusses on recent in vivo small animal imaging studies addressing vascular aspects related to $A D$. With the technical advances of imaging modalities such as magnetic resonance, nuclear and microscopic imaging, molecular, functional and structural information related to vascular pathology can now be visualized in vivo in small rodents. Imaging vascular and parenchymal amyloid- $\beta(A \beta)$ deposition as well as $A \beta$ transport pathways have been shown to be useful to characterize their dynamics and to elucidate their role in the development of cerebral amyloid angiopathy and AD. Structural and functional imaging read-outs have been employed to describe the deleterious affects of $A \beta$ on vessel morphology, hemodynamics and vascular integrity. More recent imaging studies have also addressed how inflammatory processes partake in the pathogenesis of the disease. Moreover, imaging can be pivotal in the search for novel therapies targeting the vasculature.

Keywords: Alzheimer's disease (AD), amyloid-beta (A $\beta)$, angiography, cerebral amyloid angiopathy (CAA), cerebral blood flow (CBF), magnetic resonance imaging (MRI), microscopy, transgenic mice

\section{INTRODUCTION TO CEREBROVASCULAR PATHOLOGY IN ALZHEIMER'S DISEASE}

Alzheimer's disease (AD) is the most common form of dementia in elderly individuals. The disease has been classically viewed as the accumulation of amyloid- $\beta(\mathrm{A} \beta)$, generated by proteolytic cleavage of the amyloid precursor protein (APP), in the brain parenchyma ( $\mathrm{A} \beta$ plaques), leading to $\mathrm{A} \beta$-related neuropathology and loss of cognitive function (Hardy and Selkoe, 2002). Increasing evidence has implicated cerebrovascular dysfunction in the etiology of the disease (for reviews see Thal et al., 2008a,b; Bell and Zlokovic, 2009; Weller et al., 2009; Biffi and Greenberg, 2011). Epidemiological studies indicate a strong overlap between $\mathrm{AD}$ pathology and cardiovascular disease, suggesting that they might share common mechanisms and risk factors. Among all cerebrovascular comorbidities in $\mathrm{AD}$, cerebral amyloid angiopathy (CAA) is the most common pathological finding, present in up to $90 \%$ of AD patients (Vinters, 1987; Jellinger, 2002).
CAA results from the failure to eliminate $A \beta$ from the cerebral vasculature (Weller et al., 2009). Both AD and CAA can lead to pronounced cerebrovascular dysfunction, characterized by impaired neurovascular and metabolic regulation of cerebral blood flow (CBF) and aberrations in vascular morphology and density. In addition, changes in the proteolytic microenvironment and inflammation lead to impairment of blood-brain barrier (BBB) integrity and the occurrence of cerebral microbleeds (CMBs) and intracerebral hemorrhages (Snowdon, 2003; Cordonnier and van der Flier, 2011). It has been suggested that the vascular pathology may mutually interact with neurodegeneration in $\mathrm{AD}$, and thus aggravate cognitive decline, though the relationship between these two processes is poorly understood. Hence, recent research has been increasingly focused on understanding the link between cerebrovascular alterations and $\mathrm{AD}$. This has on one hand been spurred by the engineering of transgenic animals, which display pathological features of $\mathrm{AD}$ and 
develop CAA to various degrees. These models have been proven versatile for elucidating the role of amyloid deposition, vascular dysfunction and for evaluating novel therapeutic concepts. On the other hand, research has benefited from the development of novel imaging techniques, which are capable of characterizing vascular pathology in vivo. They provide vascular structural read-outs and have the ability to assess the functional consequences of vascular dysfunction as well as to visualize and monitor the molecular processes underlying these pathological alterations.

This article focusses on recent in vivo small animal imaging studies addressing vascular aspects related to AD. We first introduce transgenic mouse models of AD displaying CAA and their main characteristics, followed by a summary of the current imaging techniques and discuss their advantages and limitations. The potential of imaging vascular pathology will be illustrated by discussing applications on the visualization of vascular amyloid deposition and amyloid clearance pathways, the assessment of the cerebrovascular architecture to elucidate the dynamics and mechanism of CAA and to understand how amyloid deposition induces vascular remodeling. The use of functional imaging read-outs to monitor the deleterious consequences of amyloid deposition, namely chronic hypoperfusion and reduced hemodynamic response are presented. The role of neurovascular inflammation, loss of BBB as well as CMBs in advanced stages of the disease are then addressed. The fact that CAA may be halted or even reversed is evaluated by a glance on therapeutic studies involving the animal models. Finally, we evaluated how biological lessons learned from these models may be translated into the clinic.

\section{TRANSGENIC MODELS OF ALZHEIMER'S DISEASE DISPLAYING CEREBRAL AMYLOID ANGIOPATHY}

To date, several mouse and rat lines have been genetically engineered to serve as preclinical models for AD. Most of these models have been generated by transgenic overexpression of the gene encoding for the human APP, which leads to progressive accumulation of $A \beta$ and amyloidosis in the brain. Some of these strains develop CAA to various degrees, which allow studying the effect of $A \beta$ accumulation on vascular function. Further strains have been established addressing the other pathological hallmark of $\mathrm{AD}$, neurofibrillary tangles, by expressing different forms of tau (Gotz et al., 1995; Duff et al., 2000; Allen et al., 2002; SantaCruz et al., 2005). Furthermore, mouse models with multiple mutations have also been engineered, e.g., APP/PS1 and 3xTg-AD, to study either the enhancement of amyloid pathology by presenilin mutations or the interaction between amyloid and tau (Blanchard et al., 2003; Oddo et al., 2003a,b). However, most studies utilize strains with a single mutation, which have the advantage of assessing one pathological process at a time without being confounded by the complex pathophysiology of sporadic AD. Transgenic mouse models are very valuable for drug discovery as the pathology usually develops within months (as compared to years or decades in AD patients) and disease pathological stages are well characterized.

Mice overexpressing APP have been utilized as valid models for CAA (summarized in Table 1). These transgenic models use various promoters to drive transgene expression in different genetic backgrounds. Interestingly, it has been shown that neuronal A $\beta$ is the driver for CAA (Calhoun et al., 1999) and an impaired $A \beta$ clearance seems to enhance CAA (Herzig et al., 2004). Early onset CAA is observed in models with multiple autosomal dominant mutations like Thyl-APP751, Tg-SwDI, TgCRND8, whereas late-onset CAA ( $>9$ months of age) is usually detected in mice with expression of mutated APP restricted to one familiar mutation as in Tg2576, PDAPP, APPDutch, APP/London, APP23, or TgAPPArc animals. CAA is observed earlier in mice that additionally carry a presenilin mutation like APPswe/PS1dE9 or Thy1-APP751SLxHMG-PS1M146L.

Experimental evidence suggests that total levels of $A \beta$ as well as the ratio of the $A \beta_{40}$ and $A \beta_{42}$ peptides $\left(A \beta_{40} / A \beta_{42}\right)$, generated by proteolytic cleavage of $\beta$ - and $\gamma$-secretase, are factors determining both onset and the severity of CAA (Herzig et al., 2004, 2007; for reviews see Herzig et al., 2006; KumarSingh, 2009). APPDutch animals displaying a very high ratio of $\mathrm{A} \beta_{40} / \mathrm{A} \beta_{42}$ develop severe CAA (Herzig et al., 2004), indicating that the majority of $A \beta$ deposited in vascular deposits is $A \beta_{40}$. Furthermore, APP23xAPPDutch double transgenic animals with an overall increase of $A \beta$ load and a high ratio $A \beta_{40} / A \beta_{42}$ show enhanced CAA compared to APP23 single transgenic mice. In contrast, APPDutchxPS45 with a lower $A \beta_{40} / A \beta_{42}$ ratio develop more pronounced parenchymal than vascular deposits (Herzig et al., 2004). Also, autosomal dominant mutations with reduced $\mathrm{A} \beta_{40} / \mathrm{A} \beta_{42}$ ratio such as the Indiana mutation in PDAPP and APP/London mice display less pronounced CAA. These observations are in line with findings in hereditary cerebral hemorrhage patients with amyloidosis of the Dutch type. Individuals with this rare autosomal dominant disorder, caused by an APP 693 mutation that leads to recurrent hemorrhagic strokes and dementia, have decreased $A \beta_{42}$ levels in the brain (Bornebroek et al., 2003). However, contrasting data have been reported for the BRI-A $\beta_{42}$ animals, where overexpression solely of $A \beta_{42}$ led to CAA, while overexpression of $A \beta_{40}$ did not (McGowan et al., 2005). Other reports suggested that $A \beta_{40}$ can inhibit fibril formation and even inhibit amyloid deposition (Jarrett et al., 1993; Kim et al., 2007). Taken together, most studies indicate that $A \beta_{42}$ might be essential for the initial amyloid deposition in vessels and that an increase of overall total $A \beta$ as well as of the $A \beta_{40} / A \beta_{42}$ ratio favors subsequent vascular $A \beta$ load.

In this review, we focus on effects of $A \beta$ on the cerebral vasculature and the consequences thereof. Since the transgenic $\mathrm{AD}$ models exhibit quite different levels of CAA vs. neuritic $\mathrm{A} \beta$ deposits, they enable studying the effect of these processes on $\mathrm{AD}$ pathology.

\section{IMAGING MODALITIES FOR THE CHARACTERIZATION OF CEREBRAL VASCULATURE}

Multimodal imaging offers an impressive number of approaches for characterizing cerebral vasculature from the cellular to the whole organ scale (Table 2). The dimensions of cerebral vessels span a range of 2-3 orders of magnitude with large arteries and veins of dimensions of approximately $1 \mathrm{~mm}$ to capillaries with typical diameters of 5-10 $\mu \mathrm{m}$. Correspondingly, the phenotypic 
Table 1 | Summary of transgenic models used in AD research and their relation to CAA development.

\begin{tabular}{|c|c|c|c|c|c|c|c|c|}
\hline $\begin{array}{l}\text { Line } \\
\text { (Alternative } \\
\text { designation) }\end{array}$ & $\begin{array}{l}\text { Construct } \\
\text { Promoter }\end{array}$ & $\begin{array}{l}\text { Familial } \\
\text { APP AD } \\
\text { mutation }\end{array}$ & $\begin{array}{l}\text { Onset of } \\
\text { amyloid } \\
\text { plaques }\end{array}$ & $\begin{array}{c}\text { CAA } \\
\text { onset }\end{array}$ & $\begin{array}{c}\text { CAA } \\
\text { severity }\end{array}$ & $\begin{array}{l}\text { Neuronal } \\
\text { loss }\end{array}$ & $\begin{array}{l}\text { Cognitive } \\
\text { defects }\end{array}$ & References \\
\hline $\begin{array}{l}\text { Tg2576 } \\
\text { (APPsw) }\end{array}$ & $\begin{array}{l}\text { hAPP695 } \\
\text { K670N/M671L } \\
\text { HamPrP }\end{array}$ & Swe & 7-10 mo & 9-12 mo & ++ & No & Yes & $\begin{array}{l}\text { Hsiao et al., 1996; Fryer } \\
\text { et al., 2003; Domnitz } \\
\text { et al., 2005; Kumar-Singh } \\
\text { et al., 2005; Perez-Cruz } \\
\text { et al., } 2011\end{array}$ \\
\hline $\begin{array}{l}\text { Thy1-APP751 } \\
\text { (TASD-41, mThy1- } \\
\text { hAßPP751) }\end{array}$ & $\begin{array}{l}\text { hAPP751 } \\
\text { K670M/N671L/N717I } \\
\text { mThy1 }\end{array}$ & $\begin{array}{l}\text { Swe } \\
\text { Lon }\end{array}$ & $3-4 \mathrm{mo}$ & 5-7 mo & + & No & Yes & $\begin{array}{l}\text { Rockenstein et al., 2001; } \\
\text { Havas et al., } 2011\end{array}$ \\
\hline $\begin{array}{l}\text { ArcAbeta } \\
(\operatorname{ArcA\beta })\end{array}$ & $\begin{array}{l}\text { hAPP695 K670N/M671L/E693G } \\
\text { MoPrP }\end{array}$ & $\begin{array}{l}\text { Swe } \\
\text { Arc }\end{array}$ & 5-7 mo & $9-15$ mo & +++ & No & Yes & $\begin{array}{l}\text { Knobloch et al., 2007; } \\
\text { Klohs et al., } 2012\end{array}$ \\
\hline TgCRND8 & $\begin{array}{l}\text { hAPP695 KM670/671NL/N717F } \\
\text { HamPrP }\end{array}$ & $\begin{array}{l}\text { Swe } \\
\text { Ind }\end{array}$ & $3 \mathrm{mo}$ & 6-7 mo & ++ & No & Yes & $\begin{array}{l}\text { Chishti et al., 2001; } \\
\text { Domnitz et al., 2005; } \\
\text { Lovasic et al., } 2005\end{array}$ \\
\hline PDAPP & $\begin{array}{l}\text { hAPP full-length } \\
\text { V717F } \\
\text { PDGFb }\end{array}$ & Ind & $6-9 \mathrm{mo}$ & $10-12 \mathrm{mo}$ & + & n.a. & Yes & $\begin{array}{l}\text { Games et al., 1995; } \\
\text { Dodart et al., 1999; Chen } \\
\text { et al., 2000; Fryer et al., } \\
\text { 2003; Nilsson et al., } \\
\text { 2004; Domnitz et al., } \\
\text { 2005; Hartman et al., } \\
\text { 2005; Daumas et al., } \\
\text { 2008; Schroeter et al., } \\
2008\end{array}$ \\
\hline $\begin{array}{l}\text { APP/London } \\
\text { (APP/Lo, } \\
\text { APP(V717I), } \\
\text { APP-Ld, APP/Ld, } \\
\text { APPN717I, } \\
\text { APP[V717I]) }\end{array}$ & $\begin{array}{l}\text { hAPP695 } \\
\text { V717I } \\
\text { mThy1 }\end{array}$ & Lon & 10-11 mo & $12-15 \mathrm{mo}$ & ++ & No & Yes & $\begin{array}{l}\text { Moechars et al., 1999; } \\
\text { Dewachter et al., 2000; } \\
\text { van Dorpe et al., 2000; } \\
\text { Tanghe et al., 2010; } \\
\text { Perez-Cruz et al., } 2011\end{array}$ \\
\hline BRI-Aß42 & $\begin{array}{l}\text { BRI-Ab42 fusion } \\
\text { MoPrP }\end{array}$ & & $3 \mathrm{mo}$ & $12 \mathrm{mo}$ & ++ & n.a. & n.a. & McGowan et al., 2005 \\
\hline $\begin{array}{l}\text { APPArcSwe } \\
\text { (tg-APP(ArcSwe), } \\
\text { TgArcSwe) }\end{array}$ & $\begin{array}{l}\text { hAPP } \\
\text { KM670/671NL/E693G } \\
\text { mThy1 }\end{array}$ & $\begin{array}{l}\text { Swe } \\
\text { Arc }\end{array}$ & 5-6 mo & $9 \mathrm{mo}$ & + & n.a. & n.a. & Lord et al., 2006 \\
\hline J20 hAPP & $\begin{array}{l}\text { hAPP } \\
\text { K670N/M671LN717F } \\
\text { PDGFb }\end{array}$ & $\begin{array}{l}\text { Swe } \\
\text { Ind }\end{array}$ & 5-7 mo & $<11 \mathrm{mo}$ & + & Yes & Yes & $\begin{array}{l}\text { Mucke et al., 2000; } \\
\text { Spilman et al., 2010; } \\
\text { Thanopoulou et al., 2010; } \\
\text { Wright et al., } 2013\end{array}$ \\
\hline
\end{tabular}


Table 1 | Continued

\begin{tabular}{|c|c|c|c|c|c|c|c|c|}
\hline $\begin{array}{l}\text { Line } \\
\text { (Alternative } \\
\text { designation) }\end{array}$ & $\begin{array}{l}\text { Construct } \\
\text { Promoter }\end{array}$ & $\begin{array}{l}\text { Familial } \\
\text { APP AD } \\
\text { mutation }\end{array}$ & $\begin{array}{l}\text { Onset of } \\
\text { amyloid } \\
\text { plaques }\end{array}$ & $\begin{array}{l}\text { CAA } \\
\text { onset }\end{array}$ & $\begin{array}{c}\text { CAA } \\
\text { severity }\end{array}$ & $\begin{array}{l}\text { Neuronal } \\
\text { loss }\end{array}$ & $\begin{array}{l}\text { Cognitive } \\
\text { defects }\end{array}$ & References \\
\hline $\begin{array}{l}\text { APP23 } \\
X \\
\text { APPDutch }\end{array}$ & $\begin{array}{l}\text { hAPP751 } \\
\text { K670N/M671L } \\
X \\
\text { E6930 } \\
\text { mThy1 }\end{array}$ & $\begin{array}{l}\text { Swe } \\
\text { Dut }\end{array}$ & n.a. & n.a. & +++ & n.a. & n.a. & Herzig et al., 2009 \\
\hline $\begin{array}{l}\text { tTA/APP } \\
\text { (APP/TTA) }\end{array}$ & $\begin{array}{l}\text { m/hAPP695 } \\
\text { K570M/N571LN617F } \\
\text { tet }\end{array}$ & $\begin{array}{l}\text { Swe } \\
\text { Ind }\end{array}$ & $6 \mathrm{mo}$ & n.a. & n.a. & n.a. & Yes & $\begin{array}{l}\text { Jankowsky et al., 2005; } \\
\text { Melnikova et al., } 2013\end{array}$ \\
\hline \multicolumn{9}{|c|}{ APPxPS TRANSGENIC MOUSE MODELS } \\
\hline $\begin{array}{l}\text { APPswe/PS1dE9 } \\
\text { (APP/PS1) }\end{array}$ & $\begin{array}{l}\text { m/hAPP695 K595N/M596L } \\
X \\
\text { hPS1 } \\
\text { dE9 } \\
\text { MoPrP } \\
\text { coinjection }\end{array}$ & Swe & $6-7 \mathrm{mo}$ & $6 \mathrm{mo}$ & ++ & n.a. & Yes & $\begin{array}{l}\text { Jankowsky et al., 2001; } \\
\text { Savonenko et al., 2005; } \\
\text { Garcia-Alloza et al., 2006; } \\
\text { O'Leary and Brown, } \\
\text { 2009; Stover and Brown, } \\
2012\end{array}$ \\
\hline $\begin{array}{l}\text { Thy1-APP751SL } \\
\text { X } \\
\text { HMG-PS1M146L } \\
\text { (APPSweLon/ } \\
\text { PS1M146L, } \\
\text { APP/PS1) }\end{array}$ & $\begin{array}{l}\text { hAPP751 } \\
\text { K670M/N671L/N717I } \\
\text { mThy1 } \\
\text { X } \\
\text { PS1 } \\
\text { M146L } \\
\text { HMG }\end{array}$ & $\begin{array}{l}\text { Swe } \\
\text { Lon }\end{array}$ & $3-5 \mathrm{mo}$ & $3-5 \mathrm{mo}$ & ++ & Yes & n.a. & $\begin{array}{l}\text { Blanchard et al., 2003; } \\
\text { Schmitz et al., 2004; El } \\
\text { Tayara et al., } 2010\end{array}$ \\
\hline $\begin{array}{l}\text { APPDutch } \\
X \\
\text { PS45 }\end{array}$ & $\begin{array}{l}\text { hAPP } \\
\text { E6930 } \\
\text { X } \\
\text { PS1 } \\
\text { G384A } \\
\text { mThy1 }\end{array}$ & $\begin{array}{l}\text { Swe } \\
\text { Dut }\end{array}$ & $3 \mathrm{mo}$ & n.a. & + & n.a. & n.a. & Herzig et al., 2004 \\
\hline $\begin{array}{l}\text { APP23 } \\
X \\
\text { PS45 }\end{array}$ & $\begin{array}{l}\text { hAPP751 } \\
\text { K670N/M671L } \\
\text { X } \\
\text { PS1 } \\
\text { G384A } \\
\text { mThy1 }\end{array}$ & Swe & $2-3 \mathrm{mo}$ & n.a. & + & n.a. & Yes & $\begin{array}{l}\text { Busche et al., 2008, } \\
\text { 2012; Beckmann et al., } \\
2011\end{array}$ \\
\hline
\end{tabular}


Table 1 | Continued

\begin{tabular}{|c|c|c|c|c|c|c|c|c|}
\hline $\begin{array}{l}\text { Line } \\
\text { (Alternative } \\
\text { designation) }\end{array}$ & $\begin{array}{l}\text { Construct } \\
\text { Promoter }\end{array}$ & $\begin{array}{l}\text { Familial } \\
\text { APP AD } \\
\text { mutation }\end{array}$ & $\begin{array}{l}\text { Onset of } \\
\text { amyloid } \\
\text { plaques }\end{array}$ & $\begin{array}{c}\text { CAA } \\
\text { onset }\end{array}$ & $\begin{array}{c}\text { CAA } \\
\text { severity }\end{array}$ & $\begin{array}{l}\text { Neuronal } \\
\text { loss }\end{array}$ & $\begin{array}{l}\text { Cognitive } \\
\text { defects }\end{array}$ & References \\
\hline $\begin{array}{l}\text { PS2APP } \\
\left(\text { PS2 }_{N 141 /} X \text { APP }_{\text {Swe }}\right)\end{array}$ & $\begin{array}{l}\text { hAPP751 } \\
\text { K670N/M671L } \\
\text { mThy1 } \\
\text { X } \\
\text { PS2 } \\
\text { N141I } \\
\text { MoPrP }\end{array}$ & Swe & $5 \mathrm{mo}$ & $12 \mathrm{mo}$ & + & n.a. & Yes & $\begin{array}{l}\text { Richards et al., 2003; } \\
\text { Woolley and Ballard, } \\
\text { 2005; Weidensteiner } \\
\text { et al., } 2009\end{array}$ \\
\hline $\begin{array}{l}\text { APPPS1 } \\
\text { (APPPS1-21) }\end{array}$ & $\begin{array}{l}\text { hAPP751 } \\
\text { K670N/M671LN717I } \\
\text { mThy1 } \\
\text { X } \\
\text { PS1 } \\
\text { L166P } \\
\text { knock-in }\end{array}$ & Swe & $2-4 \mathrm{mo}$ & $8 \mathrm{mo}$ & + & Yes & Yes & $\begin{array}{l}\text { Radde et al., 2006; Rupp } \\
\text { et al., 2011; Montagne } \\
\text { et al., 2012; Vom Berg } \\
\text { et al., } 2012\end{array}$ \\
\hline $\begin{array}{l}\text { APPxPS1-Ki } \\
\text { (APPSLPS1KI) }\end{array}$ & $\begin{array}{l}\text { hAPP751 } \\
\text { K670N/N671L } \\
\text { mThy1 } \\
\text { PS1 } \\
\text { M233T/L235P } \\
\text { mThy1 } \\
\text { coinjection }\end{array}$ & $\begin{array}{l}\text { Swe } \\
\text { Lon }\end{array}$ & $2-3 \mathrm{mo}$ & n.a. & n.a. & Yes & Yes & $\begin{array}{l}\text { Casas et al., 2004; Faure } \\
\text { et al., } 2011\end{array}$ \\
\hline $5 X F A D$ & $\begin{array}{l}\text { hAPP695 } \\
\text { K670N/M671L/I716V/N717I } \\
\text { mThy1 } \\
\text { PS1 } \\
\text { M146L/L28V } \\
\text { mThy1 } \\
\text { coinjection }\end{array}$ & $\begin{array}{l}\text { Swe } \\
\text { Lon } \\
\text { Flo }\end{array}$ & $2-3 \mathrm{mo}$ & n.a. & n.a. & Yes & Yes & $\begin{array}{l}\text { Oakley et al., 2006; } \\
\text { Kimura and Ohno, 2009; } \\
\text { Jawhara et al., } 2012\end{array}$ \\
\hline \multicolumn{9}{|c|}{ APPXPSXTAU TRANSGENIC MOUSE MODELS } \\
\hline $\begin{array}{l}3 \times T g-A D \\
(3 \times T g)\end{array}$ & $\begin{array}{l}\text { hAPP695 } \\
\text { K670M,N671L + htau (P301L) } \\
\text { mThy1 } \\
\text { coinjection } \\
\text { PS1 (M146V) } \\
\text { knock-in }\end{array}$ & Swe & $\begin{array}{l}\text { 12-15 mo } \\
\text { (heterozy- } \\
\text { gous) } \\
6 \text { mo } \\
\text { (homozy- } \\
\text { gous) }\end{array}$ & n.a. & n.a. & Yes. & Yes & $\begin{array}{l}\text { Oddo et al., 2003a,b; } \\
\text { Billings et al., 2005; } \\
\text { Bittner et al., } 2010\end{array}$ \\
\hline \multicolumn{9}{|c|}{ APP DOUBLE TRANSGENIC RAT MODELS } \\
\hline TgF344-AD & $\begin{array}{l}\text { hAPP695 } \\
\text { K595N/M596L + } \\
\text { hPS1(dE9) } \\
\text { MoPrP } \\
\text { coinjection }\end{array}$ & Swe & $6 \mathrm{mo}$ & 6-12 mo & ++ & Yes & Yes & Cohen et al., 2013 \\
\hline
\end{tabular}

Mutations: Arctic (ArC), Dutch (Dut), Florida (Flo), Indiana (Ind), London (Lon), Swedish (Swe). Classification of CAA severity: + mild, ++ significant, +++ pronounced. Abbreviations: n.a., not analysed/not available; mo, months; $X$ : cross breeding.

characterization of cerebral vasculature under normal and pathological conditions requires information at multiple length and time scales addressing various aspects of vascular anatomy and function/physiology (Figure 1).

Light-based microscopy methods such as two-photon microscopy or optical coherence tomography provide exquisite information at submicrometer resolution though they are limited to superficial structures due to light scattering by turbid tissue.
The cortex is ideally suited for in vivo microscopy of adult mice. Technically, it involves the preparation of an optical window in anesthetized animals, comprising either a thinned skull region or a sealed craniotomy. For short- and long-term imaging experiments the thinned skull preparation is the preferred method because it is the least invasive to parenchymal tissue (Helm et al., 2009). Recording duration ranges from minutes to months depending on the biological process investigated. 
Table 2 | In vivo imaging techniques applied to AD models.

\begin{tabular}{|c|c|c|c|c|}
\hline & Method & $\begin{array}{l}\text { Volume coverage } \\
\text { and resolution }\end{array}$ & $\begin{array}{l}\text { Aspect of CAA } \\
\text { addressed }\end{array}$ & Imaging strategy/tool \\
\hline \multirow{4}{*}{ 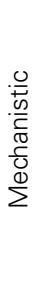 } & \multirow[t]{4}{*}{$\begin{array}{l}\text { Two-photon } \\
\text { microscopy }\end{array}$} & $\begin{array}{l}\text { 3D } \\
\text { Superficial (depth } \leq 500 \mu \mathrm{m} \text { ) }\end{array}$ & Vascular morphology/remodeling & Intravascular fluorescent dye \\
\hline & & Resolution $<1 \mu \mathrm{m}$ & Amyloid deposition & Amyloid specific dye \\
\hline & & & BBB leakage & Intravascular fluorescent dye \\
\hline & & & Molecular targets & Target-specific molecular probes \\
\hline \multirow{8}{*}{ 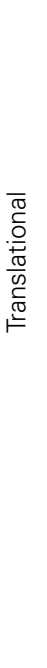 } & \multirow{5}{*}{$\begin{array}{l}\text { Magnetic } \\
\text { resonance } \\
\text { imaging } \\
\text { (MRI) }\end{array}$} & \multirow[t]{5}{*}{$\begin{array}{l}\text { 3D } \\
\text { Whole brain or selected VOI } \\
\text { Resolution } \geq 50 \mu \mathrm{m}\end{array}$} & Vascular morphology/remodeling & $\begin{array}{l}\text { MR Angiography (MRA) without (time-of-flight, } \\
\text { TOF) or with use of contrast agents (Vessel } \\
\text { size index, VSI) }\end{array}$ \\
\hline & & & Flow disturbances & $\begin{array}{l}\text { Quantitative TOF MRA or velocity encoded } \\
\text { phase mapping }\end{array}$ \\
\hline & & & Vascular reactivity & $\begin{array}{l}\text { Stimulus induced change in cerebral blood } \\
\text { volume (CBV) }\end{array}$ \\
\hline & & & Microhemorrhages & $\begin{array}{l}\text { Susceptibility weighted MRI (SWI) or } \\
\text { quantitative susceptibility mapping (OSM) }\end{array}$ \\
\hline & & & Cell migration (inflammatory cells) & Magnetically labeled cells \\
\hline & \multirow{3}{*}{$\begin{array}{l}\text { Positron } \\
\text { emission } \\
\text { tomography } \\
\text { (PET) }\end{array}$} & $3 \mathrm{D}$ & Tissue perfusion & ${ }^{15} \mathrm{H}_{2} \mathrm{O}$ PET \\
\hline & & Whole brain & Molecular targets & Target-specific radiotracer \\
\hline & & Resolution $\geq 1 \mathrm{~mm}$ & & \\
\hline
\end{tabular}

Some applications, for instance high-resolution two-photon imaging of extensive cortical areas or micrometerscale structures deep inside the cortex $(\sim 250 \mu \mathrm{m})$, require the use of an open skull window providing direct access to the brain parenchyma (Holtmaat et al., 2009). To target deeper brain structures like the hippocampus, removal of parts of the cortex have been proven to be feasible (Busche et al., 2012). It should be kept in mind that skull removal may lead to mechanical injuries to the cortical surface or immediate disturbances in local blood perfusion, BBB permeability, and brain homeostasis, while removal of whole brain structures might even lead to damage of brain structures.

Modalities such as computed tomography (CT), magnetic resonance imaging (MRI), positron emission tomography (PET), single-photon emission computed tomography (SPECT) and near-infrared fluorescence (NIRF) imaging allow for non-invasive three-dimensional (3D) coverage of large volumes at the expense of spatial resolution. Imaging solutions based on these technologies are potentially translatable. Due to its versatility, MRI has been extensively used for characterizing cerebral vasculature: gross vascular architecture, tissue perfusion, integrity of the BBB, occurrence of hemorrhages and immune cell infiltration, all have been studied both in patients and animal models of the disease. These structural and functional read-outs can be complemented by molecular information derived from the use of target specific probes (Klohs and Rudin, 2011).
A brief summary of imaging activities and techniques related to murine AD models is provided in Table 3. A glance at Tables 2, 3 reveals that both macroscopic techniques, like MRI and PET, as well as in vivo microscopy are at the center of attention. The method of choice depends on the required resolution of the method, and thus on the specific research questions addressed.

\section{VISUALIZING VASCULAR vS. PARENCHYMAL AMYLOID DEPOSITIONS}

The amyloid hypothesis proposes that $\mathrm{AD}$ is caused by an imbalance between $A \beta$ production and clearance which leads to parenchymal and vascular A $\beta$ deposits (Hardy and Selkoe, 2002). Visualizing $A \beta$ deposition in general is desirable to characterize the dynamics of this process and for testing of $A \beta$-directed therapeutics. To investigate the role of CAA in $\mathrm{AD}$ requires discriminating vascular from parenchymal $A \beta$ deposits. Differentiation of the two compartments would enable monitoring the effects of $A \beta$ removal strategies, which have been shown in some instances to increase CAA (Wilcock et al., 2004a, 2011). To date, assessment of $A \beta$ load and CAA requires time-consuming postmortem neuropathological analysis. Imaging approaches enabling to assess $\mathrm{A} \beta$ deposition at the microscopic and macroscopic scale in situ are therefore welcome. The sub-micrometer spatial resolution of in vivo microscopic techniques allows differentiating CAA from neuritic amyloid deposits in a straightforward manner based 


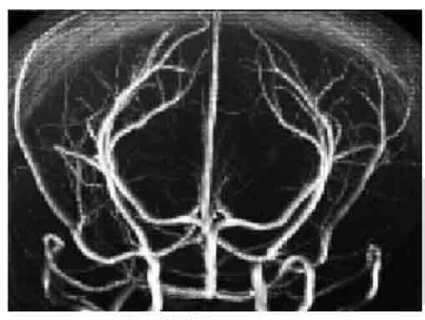

$\geq 100 \mu \mathrm{m}$

- Remodeling of large vessels (arteries) - Blood flow disturbancies
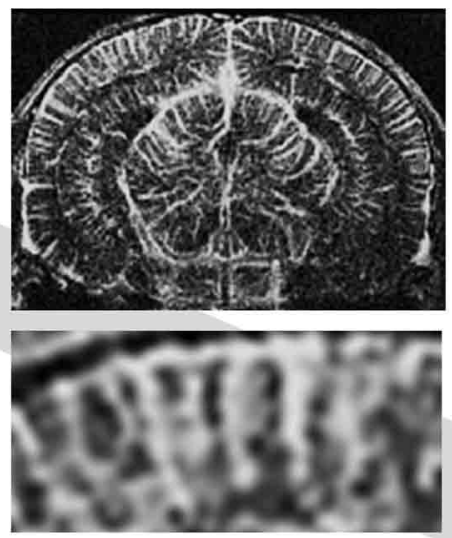

$\geq 25 \mu \mathrm{m}$

- Remodeling of medium size vessels (transcortical arteries \& veins)

- Vascular density
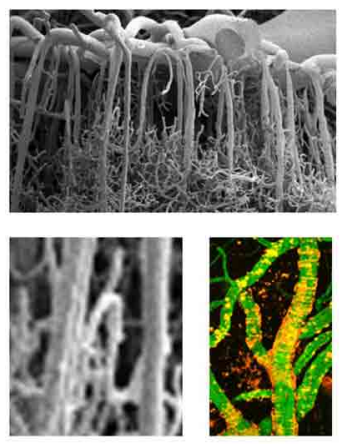

$\geq 0.25 \mu \mathrm{m}$

- Remodeling of microvessels

- Amyloid deposition
FIGURE 1|Phenotypic characterization of cerebrovascular structures at various length scales. Time-of-flight magnetic resonance angiography can depict large vessels $(\geq 100 \mu \mathrm{m})$, contrast-enhanced magnetic resonance angiography can depict medium sized vessels $(\geq 50 \mu \mathrm{m})$ and two-photon microscopy can visualize microvessels $(\geq 0.25 \mu \mathrm{m})$. on their spatial distribution within tissue. In contrast, monitoring vascular amyloid deposition using non-invasive macroscopic imaging with voxel dimensions of $\geq 50 \mu \mathrm{m}$ is hampered by the fact that spatial resolution does not allow discriminating between the parenchymal and vascular compartments. Instead plaque subtype specific labeling is required, which remains a major challenge, given the chemical and structural similarity of the amyloid deposits. As addressed next, in vivo microscopy has evolved as an indispensable tool for studying the dynamics of CAA under experimental conditions and also for the development of amyloid subtype specific probes, which can then be appropriately labeled for macroscopic imaging investigations with e.g., optical techniques or PET.

The dynamics of CAA has been studied in real time in $\operatorname{Tg} 2576$ mice using multiphoton microscopy through cranial windows (Robbins et al., 2006). Affected vessels were labeled by methoxyX04. Earliest appearance of CAA was observed as multifocal deposits of band-like $A \beta$ in leptomeningeal arteries at approximately 9 months of age. Serial imaging sessions enabled monitoring growth of these deposits as well as appearance of new bands. The CAA progression in Tg2576 mice was found to be linear in the range of 9-16 months of age (Robbins et al., 2006). In contrast, APPswe/PS1dE9 mice showed CAA deposition in leptomeningeal arteries by 6 months of age (Garcia-Alloza et al., 2006). However, compared to Tg2576 animals, CAA progressed at a lower rate in these mice, which may be accounted for an increase of the $A \beta_{42} / A \beta_{40}$ ratio in APPswe/PS1dE9 mice.

Amyloid specific dyes such as Thioflavin, Congo red or curcumin have been used for the histopathological assessment of cerebral amyloidosis and CAA. Chemical modifications of these dyes have led to the development of specific imaging probes which can be employed to detect amyloid deposition in vivo. Alternative approaches explore the use of antibodies or antibody fragments for targeting vascular $A \beta$ deposition. For this purpose, $\mathrm{A} \beta$ targeted compounds can be labeled with radionuclides such as ${ }^{11} \mathrm{C}$ and ${ }^{18} \mathrm{~F}$, fluorescent dyes or paramagnetic nanoparticles. However, the delivery of intravenously injected compounds can be affected by the status of the BBB as an impairment of the BBB function may lead to unspecific leakage of the probe. Moreover, species specific differences in the affinity sites of $A \beta$ exist (Klunk et al., 2005), which in some cases does not allow for simple translation of approaches targeting $\mathrm{A} \beta$ across different species.

Established PET tracers such as the $\left[{ }^{11} \mathrm{C}\right]$-Pittsburgh compound $\mathrm{B}$ or $\left[{ }^{18} \mathrm{~F}\right]$-florbetapir enable cerebral $\mathrm{A} \beta$ detection (Johnson et al., 2007; Wong et al., 2010), but do not allow the differentiation of neuritic plaques from CAA. Thus, a new series of $\left[{ }^{18} \mathrm{~F}\right]$-styrylpyridine derivatives has been developed which showed labeling of vascular $\mathrm{A} \beta$ in in vitro autoradiography of brain sections of patients with CAA or AD (Zha et al., 2011). Fluorescent dyes with specificity for vascular $A \beta$ have also been synthesized. For example, Han et al. (2011) found that the phenoxazine derivative resorufin binds preferentially to vascular amyloid deposits as compared to neuritic plaques in aged $\mathrm{Tg} 2576$ transgenic mice, in contrast to methoxy-X04 which binds to both (Figure 2). Along the same lines, McLean et al. (2013) developed a method to translate a panel of anti-A $\beta$ antibodies, which show excellent histological properties, into live animal imaging contrast agents. The antibodies M116 and M64 targeting neuritic plaques and M31 binding to 
Table 3 | In vivo imaging activities and techniques related to AD models.

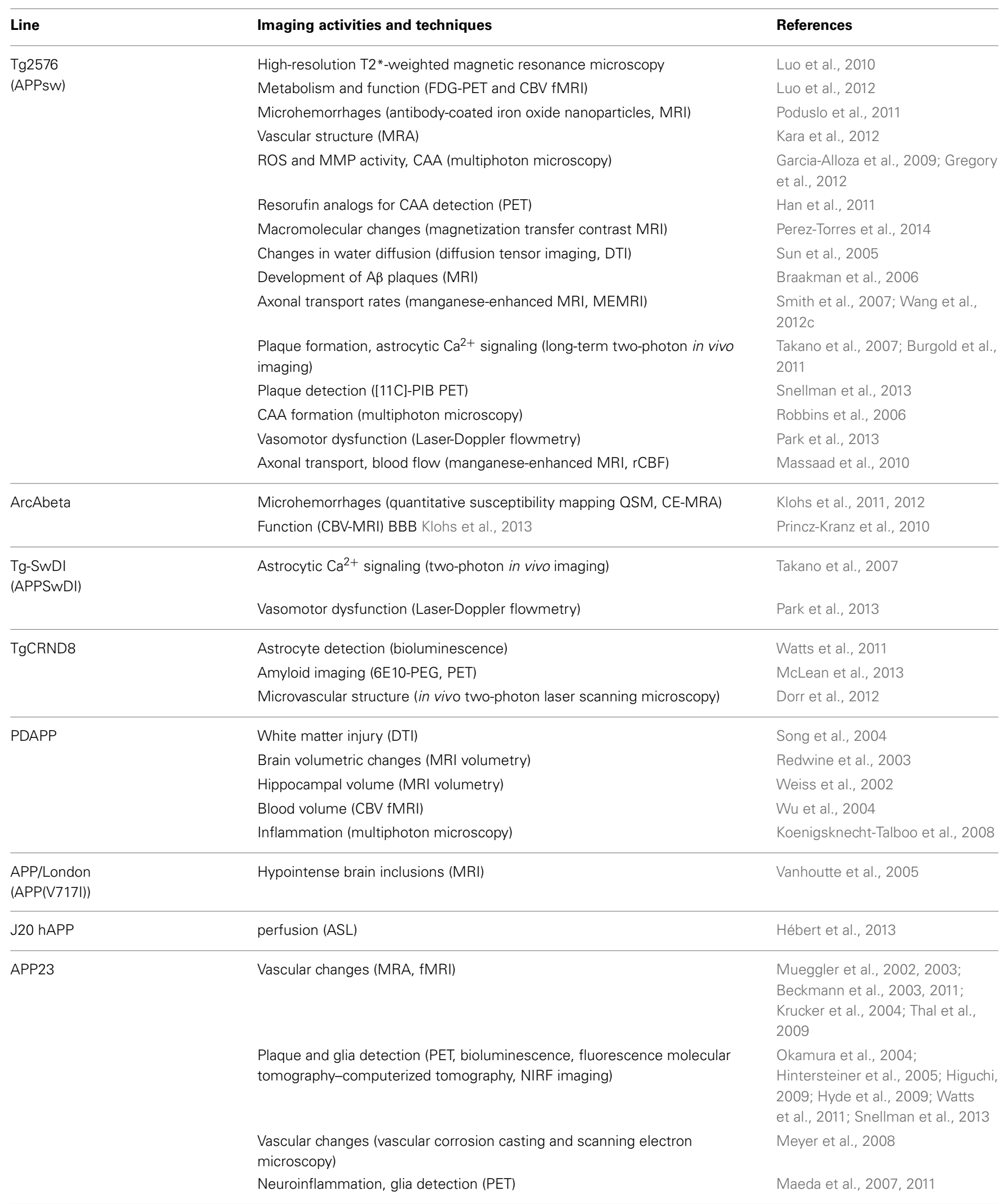


Table 3 | Continued

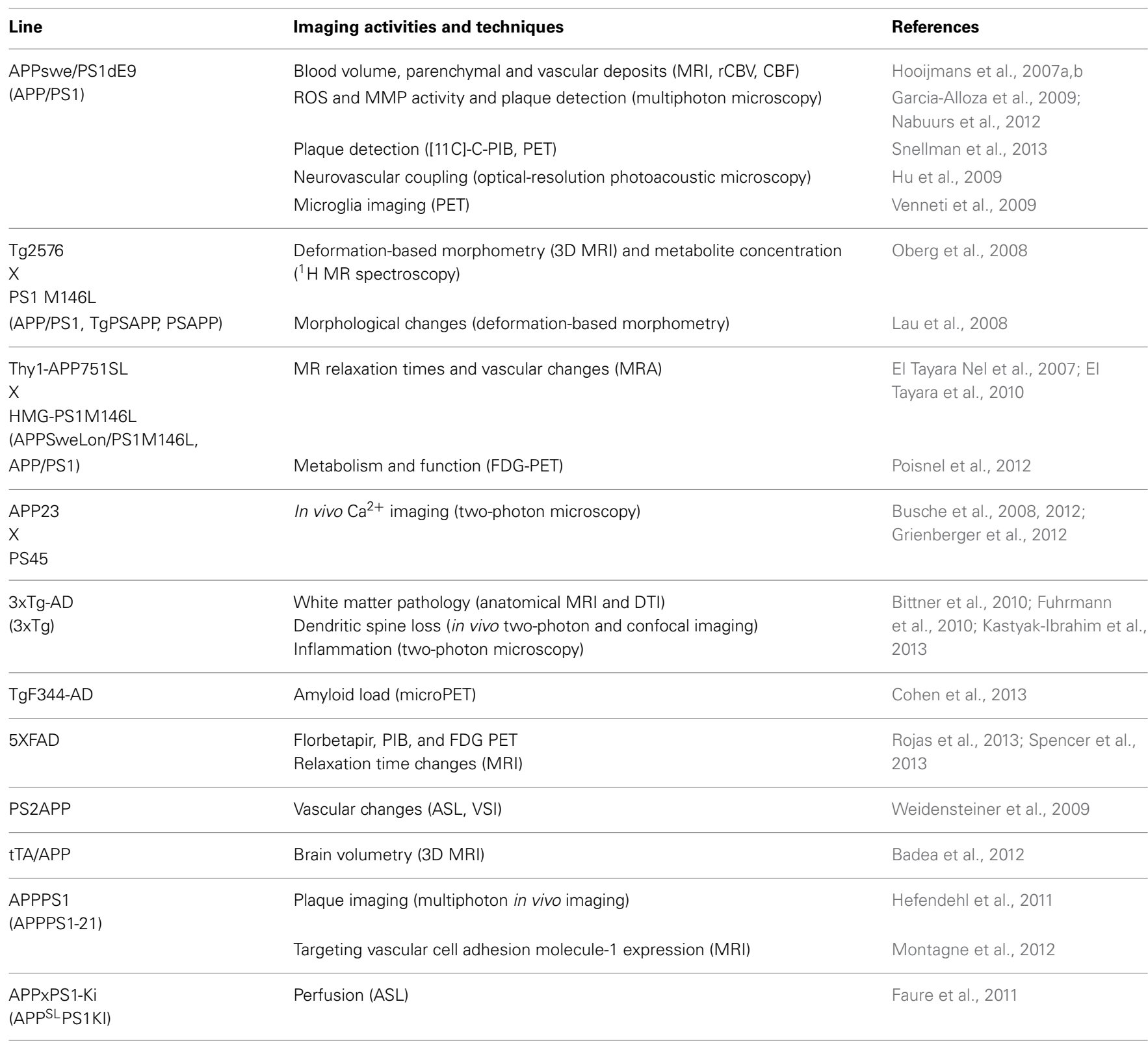

vascular $\mathrm{A} \beta$ were labeled with ${ }^{64} \mathrm{Cu}$ and injected into TgCRND8 mice. M31 and M116 were found to be significantly retained in the brains of transgenic mice after intravenous injection, while M64 was not (Figure 3). Immunohistological examination confirmed the specificity of the antibodies for either vascular or parenchymal A $\beta$ deposits. Similarly, Nabuurs et al. (2012) investigated the properties of two heavy chain antibody fragments, ni3 A and pa2 $\mathrm{H}$ (Harmsen and De Haard, 2007; Rutgers et al., 2009), which in APP/PS1 mice showed affinity for neuritic plaques and CAA, in contrast to observations in human tissue, where ni3A was found to specifically target vascular $A \beta$. An antibody-based approach for MRI detection was developed by Poduslo et al. (2011). The monoclonal antibody, IgG4.1, was labeled with monocrystalline iron oxide nanoparticles. These conjugated nanoparticles bound to vascular amyloid deposits in arterioles of $\mathrm{Tg} 2576$ mice after infusion into the external carotid artery. The selectivity of the nanoparticle approach was fostered by the fact that the nanoparticles cannot cross the $\mathrm{BBB}$ and thus remained in the vascular compartment.

In summary, several studies have successfully demonstrated that CAA can be visualized in transgenic mice in vivo using different targeting strategies. While microscopic techniques are invasive and therefore confined to yield mechanistic information in animals, they constitute an important complement to macroscopic imaging approaches like PET and MRI which can also be used in humans. These imaging assays could be used in the future to address how vasculopathy is temporally linked to vascular $A \beta$ deposition, but also how risk factors of $\mathrm{AD}$, for example hypertension, affects this process. Moreover, the tools might be useful to evaluate $A \beta$ removal strategies. 

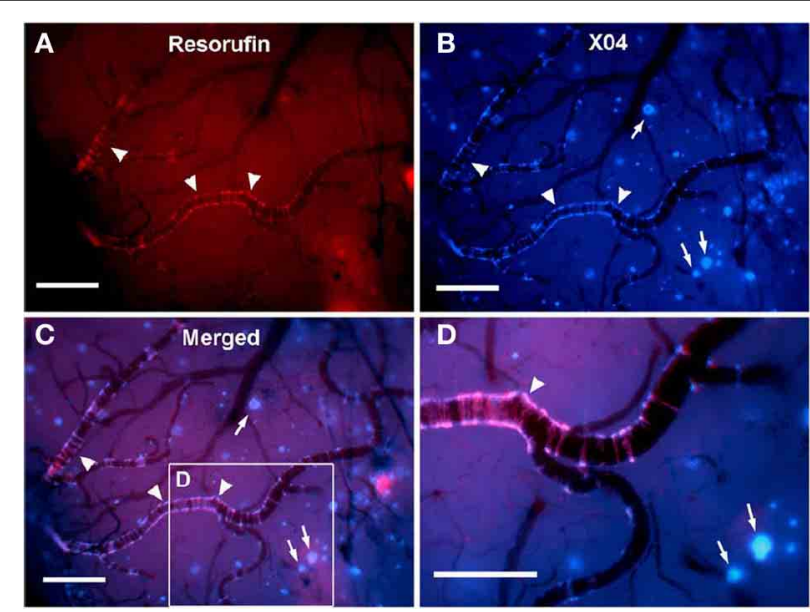

FIGURE 2 | In vivo live imaging of CAA amyloid deposits through cranial window. Closed cranial windows were prepared on the right parietal bone of 16-month-old Tg2576 mice and the congophilic amyloid binding dye, methoxy-X04 (X04), was administered (6 mg/kg i.p.). On the next day, $2 \mu \mathrm{M}$ resorufin (dissolved in artificial CSF) was superfused over the brain through a closed cranial window for $5 \mathrm{~min}$. After washing with artificial CSF for $10 \mathrm{~min}$, live fluorescent images of resorufin (red) and X04 (blue) were taken. (A) Intense fluorescent labeling detected within the walls of the leptomeningeal arteries (arrowheads) but not in neuritic plaques after topical application of resorufin. (B) In contrast, topical application of methoxy-X04 labeled $A \beta$ aggregates in both cerebral arteries (arrowheads) and parenchymal neuritic plaques (arrows). (C) Resorufin- and X04-images merged. (D) Magnified detail of (C). Scale bars: $100 \mu \mathrm{m}$. Reproduced with permission from Han et al. (2011), (C 2011 Han et al.

\section{IMAGING CEREBRAL AMYLOID CLEARANCE}

It has been implicated that $A \beta$ accumulation in the brain is not only the result of faulty $A \beta$ production but also of an impaired $\mathrm{A} \beta$ clearance (Bell and Zlokovic, 2009). Mechanisms of cerebral $\mathrm{A} \beta$ clearing include degradation by proteases, interstitial fluid drainage, and transport of $\mathrm{A} \beta$ across the BBB (Weller, 1998; Deane et al., 2004, 2008). As discussed in the present section, imaging approaches have revealed aberrant vascular clearance mechanisms in transgenic models of AD.

Arbel-Ornath et al. (2013) have used multi-photon microscopy to visualize interstitial fluid drainage along perivascular spaces in APPswe/PS1dE9 in real time. The kinetics of dye clearance was studied after parenchymal dye injections in transgenic mice and wildtype controls $2.5-3$ and 6-8 months of age. A significant impairment of the interstitial fluid drainage was observed in the old transgenic mice compared to young transgenic mice and age-matched wildtype mice.

Moreover, it has been shown that $A \beta$ is a substrate for efflux transporters, enabling to traffick $A \beta$ across the BBB (Kuhnke et al., 2007). Imaging strategies have been developed to visualize efflux transporter function by quantifying the uptake of substrates of these transporters. For example, (R)-[ $\left.{ }^{11} \mathrm{C}\right]$-verapamil has been developed as a PET tracer to study P-glycoprotein function (van Assema et al., 2012). Higher (R)-[ $\left.{ }^{11} \mathrm{C}\right]$-verapamil binding potential values were observed in $\mathrm{AD}$ patients compared to healthy controls, indicative of a decreased P-glycoprotein function.
In a different approach the role of the drug efflux transporter ABCG2 was studied in a transgenic mouse model. ABCG2 is a $72 \mathrm{kDa}$ transmembrane protein that forms functional homodimers and operates as BBB drug efflux transporter (Doyle and Ross, 2003). It has been shown that this transporter is significantly upregulated in $\mathrm{AD} / \mathrm{CAA}$ brains at both the $\mathrm{mRNA}$ and protein levels (Zhang et al., 2003). It has been shown that ABCG2 is also increased in Tg-SwDI and 3XTg-AD mouse models (Xiong et al., 2009). The role of ABCG 2 in $A \beta$ transport at the BBB was investigated by Xiong et al. (2009) in Abcg2-null and wildtype mice after intravenous injection of Cy5.5-labeled $A \beta_{1-40}$ or scrambled $\mathrm{A} \beta_{1-40}$. NIRF imaging of live animals showed that Abcg2-null mice accumulated significantly more $A \beta$ in their brains than wildtype mice (Figure 4), a finding that was confirmed by immunohistochemistry. These results suggest that ABCG2 may act as a gatekeeper at the $\mathrm{BBB}$ to prevent blood $\mathrm{A} \beta$ from entering into the brain.

Taken together, these imaging studies provide a mechanistic link between cerebrovascular disease and AD where an impaired $\mathrm{A} \beta$ clearance promotes further amyloid deposition. If a defective clearance might constitute an initiating event for $A \beta$ deposition needs to be investigated, but should be considered a new target for therapy in $\mathrm{AD}$ and $\mathrm{CAA}$.

\section{DETECTION OF CHRONIC CEREBRAL HYPOPERFUSION}

This section is devoted to studies comprising the use of microscopic or macroscopic imaging techniques to assess alterations in hemodynamic function due to deposition of $\mathrm{A} \beta$ in and around vessels as well as to changes in vasoactive mediators. For example, Dorr et al. (2012) observed a prolonged transit time of a fluorescent dye bolus in TgCRND8 mice compared to wildtype littermates using two-photon microscopy. Assessment of hemodynamic parameters covering the whole brain can be made with MRI. For dynamic susceptibility contrast MRI (DSC-MRI), $\mathrm{T}_{2}$ or $\mathrm{T}_{2}^{*}$-weighted images are acquired serially. Regional changes in MRI signal intensity are measured as the contrast agent traverses the cerebral vasculature during its first-pass following intravenous bolus injection (Villringer et al., 1998). This information is then converted into contrast-time curves. The intravascular indicator dilution theory has been used to derive the hemodynamic parameters mean transient time, cerebral blood volume (CBV) and flow (CBF). Determination of absolute hemodynamic parameters requires calibration of the perfusion maps by the arterial input function (Rausch et al., 2000). Moreover, the theory assumes that the contrast agent remains intravascular during its passage. This is often not the case under pathological conditions where the BBB function may be compromised, thus leading to leakage of the injected tracer. Modeling of the leakage contribution to the image signal intensity changes has been used to obtain information on the vascular transfer constant, i.e., BBB permeability (Johnson et al., 2004). Instead of introducing an exogenous label, moving blood can also be labeled magnetically. These MRI methods are based on arterial water as a freely diffusible tracer (Williams et al., 1992). For arterial spin labeling (ASL) a non-equilibrium state (typically spin inversion) is generated to tag inflowing spins at a level proximal to the imaging slab. Images are recorded following a transit delay to allow these tagged spins to enter the imaging 


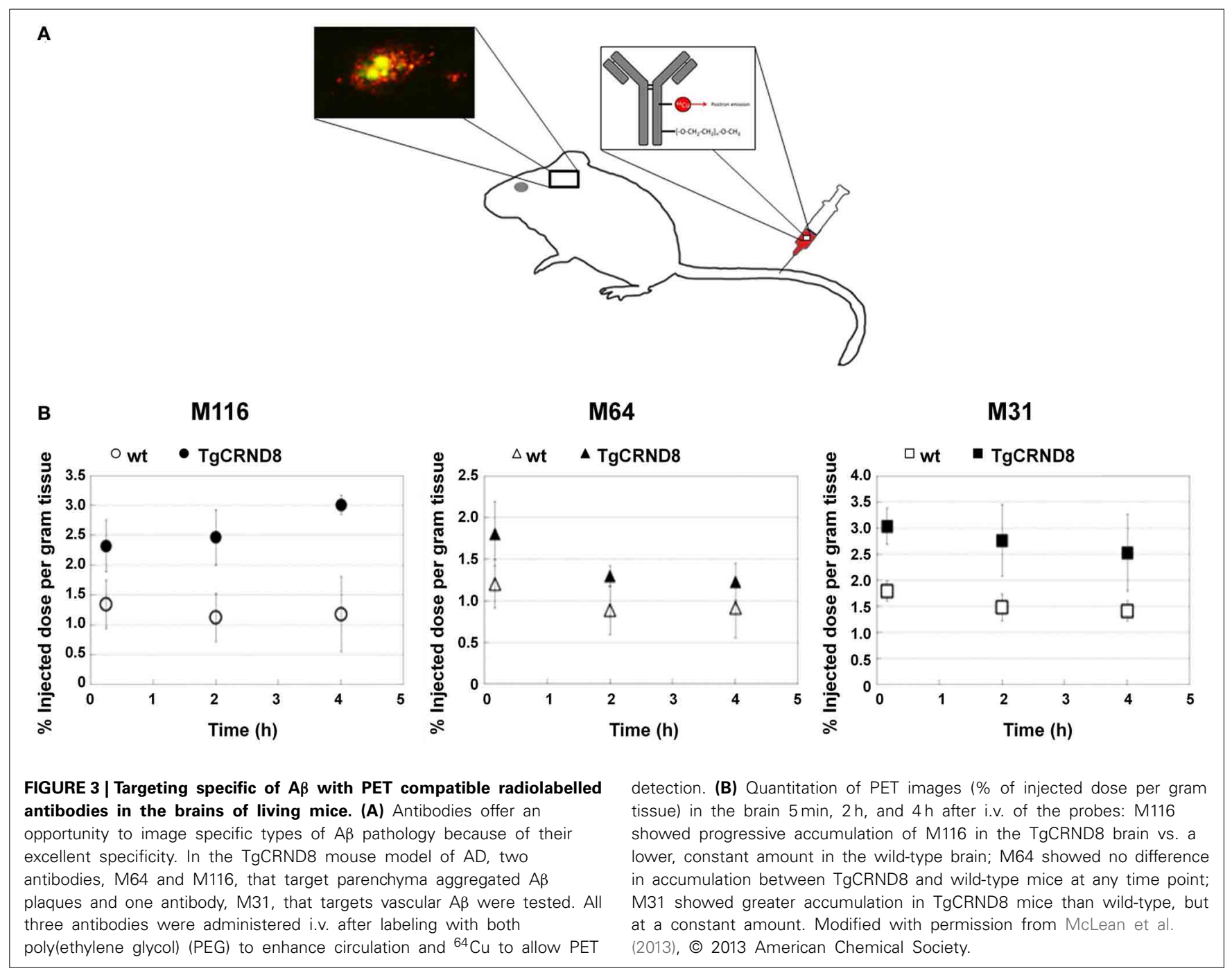

plane and exchange with tissue. Control images are required to compensate for direct saturation effects (Williams et al., 1992). Quantitative CBF values can be obtained from ASL images.

Cerebral hypoperfusion has been observed in AD patients using MRI (Johnson et al., 2005; Chen et al., 2011a), and has been suggested to be an early biomarker for the disease (Alsop et al., 2010; Chao et al., 2010). However, the mechanism underlying the perfusion deficits are poorly understood (Chen et al., 2011a). A decreased metabolic demand (Chen et al., 2011b) and decreased microvascular density (Buee et al., 1994) have been suggested as plausible causes, however, studies linking directly perfusion with pathological and molecular postmortem read-outs have not been attempted in humans and might be difficult to achieve. Studies assessing impairment of hemodynamic function in mice overexpressing APP can be pivotal in this regard, as a correlation of imaging studies with postmortem analysis of brain tissue can be conveniently performed. In several studies ASL was applied to APP mouse strains which have only sporadic CAA. A significant reduction in $\mathrm{CBF}$ has been observed in the occipital cortex of 10- to 17-month-old PS2APP (Weidensteiner et al., 2009), in

6-month-old APPxPS1-Ki (Faure et al., 2011), in 12-month old APP/PS1 (Poisnel et al., 2012), in 3-, 12- and 18-month-old J20 hAPP (Hébert et al., 2013) (Figure 5), and in 12- to 16-month-old Tg2576 mice (Massaad et al., 2010) compared to the respective age-matched controls. Perfusion was normal in subcortical (thalamic) areas in the transgenic mice (Faure et al., 2011; Poisnel et al., 2012). Reduced CBV levels at rest were also observed in the cerebral cortex, hippocampus, and thalamus of PDAPP mice compared to wildtype controls, while values were similar in other brain regions (Wu et al., 2004). In contrast, Hooijmans et al. (2007a) reported that CBF was not significantly reduced in 18month-old APP/PS1 mice when performing bolus tracking of $\mathrm{D}_{2} \mathrm{O}$ using deuterium MRS.

The question which needs to be addressed is why these mice show reduced cerebral perfusion. A histopathological study has shown a decreased capillary density around senile $A \beta$ plaques (Koutnetsova et al., 2006) which might explain the perfusion deficit, but areas of decreased perfusion did not correlate with plaque load (Weidensteiner et al., 2009). Another possibility is that reduced CBF may be due to lower cerebral metabolic demand 

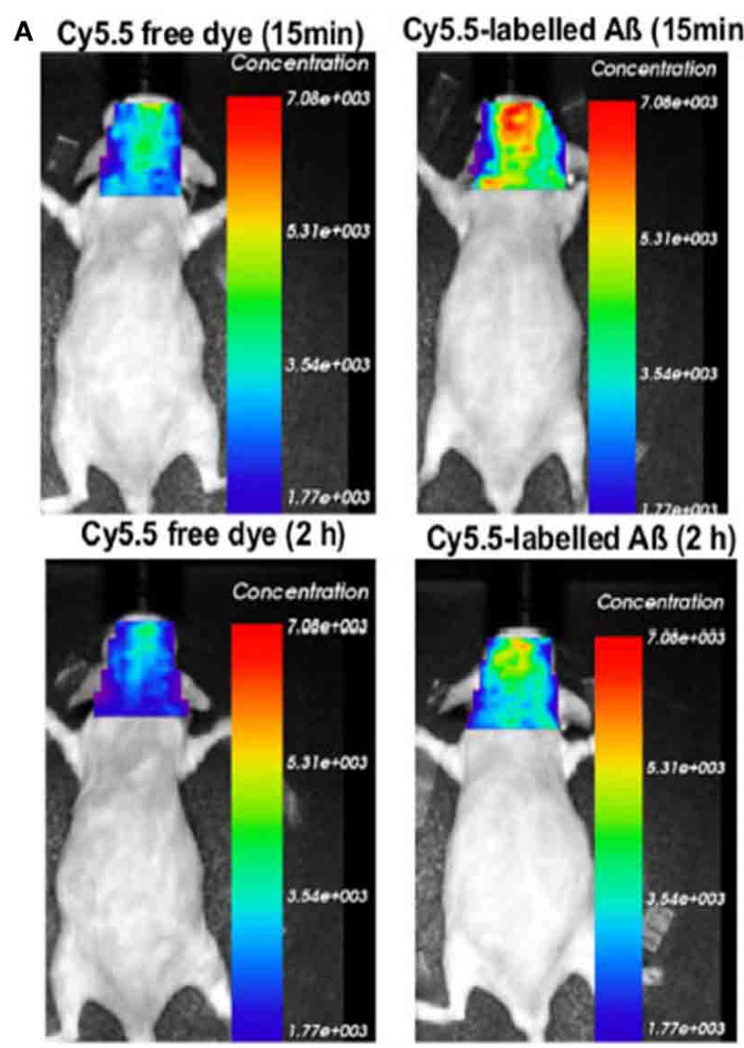

B
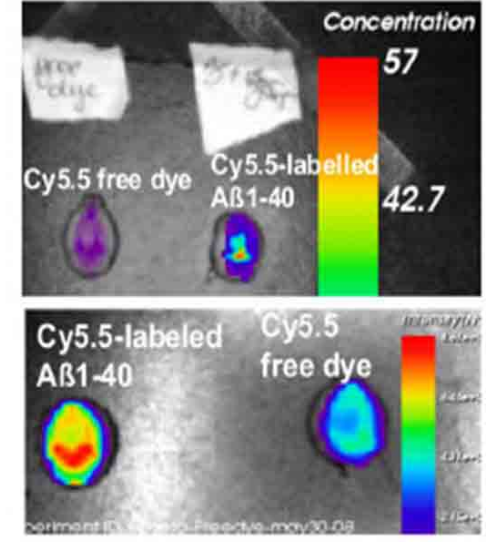

FIGURE 4 | Absence of Abcg2 allows more $A \beta$ peptides to be transported into the brain. (A) Two pairs of Abcg2 knockout mice were injected i.v. Cy5.5-free dye or Cy5.5-labeled $A \beta_{1-40}$ peptides in equal fluorescence intensity. Animals were scanned alive using a NIRF imager at $15 \mathrm{~min}$ and $2 \mathrm{~h}$. (B) NIRF scans of ex vivo brains collected at the end of the experiment. Signal intensity was significantly higher in the brains of
Abcg knockout mice injected with Cy5.5-labeled A $\beta$ peptides compared with Cy5.5 free dye ( $t$-test, $p<0.001)$. This demonstrates that Cy5.5 was brought into the brain as a form of Cy5.5-labeled $A \beta_{1-40}$ peptide, indicating that $A b c g 2$ is required at the $B B B$ to prevent the entry into the brain of circulating $A \beta$ peptides. Modified with permission from Xiong et al. (2009), (c) 2009 Society for Neuroscience. of the brain tissue in APP mice. However, a study comparing cerebral glucose metabolism as assessed with $\left[{ }^{18} \mathrm{~F}\right]$-fluoro2-deoxy-D-glucose PET and ASL-derived perfusion showed no correlation between the two read-outs (Poisnel et al., 2012). Cerebral glucose uptake decreased in the hippocampus, cortex and striatum of 3-month-old APP/PS1 mice, but increased in these brain regions in 12-month-old mice at an age when $\mathrm{CBF}$ is compromised, thus suggesting alternative mechanisms. Several studies using transgenic APP mice demonstrated alterations in vasoactive signaling (Niwa et al., 2001) and in the renin-angiotensin system (Takeda et al., 2009), as well as the generation of reactive oxygen species (Iadecola et al., 1999; Tong et al., 2005) in the brains of APP mice, all of which can directly affect vascular tone. Impairment of vascular function is observed in APP overexpressing mice prior the onset of plaque deposition and appears to be mediated by soluble $A \beta$ (Han et al., 2008; Park et al., 2013). Indeed hypoperfusion was observed in mouse strains at this young age (Faure et al., 2011; Hébert et al., 2013).

Vascular deposition of $A \beta$ is not a prerequisite for vascular dysfunction in $\mathrm{AD}$, but CAA aggravates the functional deficit (Park et al., 2013). A $\beta$ can exert direct vascular effects by attenuating the endothelium-dependent vasodilation (Paris et al., 2000, 2003;
Luo et al., 2008), triggering the production of reactive oxygen species (Tong et al., 2005; Park et al., 2008; Massaad et al., 2010) and inducing remodeling of the vessel wall (Merlini et al., 2011). In addition, vascular accumulation of $\mathrm{A} \beta$ has been associated with the deposition of fibrin, which can lead to vessel stenosis and occlusion (Paul et al., 2007; Cortes-Canteli et al., 2010; Klohs et al., 2012). Cerebral hypoperfusion accelerates CAA (Okamoto et al., 2012), induces oxidative stress and alterations of the reninangiotensin system (Washida et al., 2010), and may thus initiate a vicious cycle. Moreover, it has been shown that transgenic mice overexpressing APP have an impaired cerebral autoregulation (Niwa et al., 2002). The disability of the cerebral vasculature in the presence of $A \beta$ to respond to changes in perfusion pressure constitutes another mechanism of vascular pathology in AD.

Hypoperfusion seems to be a critical process in the pathogenesis of $\mathrm{AD}$ and further investigation into its mechanism is warranted for developing therapeutic interventions that can abrogate the functional deficits. MRI has been demonstrated to be a robust technique to assess perfusion in large areas of the human and small animal brain, with or without administration of contrast agent. To obtain information at a higher spatial resolution, laser Doppler flowmetry or two-photon microscopy may 


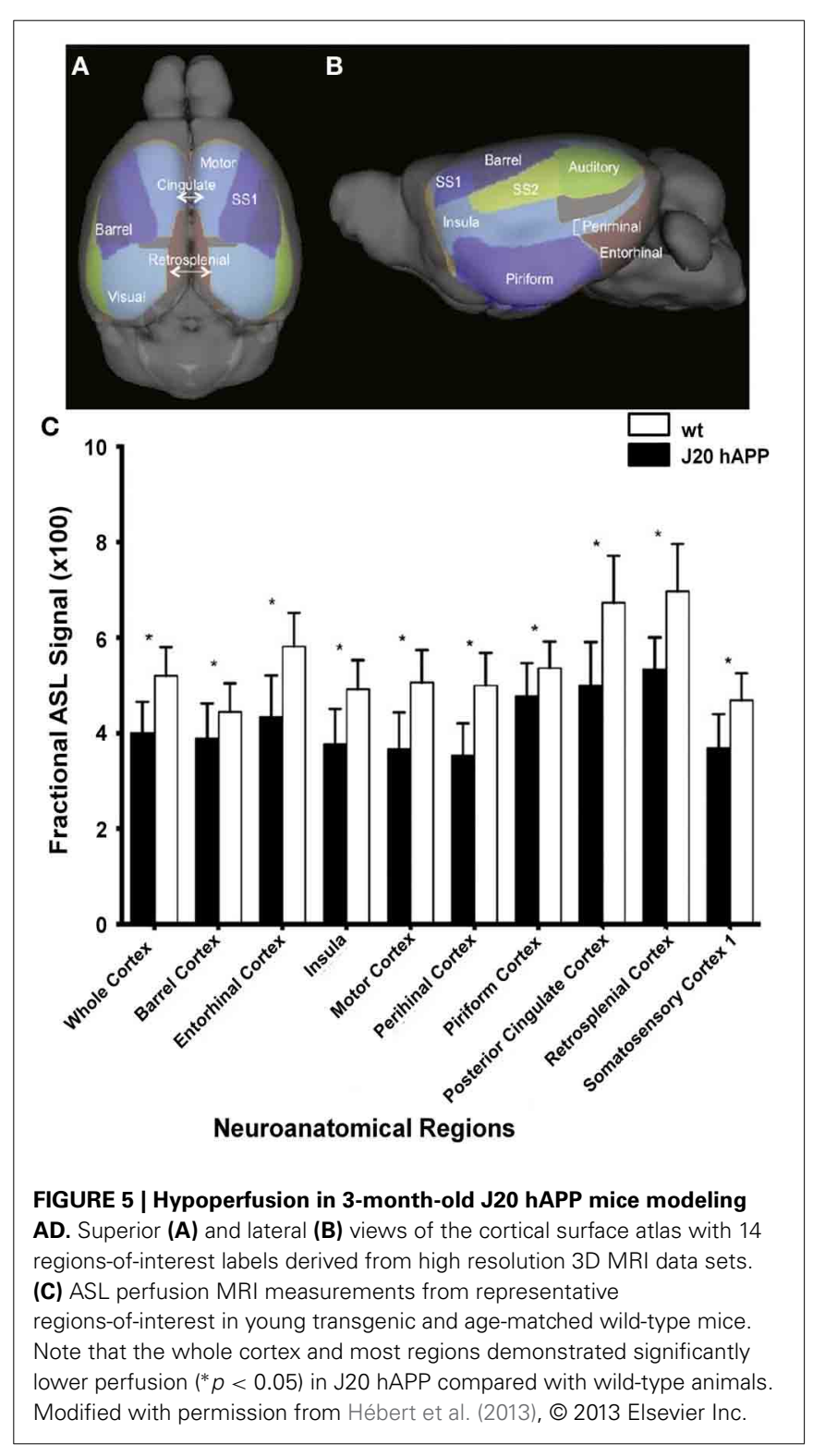

be applied. But for this, cranial windows are necessary, and the information is obviously limited to upper cortical regions.

\section{ALTERATION OF STIMULUS EVOKED RESPONSE IN FUNCTIONAL IMAGING - CHANGED NEUROVASCULAR COUPLING OR IMPAIRED NEURONAL FUNCTION?}

Functional imaging read-outs may constitute early sensitive markers of underlying pathology, since alterations in neuronal function and vascular reactivity are expected to precede any gross changes in anatomy as detected with structural imaging techniques. One caveat for functional imaging studies are that they are routinely performed in anesthetized animals. As the anesthetic may affect neuronal activation and/or neurovascular coupling and thus have an effect on hemodynamic read-outs (Masamoto and Kanno, 2012), the protocol needs to be carefully controlled. It is discussed next how imaging based on CBF and CBV readouts are suitable to conduct functional imaging studies in order to investigate changes in these parameters in response to neuronal activation in transgenic animals modeling AD.

Two-photon imaging has been shown to be a unique approach to studying vascular dysfunction in mouse models of AD, by evaluating neurovascular function e.g., through analyses of functional hyperemia evoked by sensory stimulation. Using this technique, Takano et al. (2007) demonstrated in vivo that reactive changes of astrocytes and abnormalities of the microcirculation occur in early stages of the disease preceding amyloid deposition and neuronal loss. In contrast to the low $\mathrm{Ca}^{2+}$ signaling activity in nonstimulated control animals, astrocytes in 2-4-month-old Tg2576 mice exhibited a higher frequency of spontaneous $\mathrm{Ca}^{2+}$ oscillations. Animals with abnormal astrocytic activity also displayed instability of the vascular tone with oscillatory cycles of relaxation/constriction of small arteries. $A \beta$ administration increased the frequency of spontaneous astrocytic $\mathrm{Ca}^{2+}$ increases. Because astrocytes control local microcirculation and contribute to functional hyperemia (Anderson and Nedergaard, 2003; Takano et al., 2006), abnormal astrocytic activity may contribute to vascular instability in $\mathrm{AD}$ and thereby to compromised neuronal function.

Dorr et al. (2012) observed a prolongation of bolus transit times of a fluorescent dye in TgCRND8 mice during hypercapnia using two-photon microscopy. While in wildtype mice, due to $\mathrm{CO}_{2}$-induced vessel dilatation, the hypercapnic challenge led to a reduction of transit time as compared to animals breathing air, the opposite effect has been observed in transgenic animals. Also in the transgenic group there was an increase in transit time with age, i.e., with more severe $A \beta$ pathology. It was concluded that this paradoxical response to hypercapnia resulted from compromised $\mathrm{CO}_{2}$-induced dilatation of the feeding arteries/arterioles in the presence of preserved venous dilatation and reflected a profoundly impaired vascular function in TgCRND8 mice.

Functional MRI (fMRI) comprises a number of techniques to non-invasively study brain function in humans and animals. In addition to $\mathrm{CBV}$ and $\mathrm{CBF}$ read-outs, a blood oxygenation level dependent (BOLD) contrast can be used for fMRI (Ogawa et al., 1992). fMRI can be performed at rest (Jonckers et al., 2011) or with different types of physiological stimuli like sensory, thermal, or electrical stimulation (Mueggler et al., 2003; Bosshard et al., 2010). Moreover, pharmacological fMRI can measure the hemodynamic responses induced by central nervous system active drugs or vasoactive compounds and can thus be used as surrogate reflecting the effects of these drugs on neural transmission and/or vessel function.

APP23 mice of various ages have been analyzed using fMRI (Mueggler et al., 2002, 2003). CBV changes were detected in 6-, 13-15- and 25-month-old mutant mice in response to pharmacological stimulation using the $\mathrm{GABA}_{A}$ receptor antagonist, bicuculline, physiological stimulation by inducing hypercapnia using the carbonic anhydrase inhibitor, acetazolamide, and peripheral sensory activation using electrical stimulation of the hind paws. In 13-15- and 25-month-old APP23 mice, all three stimulation paradigms evoked CBV responses that were significantly smaller when compared to age-matched, control littermates (Mueggler et al., 2002, 2003). In young animals of 6 months of age, there was no difference between the transgenic and wildtype group. Princz-Kranz et al. (2010) demonstrated a 
diminuished CBV response upon stimulation with acetazolamide in the cortex of 16- and 23-month-old $\operatorname{arcA} \beta$ mice compared to age-matched wildtype littermates, while there was no difference between 3-month-old ArcA $\beta$ mice and controls (Figure 6). Both the rate of vascular adaptation (vascular reactivity) and the extent of the dilatation (as a measure for the reserve capacity) were found to be impaired in aged $\operatorname{Arc} A \beta$ mice.

A challenge in $\mathrm{FMRI}$ is the interpretation in animal models of $\mathrm{AD}$. Under physiological conditions neurovascular coupling is rather tight (Logothetis et al., 2001; Schulz et al., 2012), but under pathological conditions a reduced fMRI response may indicate either a decrease in neuronal activity, an impaired neurovascular coupling or both. Sanganahalli et al. (2013) have shown in a non-transgenic rat model without CAA that the cortical BOLD response and neuronal activity upon sensory stimulation are reduced in rats with inducible amyloid pathology while the neurovascular coupling remains unaffected. But neurovascular coupling may be impacted in the presence of CAA as $A \beta$ exerts direct vascular effects. Luo et al. (2008) intravenously injected $A \beta_{1-40}$ in anesthetized $C 57 \mathrm{BL} / 6$ mice.Injection of the peptide led to a significant reduction in CBV in a dosedependent and region-specific manner while the injection of phosphate buffered solution or of the reversed peptide, $A \beta_{40-1}$, did not induce any significant change in vascular response. This vasconstrictive effect might also explain the impaired vascular reactivity in mice with CAA upon acetazolamide and hypercapnia challenge (Mueggler et al., 2003; Princz-Kranz et al., 2010; Dorr et al., 2012). Given the attractiveness of performing fMRI also in AD patients, further studies are warranted to examine how changes in neurovascular mediators impact fMRI read-outs.

\section{VISUALIZING AMYLOID-INDUCED VASCULAR REMODELING}

Changes in hemodynamics of the vasculature will inevitably lead to vascular remodeling. In patients, $A \beta$ deposits are seen in leptomeningeal and cortical arteries, and less frequently in veins and capillaries (Buee et al., 1994; Thal et al., 2008a,b). Transgenic mice show a larger heterogeneity of phenotypes with capillaries and large arteries affected by $\mathrm{A} \beta$ deposition. Imaging approaches targeting the vasculature at a phenotypic level are attractive tools to study remodeling of the vascular architecture as a consequence of CAA. The use of MRI to detect vascular remodeling in transgenic models is discussed in this section.

Magnetic resonance angiography (MRA) comprises a number of MRI techniques capable of visualizing the vascular architecture non-invasively. The method has limited spatial resolution, but is translational and routinely used in the clinics. Time-of-flight MRA (TOF-MRA) generates contrast between signals arising from stationary tissue and flowing blood. Maximum intensity projection or volume-rendered visualization delivers $3 \mathrm{D}$ representations of the cerebral vasculature in humans (Talagala et al., 1995) and rodents (Beckmann et al., 1999; Reese et al., 1999; Beckmann, 2000). However, the technique is inherently dependent on the orientation of the blood vessels with respect to the imaging plane and the actual flow velocity of the blood (Lin et al., 1997; Reese et al., 1999). While TOF-MRA can depict major brain arteries, parts of the vasculature such as small intracortical arteries, which branch off the larger cerebral vessels, and veins displaying slower blood flow velocities than arteries, are difficult to be visualized. The quality of TOF-MR angiograms is governed by the vascular anatomy and the blood flow characteristics. Signal voids in TOF-MRA may indicate absence of flow, low flow velocity, or turbulent flow. Microturbulences for instance translate into MRA signal voids due to the loss of signal coherence despite the fact that the vessel is still fully perfused (Krucker et al., 2004). Nevertheless, the degree of vasculopathy may be graded based on number and extent of signal voids detected on the angiograms in a semiquantitative manner (El Tayara et al., 2010; Kara et al., 2012). In contrast-enhanced MRA (CE-MRA) a paramagnetic contrast agent is intravenously administered, which causes a signal loss due to increased signal dephasing (El Tayara et al., 2010; Klohs et al., 2012). The CE-MRA data image can be used like in TOF-MRA data to visualize the 3D vessel architecture. However, in CE-MRA flow and motion artifacts are smaller compared to TOF-MRA (Mellin et al., 1994; Lin et al., 1997).

TOF-MRA has been applied to probe vascular remodeling in APP23 mice in vivo (Beckmann et al., 2003). Flow voids were detected at the internal carotid artery of 11-month-old APP23 mice. At the age of 20 months, additional flow disturbances were observed in the circle of Willis. Vascular corrosion casts (Krucker et al., 2004; Meyer et al., 2008) obtained from the same mice revealed that vessel elimination, deformation, or both had taken place at the sites where flow voids were detected by TOFMRA. The detailed 3D architecture of the vasculature visible in the casts assisted the identification of smaller vessels most likely formed as substitution or anastomosis within the Circle of Willis. Thal et al. (2009) observed blood flow disturbances in TOF-MR angiograms in 25- to 26-month-old APP23 mice which corresponded to CAA-related capillary occlusion in the branches of the thalamoperforating arteries as seen with histology. El Tayara et al. (2010) evaluated vascular alterations in APP/PS1 and in PS1 mice. The double transgenic model is relatively aggressive as extracellular amyloid deposition starts at the age of 2.5 months (Blanchard et al., 2003). However, unlike plaque deposition, severity of cerebrovascular alterations is stabilized in older animals. Alterations of the middle cerebral artery were detected in old APP/PS1 mice by evaluating the severity of signal voids and the reduction of patent length of the vessel using TOF-MRA and CE-MRA. MRA obtained at very high magnetic fields $(17.6 \mathrm{~T})$ improved the capability to visualize smaller vessels (Kara et al., 2012). Visual and quantitative analysis of angiograms revealed severe blood flow defects in large and medium sized arteries in Tg2576 mice (Figure 7). In particular blood flow defects were observed in the middle cerebral and in the anterior communicating artery in Tg2576 mice. Histological data show that $A \beta$ deposits in the vessel wall may be responsible for impaired CBF.

The use of cryogenic radiofrequency probes improves the quality of mouse brain angiograms at lower magnetic fields (Baltes et al., 2009). Klohs et al. (2012) employed this technology to quantitatively assess age-dependent changes of the cortical vasculature in the $\operatorname{Arc} \mathrm{A} \beta$ model of cerebral amyloidosis. To estimate the density of the cortical microvasculature in vivo, CE-MRA was used, based on the acquisition of data before and 


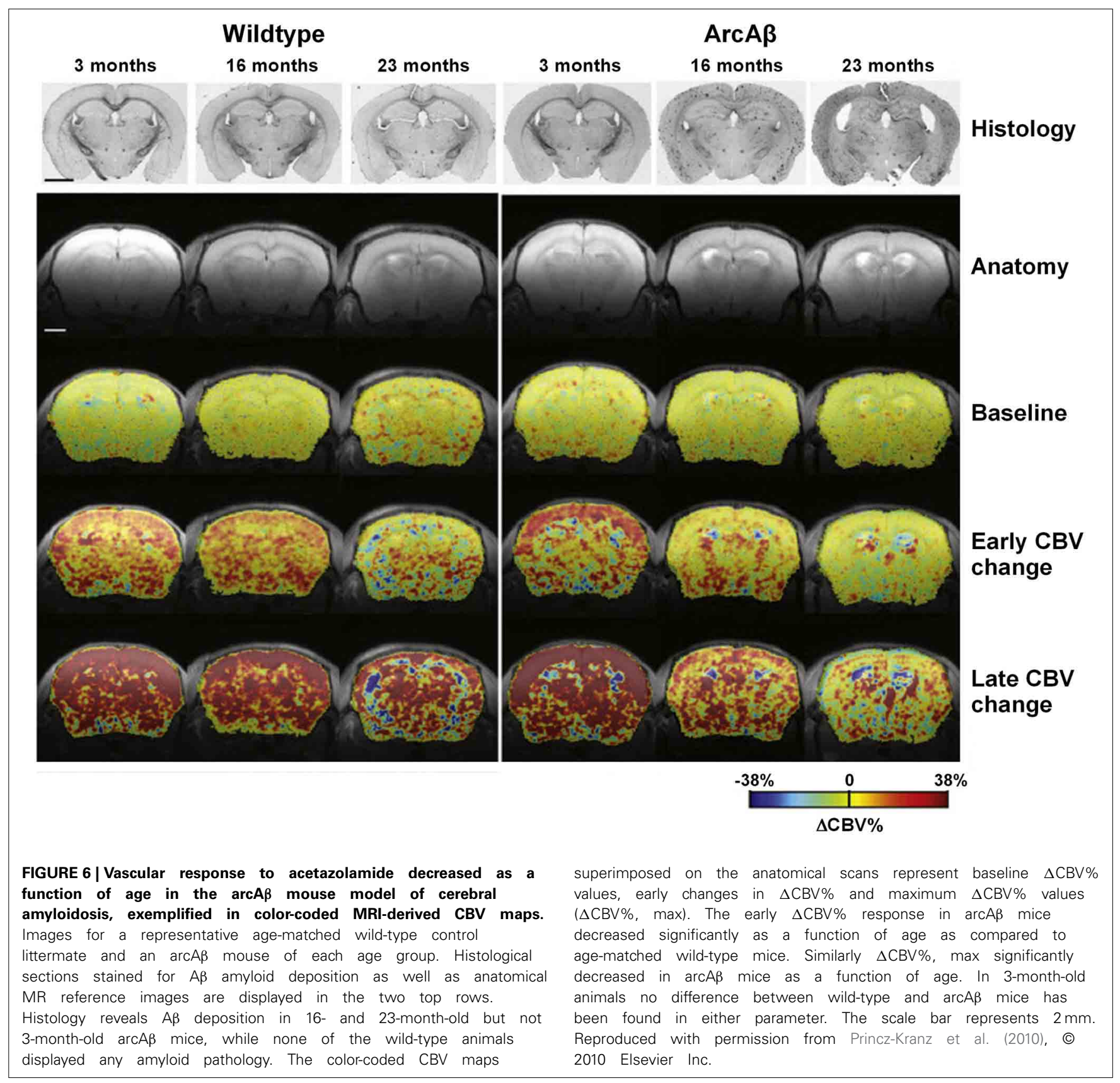

after administration of superparamagnetic iron oxide (SPIO) nanoparticles allowing the visualization of intracortical microvessels with high-resolution. A significant reduction in the number of functional vessels (radii of $20-80 \mu \mathrm{m}$ ) has been observed in 24 -month-old ArcA $\beta$ mice compared with age-matched wildtype mice, whereas there was no difference between transgenic and wildtype mice at 4 months of age. Immunohistochemistry demonstrated strong fibrinogen and $A \beta$ deposition in small- and medium-sized vessels, but not in large cerebral arteries, of 24month-old ArcA $\beta$ mice. The reduced density of transcortical functional vessels may thus be attributed to vascular occlusion caused by deposition of $A \beta$ and fibrin, which translated into impaired perfusion. Fibrin deposition has been observed previously in TgCRND8 mice (Paul et al., 2007; Cortes-Canteli et al., 2010) and since fibrin-binding probes are currently under development (Starmans et al., 2013) it may become possible to visualize cerebral fibrin deposition in these transgenic models in vivo in the near future.

The microvasculature which includes capillaries cannot be visualized directly with current MRA techniques. For this purpose, methods have been developed based on measuring the changes in the relaxation rates $\mathrm{R}_{2}^{*}$ and $\mathrm{R}_{2}$ after administration of a paramagnetic contrast agent with long blood half-life. Relaxation has been exploited in vessel size imaging, where maps can provide insight into the composition of vessel sizes in the brain in vivo (Tropres et al., 2001). A method closely related is to measure the relaxation rate shift index $\mathrm{Q}$ (Jensen and Chandra, 2000), where the index is sensitive to the density but not the 

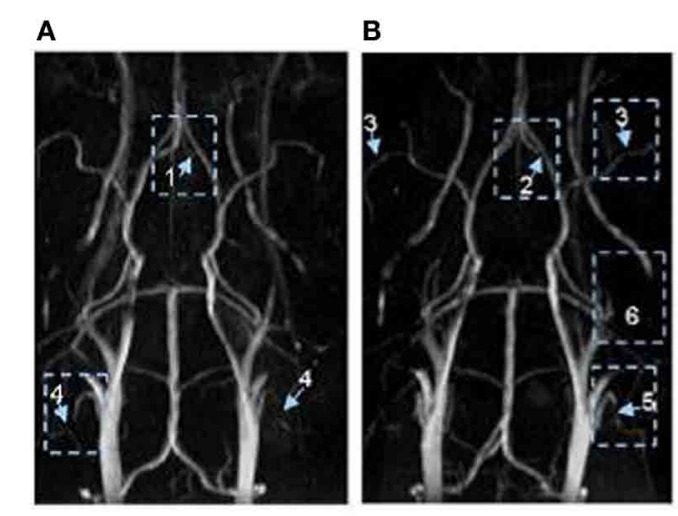
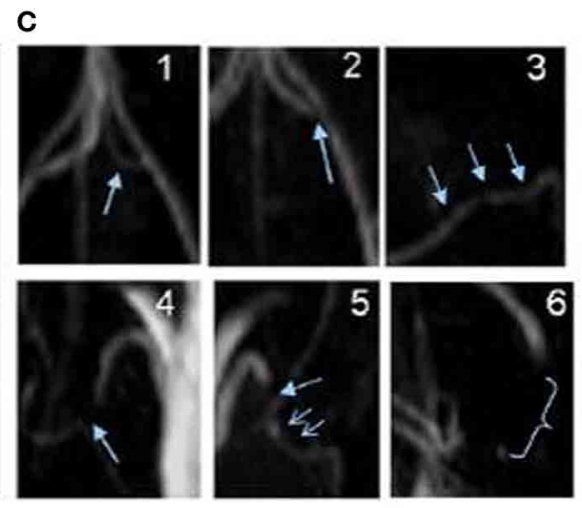

D

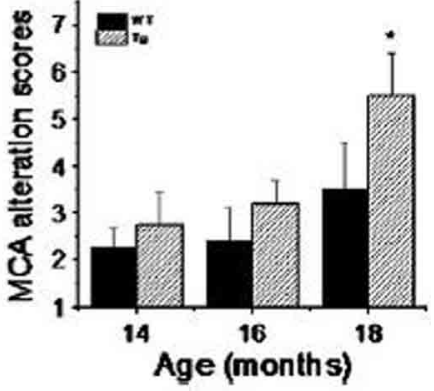

void (as observed in the external carotid artery on both sides in image A); 5, a combination of an extended void and several small signal voids (as observed in the external carotid artery on both sides in image B); 6, the signal is no longer visible (as shown at the pterygo portion of the pterygopalatine artery in image $\mathbf{A}, \mathbf{B}$ ). The enlarge view of alterations is shown in (C). (D) MCA alteration mean score in control and Tg2576 mice with age. Values are mean $\pm \mathrm{SE}$ (error bars); one-tail student $t$-test; $* P<0.05 ; n=4$. Reproduced with permission from Kara et al. (2012), (C) 2011 Elsevier Inc. size of microvessels. Weidensteiner et al. (2009) determined vessel size and density in different brain regions in PS2APP mice but observed no significant differences to wildtype littermates. However, in this strain CAA is sparse and affects only large arteries.

MRI has rendered itself the most versatile methodology to visualize vascular networks of large regions or even of the whole brain while retaining a sufficient high resolution to assess smaller vessels and to provide an estimation of microvascular density. Despite the fact that in transgenic mouse models it has been shown that CAA affects the cerebral vasculature at different hierarchical levels, what causes such structural alterations in cerebral vessels is not yet known. Chronic changes in levels of vasoactive mediators like soluble $A \beta$, vascular endothelial growth factor, transforming growth factor-1, and altered signaling or density of vascular receptors might be implicated and future imaging studies might address this by visualizing vascular remodeling in models where these medidators are modified. Moreover, imaging studies might be useful to elucidate the role of risk factors of $\mathrm{AD}$ like diabetes and hypertension on the vasculature of the $\mathrm{AD}$ brain. Indeed, hypertension, atherosclerosis, diabetes, dyslipidemia and adiposity may impact on vascular structure and function to promote neurodegenerative processes and instigate AD (see Kalaria et al., 2012 for a recent review). The presence of vascular pathology involving arterial stiffness, arteriolosclerosis, endothelial degeneration and BBB dysfunction leads to chronic cerebral hypoperfusion, which in turn induces several features of $\mathrm{AD}$ pathology including selective brain atrophy, white matter changes and accumulation of abnormal proteins such $A \beta$. To our knowledge, no imaging studies addressing specific questions related to atherosclerosis in $\mathrm{AD}$ mouse models have been reported so far. Nevertheless, it is worth stressing the fact that very important developments have been achieved in molecular imaging of atherosclerosis (the interested reader is referred to reviews by
Lobatto et al., 2011; Owen et al., 2011). Linking plaque anatomy and function to inflammation may help considerably to elucidate the mechanisms and complications related to atherosclerosis in AD.

\section{TARGETING NEUROVASCULAR INFLAMMATION}

A hallmark of AD is neuroinflammation which has been implicated to drive and even trigger neurodegeneration (Krstic and Knuesel, 2013). Inflammation involves also the cerebral vasculature, though the role of inflammation in the vasculopathy is not well understood. Macrophages and microglia surround amyloid affected vessels (Maat-Schieman et al., 1997; Vinters et al., 1998) and circulating macrophages have been shown to migrate from the lumen into the vessel wall (Vinters et al., 1998). Intercellular adhesion molecule-1 is upregulated at the endothelium in the AD brain (Frohman et al., 1991). Moreover, the inflammatory response of the vasculature is increased in the presence of $A \beta$ (Vromman et al., 2013). A few imaging studies suggesting that inflammation might have deleterious consequences on vascular function are discussed next.

Different strategies to image vascular inflammation have been pursued comprising the labeling of inflammatory cells, the use of fluorogenic substrates for enzymes and fluorescent or PET probes targeted against inflammatory receptors (Wunder and Klohs, 2008; Wunder et al., 2009; Aalto et al., 2011; Li et al., 2013). Garcia-Alloza et al. (2009) have observed a strong association between CAA, matrix metalloproteinases and oxidative stress in leptomeningeal vessels of APPswe/PS1dE9 and Tg2576 with multiphoton microscopy and fluorogenic probes. The matrix metalloproteinases activity was found to be associated with matrix degradation and loss of vascular integrity.

In a different approach, mice of different transgenic lines have been examined with MRI following the intravenous administration of SPIO nanoparticles (Beckmann et al., 2011), which 
were hypothesized to having been taken up by circulating monocytes through absorptive endocytosis (Weissleder et al., 1990; Beckmann et al., 2009). Foci of signal attenuation were detected in cortical and thalamic brain regions of aged APP23 mice (Figure 8). Histology confirmed the presence of iron-containing macrophages in the vicinity of CAA-affected blood vessels, suggesting that the foci of signal attenuation detected in vivo might be associated with CAA in the transgenic model. A fraction of the sites additionally showed thickened vessel walls and vasculitis. Consistent with the visualization of CAA-associated lesions, MRI detected a much smaller number of attenuated signal sites in APP23xPS45, APP24, and APP51 mice, which develop significantly less CAA and microvascular pathology than APP23. These results are consistent with monocytes and microglia being involved in amyloid deposition in the wall of capillaries and in perivascular plaques (Wegiel et al., 2004). Montagne et al. (2012) have used an antibody targeting the vascular adhesion molecule- 1 (VCAM-1) coupled to microparticles of iron oxide (MPIO). After injection of the probe MRI showed a significantly higher number of signal voids in the brains of 20-month-old APP/PS1 compared to age-matched wildtype controls. Immunohistochemistry revealed that VCAM-1 was overexpressed in APP/PS1 mice in all the brain regions studied (cortex, hippocampus and cerebellum). Despite APP/PS1 mice develop only minimal amyloid angiopathy (Radde et al., 2006) a significant cerebrovascular inflammation was detected in the cerebellum of these animals, which was associated with intravascular $\mathrm{A} \beta$ deposition (Montagne et al., 2012). Interestingly, the expression of VCAM-1 was significantly higher in the cerebellum compared to the cortex in transgenic mice. Accordingly, signal voids induced by MPIOs- $\alpha$ VCAM- 1 and detected by MRI were significantly increased in APP/PS1 mice in all structures compared to age-matched wildtype mice.

Microglial-vascular interactions may play a critical role in the amplification and perpetuation of inflammatory reactivity in $\mathrm{AD}$ brain. Indeed, post-mortem examination of medial temporal cortical tissue from humans revealed that microgliosis was progressively increased from non-demented controls to mild AD to severe $\mathrm{AD}$ with the latter demonstrating areas of clustered microglia (Jantaratnotai et al., 2010). Microglial clusters in severe $\mathrm{AD}$ brain were in close proximity with extravascular laminin and also plasma protein, fibrinogen, implicating vascular perturbation as a component of inflammatory reactivity. Microscopy studies of microglial function in murine AD models may help to better understand microglial-vascular interactions.

So far high resolution in vivo studies of microglial function were conducted in mice with genetically labeled microglia. However, because of the low expression levels of green fluorescent protein, some mouse lines are less suitable for studying the role of microglia under pathological conditions. The availability of a non-genetically encoded, easy to use marker, enabling high quality staining of microglia in any mouse strain at any experimental age would obviously be very attractive. Schwendele et al. (2012) utilized tomato lectin from Lycopersicon esculentum (Acarin et al., 1994; Boucsein et al., 2000) for high resolution in vivo imaging of microglia. A brief pressure injection of tomato lectin conjugated with a fluorescent dye (DyLight $\left.{ }^{\circledR} 594\right)$ into the mouse cortex resulted in robust staining of microglial cells and blood vessels. The latter were easily distinguished from microglia based on their morphological appearance. The reliability of the in vivo staining protocol was tested in different mouse lines.

Since vascular inflammation has been implicated to partake in the deleterious consequences of CAA like degeneration of vascular smooth muscle cells and hemorrhage (Maat-Schieman et al., 1997), but still very little is known between the interaction of inflammation and vascular pathology. Further studies are warranted to investigate when and how inflammation is involved.

\section{DETECTION OF BLOOD-BRAIN BARRIER INTEGRITY LOSS AND OF CEREBRAL MICROBLEEDS}

Severe CAA is characterized by the degeneration of the vessel wall, leading to a double-barreled appearance of the vessels with an intact adventitia, a thickened basement membrane that contains $\mathrm{A} \beta$-deposits, and a widely degenerated smooth muscle cell layer (Thal et al., 2008a). Areas of fibrinoid necrosis can be frequently observed in these vessels. Degeneration of vascular smooth muscle cells lead to a loss of BBB function and eventually to vessel rupture with the occurrence of $\mathrm{CMBs}$ and hemorrhage. In this section, we address the detection of BBB leakage and of CMBs using MRI.

Imaging of the BBB with MRI has been widely applied to pathologies such as brain tumors and metastases, stroke and head trauma (Giesel et al., 2010). In dynamic contrast-enhanced MRI (DCE-MRI), a series of images is acquired during intravenous bolus injection of Gd-based contrast agents. Kinetic modeling of the contrast agent can provide information on vascular leakage (Tofts and Kernode, 1991). The method has for example been used to predict the occurrence of hemorrhage after ischemic stroke (Kassner et al., 2005). Klohs et al. (2013) have performed a longitudinal MRI study where DCE-MRI was applied in ArcA $\beta$ and wildtype mice. While vascular leakage of the contrast agent was significantly associated with age, there was no effect of genotype. This finding was surprising as compromised BBB function has been described for the $\operatorname{ArcA} \beta$ strain (Merlini et al., 2011). When aged $\operatorname{Arc} A \beta$ mice were injected intravenously with Trypan blue, leakage of the dye was observed around $A \beta$-affected vessels. Moreover, aged ArcA $\beta$ mice showed $\mathrm{CMBs}$ indicative of severe vascular pathology (Klohs et al., 2011, 2013).

The observation made in the transgenic animals is in line with studies in $\mathrm{AD}$ and MCI patients, where no differences in contrast agent kinetics have been detected with respect to healthy controls (Caserta et al., 1998; Starr et al., 2009). The discrepancy of the DCE-MRI findings might be explained by the fact that BBB dysfunction in $\mathrm{AD}$ is subtle and diffuse when compared to diseases such as brain tumors, multiple sclerosis and stroke, for which the impairment is relatively large and focal (Giesel et al., 2010). Hence, DCE-MRI may not be sensitive enough for detecting BBB impairment in mouse models of $\mathrm{AD}$ in vivo.

CMBs and hemorrhages can be detected with CT and MRI techniques with the latter being more often used for diagnosis (Sperling et al., 2011). T $\mathrm{T}_{2}^{*}$-weighted gradient-echo MRI protocols, which are sensitive to paramagnetic iron compounds such as hemosiderin found in blood degradation products, reveal CMBs in patients as focal hypointensities typically occurring as round or ovoid areas (Pettersen et al., 2008; Ayaz et al., 


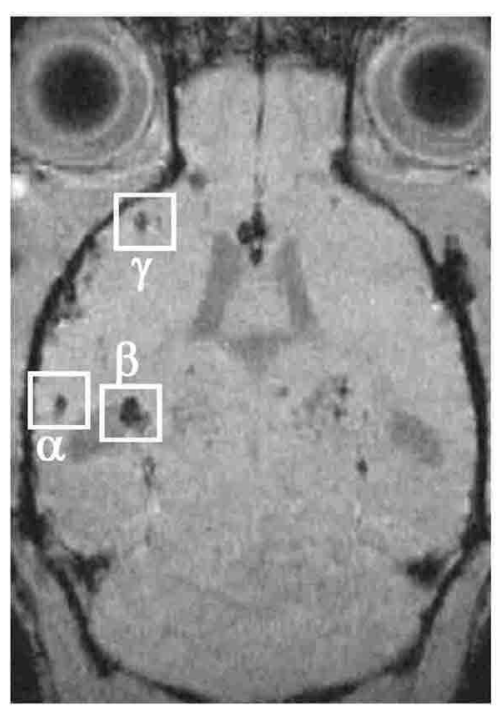

$\alpha$

Perls/Congo red (bright field )

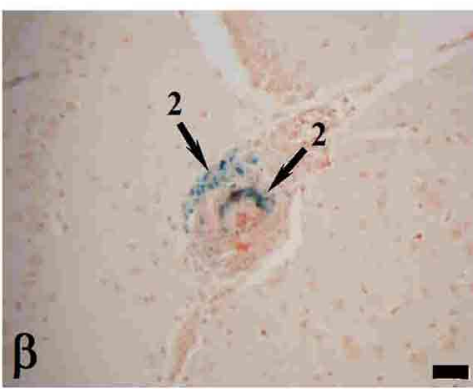

Perls/Congo red (bright field)

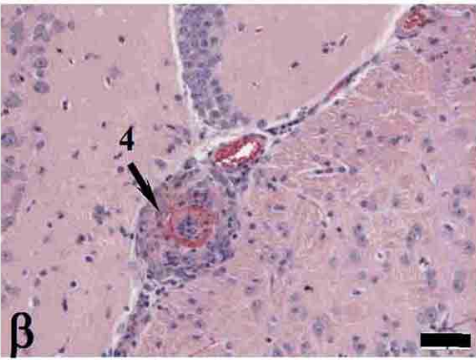

\section{Hematoxylin eosin}

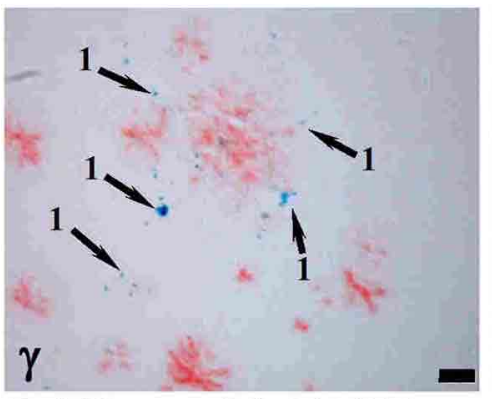

Perls/Congo red (bright field)

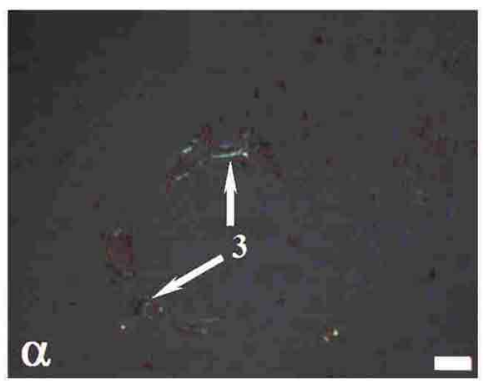

Perls/Congo red (polarized)

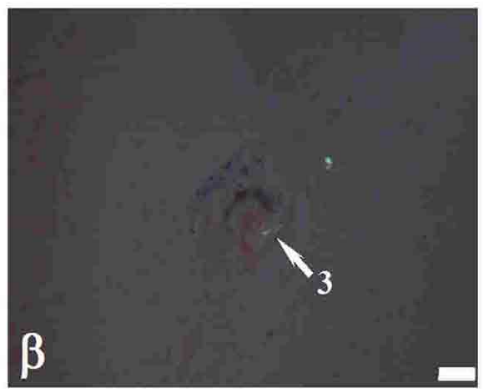

Perls/Congo red (polarized)
FIGURE 8 | MRI detection of CAA-related microvascular alterations utilizing superparamagnetic iron oxide (SPIO) particles. Histological examination of cerebral cortex sites with foci of attenuated MRI signal $(\alpha, \beta, \gamma)$. At $24 \mathrm{~h}$ following SPIO administration, a male 28-month-old APP23 mouse was analyzed in vivo by MRI and processed for histology immediately thereafter. Perls/Prussian blue staining showed iron-loaded macrophages in CAA-laden vessels (Congo red positive) at both sites ( $\alpha$ and $\beta$ ). While the vessel walls were thickened at both $\alpha$ and $\beta$ locations, only site $\beta$ showed in addition vasculitis characterized by lymphocyte infiltration (Hematoxylin eosin). At site $\gamma$, isolated iron-loaded macrophages were present close to amyloid vessels. 1, Iron in isolated macrophages; 2, iron in macrophages at the vessel wall; 3 , amyloid deposit in vessel wall; 4, vasculitis; P, amyloid plaque. Scale bars, $50 \mu \mathrm{m}$. Congo red-stained sections were observed under bright field or polarized light. Reproduced from Beckmann et al. (2011), (c) 2011 the authors.
2010; Sperling et al., 2011). The occurrence of CMBs has also been reported for transgenic APP mice with CAA. For example, Beckmann et al. (2011) described the presence of foci of low signal intensity in cortical and thalamic brain regions of aged
APP23 mice. Klohs et al. (2011) demonstrated in ArcA $\beta$ mice that quantitative susceptibility mapping provides increased detection sensitivity of CMBs and improved contrast when compared with conventional $\mathrm{T}_{2}^{*}$-weighted gradient-echo magnitude 

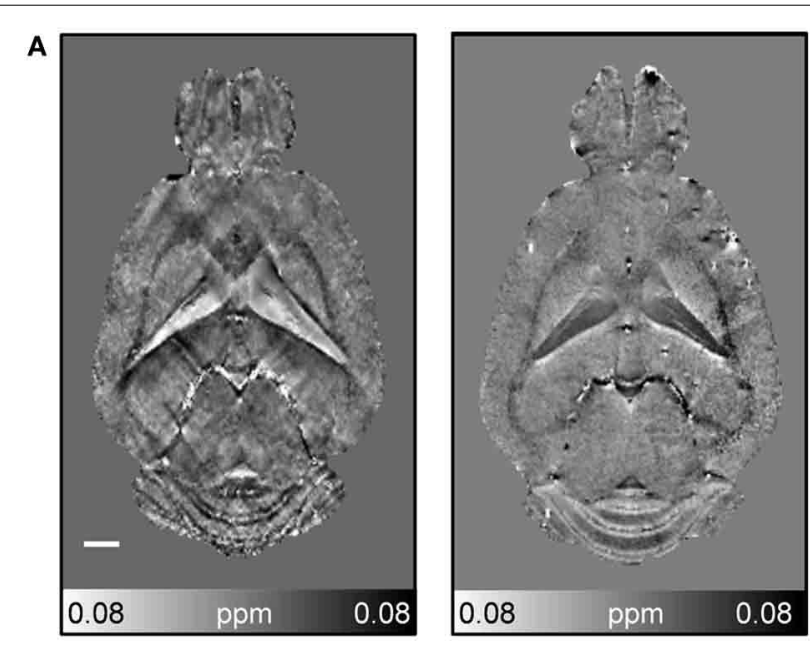

B
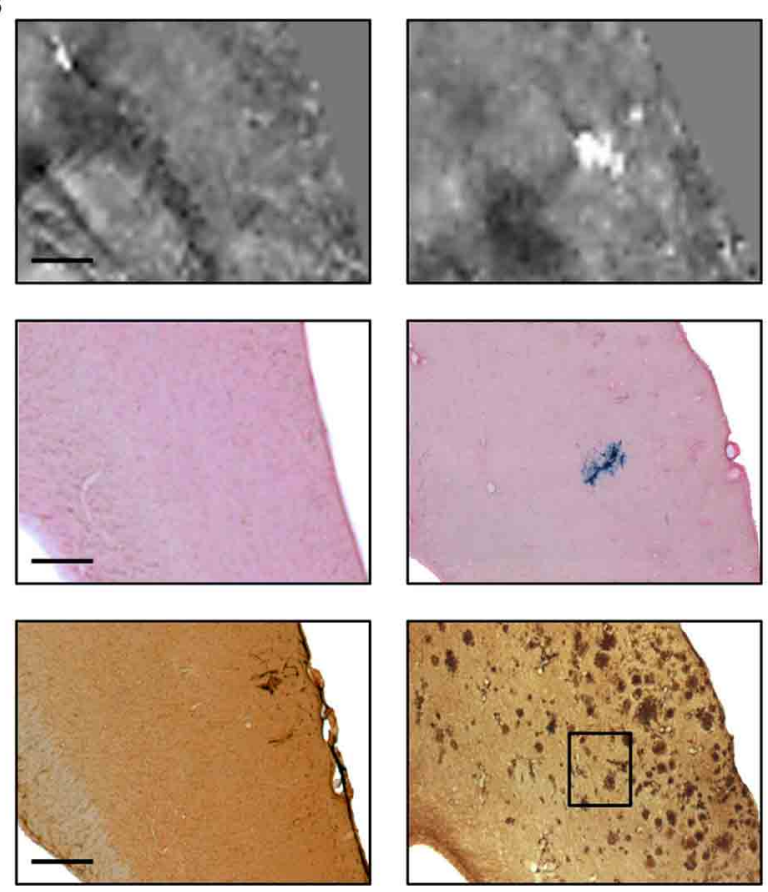

FIGURE 9 | Detection of CMBs using quantitative susceptibility mapping MRI. (A) Horizontal quantitative susceptibility maps of an 18-month-old wild type animal and of an age-matched transgenic arcA $\beta$ mouse. (B) Quantitative susceptibility maps with corresponding tissue section after Prussian blue/eosin staining and anti-A $\beta$ immunohistochemistry. Focal areas of high susceptibility in the cortex of 18-month old arcA $\beta$ mice correspond to areas of focal iron accumulation, indicating the occurrence of cerebral microbleeds in this mouse strain. Modified from Klohs et al. (2011), @ 2011 ISCBFM.

imaging (Figure 9). Quantitative susceptibility maps were generated from phase data acquired with a high-resolution $\mathrm{T}_{2}^{*}$ weighted gradient-echo sequence depicting both the localization and spatial extent of CMBs with high accuracy.

Taken together, assessment of BBB with current DCE-MRI methods does not seem to be sensitive enough to detect vascular leakage. Advances in imaging technology enable the improved diagnostic detection of CMBs in patients and animal models. The assessment of CMB load can be used in studies to estimate the severity of CAA and to monitor the effect of therapy.

\section{ASSESSING THE EFFECTS OF THERAPIES TARGETING VASCULAR PATHOLOGY IN AD}

Clinical therapeutic trials in $\mathrm{AD}$ patients performed so far were disappointing. Based on activities in animal models suggesting that prevention or early intervention may be a viable strategy for $\mathrm{AD}$ treatment, there is a trend toward treating patients at very early stages of disease or even preventatively (Bateman et al., 2012; Fleisher et al., 2012). Obviously, biomarker development, including imaging, is an essential part of this endeavor, in order to select the right patients to be treated early (Reiman et al., 2012). In this section, we briefly discuss a few therapy-intervention studies in animals addressing vascular pathology related to AD.

Therapeutic strategies have targeted APP processing, as well as the trafficking of soluble $\mathrm{A} \beta$ and strategies to remove aggregated A $\beta$. Gregory et al. (2012) analyzed in Tg2576 mice A $\beta$ deposition in vessels and clearance from vascular walls and their relationship to the concentration of $A \beta$ in the brain. Levels of $\mathrm{A} \beta$ in the brain were modulated either by peripheral clearance through administration of gelsolin which binds with high affinity to plasma A $\beta$ (Matsuoka et al., 2003), or by directly inhibiting its formation via administration of LY-411575, a small-molecule $\gamma$-secretase inhibitor. Both gelsolin and LY-411575 reduced the rate of CAA progression in $\operatorname{Tg} 2576$ mice in the absence of an immune response. The progression of CAA was also halted when gelsolin was combined with LY-411575. These data suggest that CAA progression can be prevented with non-immune therapy approaches that may reduce the availability of soluble $A \beta$. Yet there was no evidence for substantial clearance of $A \beta$ already deposited at vessels.

Yang et al. (2011) assessed the therapeutic potential of blocking apolipoprotein $\mathrm{E}$ (ApoE)/A $\beta$ interactions, by administering an $A \beta$ fragment $\left(A \beta_{12-28 \mathrm{P}}\right)$ to young TgSwDI mice (from 3 to 9 months of age). Increased cognitive function, decreased cortical, hippocampal and thalamic fibrillar vascular amyloid burden, and decreased extent of cerebral hemorrhages was found in treated compared with untreated TgSwDI mice. While this therapeutic strategy holds promise in young mice, it would be of interest to verify whether it would be effective in older animals.

Two studies demonstrated the stereoisomer of inositol, scylloinositol, to have potential therapeutic properties to treat CAA. When given orally to TgCRND8 mice, scyllo-inositol inhibited $\mathrm{A} \beta$ aggregation into high-molecular-weight oligomers in the brain and ameliorated several AD-like phenotypes in these mice, including impaired cognition, altered synaptic physiology, and cerebral A $\beta$ pathology (McLaurin et al., 2006). These therapeutic effects, which occurred regardless of whether the compound was given before or well after the onset of the $\mathrm{AD}$-like phenotypes, support the idea that the accumulation of $A \beta$ oligomers plays a central role in the disease pathogenesis. Multiphoton laser scanning microscopy examinations of TgCRND8 mice in vivo revealed that structural changes of cortical arterioles (increase in tortuosity and decrease in caliber) with amyloid- $\beta$ peptide accumulation were accompanied by progressive functional compromise, 
reflected in higher dispersion of microvascular network transit times, elongation of the transit times, and impaired microvascular reactivity to hypercapnia in the transgenic mice (Dorr et al., 2012). However, administration of scyllo-inositol rescued both structural and functional impairment of the cortical microvasculature (Figure 10). Overall, these results suggest microvascular impairment to be directly correlated with $A \beta$ accumulation, highlighting the importance of targeting CAA clearance for effective diagnosis, monitoring of disease progression and treatment of AD.

Epidemiological studies have provided evidence that statins, cholesterol-lowering drugs broadly used in the treatment of cardiovascular diseases, have therapeutic potential in AD (Jick et al., 2000; Wolozin et al., 2000) and to a slower cognitive decline in mild-to-moderate AD patients (Sparks et al., 2006). Studies in animals have revealed that the effects of statin treatment are not due to their vascular and anti-inflammatory effects rather than their cholesterol-lowering effect. Tong et al. (2012) reported that a 3-6 months treatment with simvastatin completely rescued cerebrovascular reactivity, basal endothelial nitric oxide synthesis, and activity-induced neurometabolic and neurovascular coupling in adult (6 months) and aged (12 months) J20 hAPP transgenic mice. Remarkably, simvastatin fully restored short- and long-term memory in adult mice, but not in aged $\mathrm{AD}$ mice. These beneficial effects occurred without any decreasing effect of simvastatin on brain $A \beta$ levels or plaque load. However, in $\mathrm{AD}$ mice with recovered memory, protein levels of the learningand memory-related immediate early genes c-Fos and Egr-1 were normalized or upregulated in hippocampal CA1 neurons, indicative of restored neuronal function. Simvastatin also restored the $\mathrm{CBF}$ response in the somatosenory cortex to whisker simulation in 6- and 12-month-old J20 hAPP mice, and restored whiskerstimulated cerebral glucose uptake in the somatosensory cortex of 12-month-old APP mice as assessed by FDG-PET. These findings disclose new sites of action for statins against $A \beta$-induced neuronal and cerebrovascular deficits that could be predictive of therapeutic benefit in $\mathrm{AD}$ patients. They further indicate that simvastatin and, possibly, other brain penetrant statins bear high therapeutic promise in early $\mathrm{AD}$ and in patients with vascular diseases who are at risk of developing $\mathrm{AD}$.

Treatment with angiotensin receptor blockers has been associated to reduce AD-related pathology (Hajjar et al., 2012) or with a lower risk and slower disease progression compared to other antihypertensive agents ( $\mathrm{Li}$ et al., 2010). These data indicate that angiotensin receptor blockers not only decrease blood pressure but also decrease vascular inflammation may effectively reduce the risk of developing AD (Hajjar et al., 2012). Wang et al. (2007) screened 55 clinically prescribed antihypertensive medications for AD-modifying activity using primary cortico-hippocampal neuron cultures generated from $\mathrm{Tg} 2576$ mice. Despite 7 antihypertensive agents reduced $\mathrm{A} \beta$ accumulation, only valsartan was capable of attenuating oligomerization of $\mathrm{A} \beta$ peptides into high-molecular-weight oligomeric peptides, known to be involved in cognitive deterioration. Preventive treatment of Tg2576 mice with valsartan significantly reduced AD-type neuropathology and the content of soluble extracellular oligomeric $\mathrm{A} \beta$ peptides in the brain. Most importantly, valsartan administration also attenuated the development of $\mathrm{A} \beta$ mediated cognitive deterioration. These preclinical studies suggest that certain antihypertensive drugs may have $\mathrm{AD}$-modifying activity and may protect against progressive $A \beta$-related memory deficits in subjects with $\mathrm{AD}$ or in those at high risk of developing AD.

$\mathrm{A} \beta$ removing therapies are currently tested in clinical trials and have also been studied in transgenic animals, yielding conflicting results. Using multiphoton microscopy, Prada et al. (2007) showed that anti-A $\beta$ passive immunotherapy can remove cerebral A $\beta$ in Tg2576 mice, depending on the duration of treatment. Clearance of CAA and neuritic deposits was detected within 1 week after a single administration of 10D5, an antibody against the $\mathrm{N}$-terminal of $\mathrm{A} \beta$, directly to the brain, but the effect on CAA was only transient. Moreover, the progression rate of CAA became greater in the antibody treated group, suggesting that vascular $A \beta$ deposition may accelerate after shortlived clearance. Chronic administration of the antibody over 2 weeks led to a more robust clearance of CAA. Other studies have shown that $A \beta$ immunotherapy may also at least transiently worsen CAA, with increased incidence of cerebral microhemorrhages in aged transgenic mice (Bard et al., 2000; Pfeifer et al., 2002; Wilcock et al., 2006; Schroeter et al., 2008; Thakker et al., 2009). This is in line with a study where SPIO-enhanced MRI revealed a higher number of sites with signal attenuation in APP23 mice following a chronic treatment with the A $\beta$ antibody $\beta 1$ (Beckmann et al., 2011). Histological analyses demonstrated an increased number of CAA vessels and of iron loaded macrophages in the vicinity of CAA vessels, for mice receiving the $\beta 1$ antibody. In addition, a study using $\mathrm{T}_{2}^{*}$-weighted MRI for the detection of CMBs in Tg2576 mice treated with either a non-selective antibody (6G1) targeting soluble and insoluble $\mathrm{A} \beta$ or a more selective antibody (8F5) targeting primarily soluble $\mathrm{A} \beta$ (Luo et al., 2010). Both antibodies increased CMB incidence in aged APP transgenic mice compared with baseline or vehicle treatment.

It has been hypothesized that the antibodies exert their beneficial as well as their deleterious effects via an antibody Fc domain-mediated microglial activation and $\mathrm{A} \beta$ phagocytosis (Bard et al., 2000; Wilcock et al., 2004b). KoenigsknechtTalboo et al. (2008) demonstrated that the effects of antibodies that recognize aggregated $A \beta$ are rapid and involve microglia. The anti-A $\beta$ antibody, m3D6, that binds to aggregated $\mathrm{A} \beta$ (Cirrito et al., 2003), was administered to PDAPP mice, an AD mouse model that was bred to contain fluorescent microglia. Three days after systemic administration of m3D6, there was a marked increase in both the number of microglial cells and processes per cell visualized in vivo by multiphoton microscopy (Figure 11). These changes required the Fc domain of m3D6 and were not observed with $\mathrm{mHJ} 5.1$, an antibody specific to soluble $\mathrm{A} \beta$.

Taken together, these studies demonstrate the potential of animal studies in therapy studies. Imaging studies are expected to play a pivotal role in this regard; their application ranging from safety testing of putative drugs e.g., detection of microbleeds, to elucidating mechanism of action, to monitoring of treatment efficacy. 


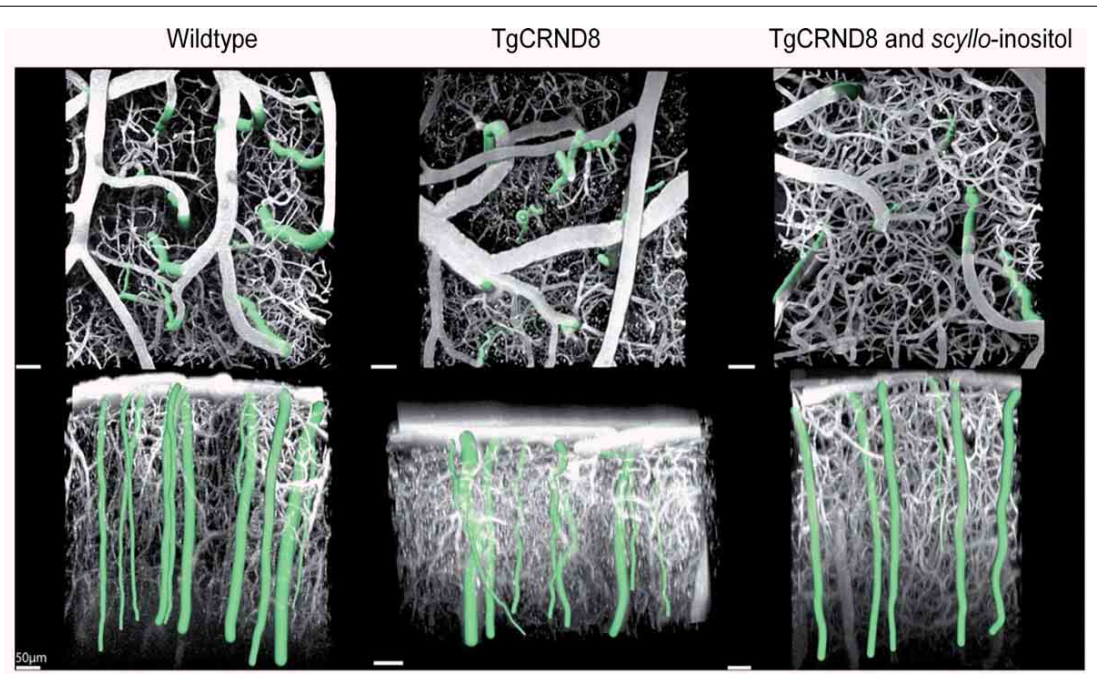

FIGURE 10 | Segmentation of cortical penetrating vessels overlaid on maximum intensity projections of cortical microvasculature obtained from in vivo two-photon fluorescence microscopy images of the cortical microcirculation of 6.5-12-month-old mice: parallel to cortical surface (top row) and perpendicular to cortical surface (bottom row). Penetrating vessels for each individual mouse are highlighted. Average tortuosity of penetrating vessels for each sample subject (mean \pm standard error): wild-type mice $1.03 \pm 0.003$, transgenic TgCRND8 mice $1.10 \pm 0.006$, scyllo-inositol-treated TgCRND8 mice $1.03 \pm 0.005$. Reproduced with permission from Dorr et al. (2012), @ 2012 the authors.
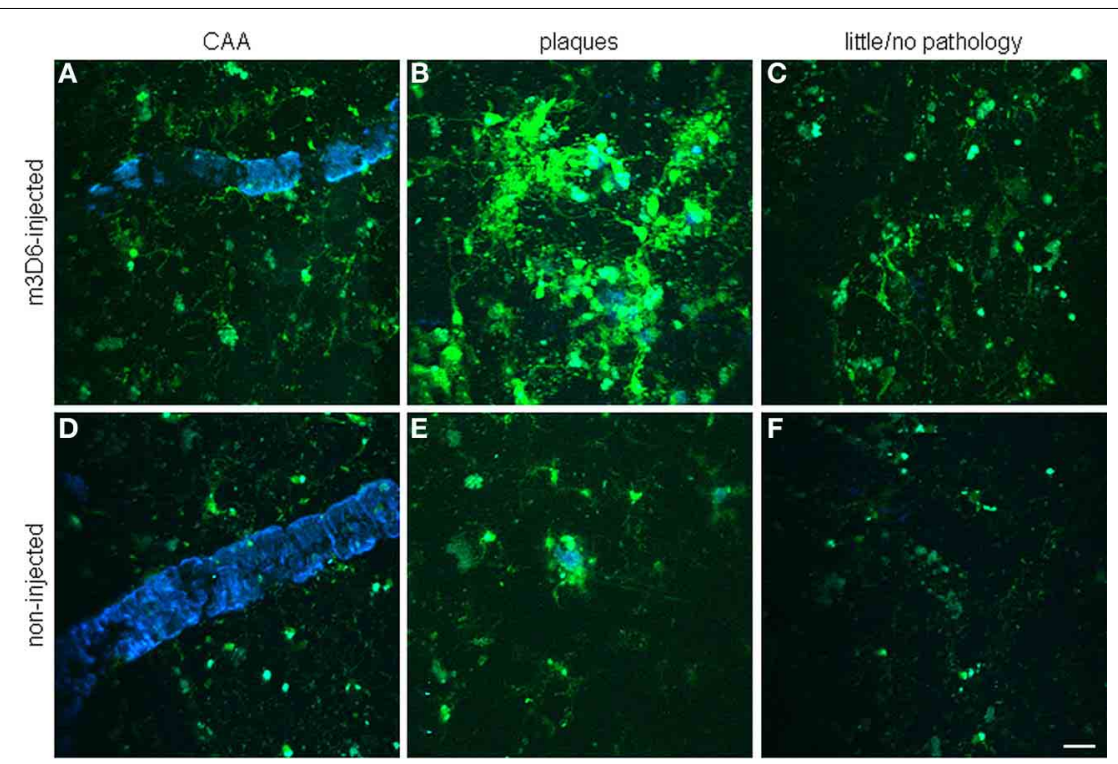

FIGURE 11 | Rapid microglial response around amyloid pathology after systemic anti-A $\beta$ antibody administration in PDAPP mice. Peripheral m3D6 administration results in marked morphological changes in microglia. Three-dimensional reconstructed z-series stack two-photon microscopy images taken of 22-month-old PDAPP \pm ;CX3CR1/green fluorescent protein \pm mice injected with $500 \mu \mathrm{g}$ of m3D6 (A-C), an anti-A $\beta$ antibody, or not injected (D-F). Green fluorescent protein-labeled microglia are green. Fibrillar amyloid was labeled with methoxy-XO4 (blue). Scale bar, $20 \mu \mathrm{m}$. Reproduced with permission from Koenigsknecht-Talboo et al. (2008), @ 2008 Society for Neuroscience.

\section{TRANSLATING IMAGING FINDINGS FROM ANIMAL MODELS} OF AD

Translational research from animal models to clinical studies and from human studies back to animal models is relevant for the development and validation of imaging biomarkers of AD. In particular, MRI as well as PET assays are well suited for translational applications. While many imaging findings presented here, for example chronic cerebral hypoperfusion or the occurrence of CMBs, have been observed both in transgenic mice overexpressing APP and in AD patients, some studies have reported a lack of concordance between imaging findings in mice and men. For example, the uptake of an amyloid PET tracer reflected the amount of $A \beta$ in $A D$ patients but not in transgenic mice due to species-specific differences in the affinity sites of $\mathrm{A} \beta$ between mice and humans (Klunk et al., 2005). In another example, Luo et al. (2012) observed a glucose hypermetabolism 
in the brain of 7-month-old Tg2576 mice, despite the fact that hemodynamic read-outs were not different to wildtype mice. This is in contrast to AD patients, where glucose hypometabolism and hypoperfusion were concomitantly observed (Nagata et al., 2000). The increase in glucose metabolism in $\mathrm{Tg} 2576$ has been attributed to a neuronal compensatory mechanism due to the APP overexpression and might thus constitute an artifact of the model.

In general, there are limitations in employing models for developing biomarkers of AD. Transgenic strains overexpressing APP have been widely used because they reproduce essential histopathological features and molecular mechanisms of AD. But these models might resemble more the familial forms of $\mathrm{AD}$ ( $<1 \%$ of $\mathrm{AD}$ cases) or Down syndrome rather than the sporadic, late-onset form of $\mathrm{AD}$. Some double and triple transgenic lines have been generated to overlay amyloid with tau and presenilin pathology (Blanchard et al., 2003; Oddo et al., 2003a,b). But even these strains do not recapitulate the complex pathophysiology of sporadic AD, which affects most AD patients. Moreover, while it is advantageous from an experimental perspective that the disease pathology in animals develops quickly, it could be an important feature of human $\mathrm{AD}$ that converging mechanisms which contribute to the impairment of brain function occur over a very long span and might be modulated by life-style choices and comorbidies.

Additional challenges occur when developing new therapies. Main potential reasons for the lack of concordance between preclinical models and human clinical trials could be wrong targets, incomplete models, lack of individual variability in the animal models, patients enrolled too late and comorbidities. As patients participating in clinical trials are heterogenous whereas most models utilize in-bred mouse strains, evaluating novel treatments in multiple lines may help to address this point. Also, the lack of substantial cell loss in the majority of rodent models may indicate that they better represent some aspects of the prodromal phase of the disease.

Emerging studies foster the relationship between vascular disease and tauopathy in AD. Recently, several post mortem studies on the brains of $\mathrm{AD}$ patients provided evidence that cardiovascular pathology like atherosclerosis is highly correlated with neuritic plaques, tau neurofibrillary tangles, and CAA (Roher et al., 2003; Beach et al., 2007; Yarchoan et al., 2012). However, imaging approaches addressing vascular aspects have not been applied to transgenic tau models so far. Similarly to the use of probes for targeting amyloid, such studies may profit from the recent development of PET tracer to image tau (Okamura et al., 2012; Maruyama et al., 2013).

Finally, animal models displaying chronic hypoperfusion (Shibata et al., 2004) or multiple microinfarcts (Wang et al., 2012b) and spontaneous hypertensive rats (Calcinaghi et al., 2013) are being used to investigate the role of vascular risk factors and pathological mechanisms in the etiology of dementia.

\section{CONCLUSION}

The potential of imaging techniques to study cerebrovascular pathology in animal models of $\mathrm{AD}$ has just been started to be fully exploited. The presented examples using genetically engineered mice demonstrate the extreme versatility of the application of imaging tools, which can provide information on gross vascular morphologyand probehemodynamic function down to address the basic mechanisms underlying CAA and neurovascular dysfunction. While the microscopic techniques are inherently invasive and thus nottranslatableto AD patients, thenon-invasivetechniqueslikePET and MRI can be translated and might thus provide biomarkers of the disease. Imaging of animal models is ideally suited for developing such diagnostic assays. But challenges remain in the selection of a suitable animal model to address a specific research question related to the vascular aspects of $\mathrm{AD}$.

\section{REFERENCES}

Aalto, K., Autio, A., Kiss, E. A., Elima, K., Nymalm, Y., Veres, T. Z., et al. (2011). Siglec-9 is a novel leukocyte ligand for vascular adhesion protein-1 and can be used in PET imaging of inflammation and cancer. Blood 118, 3725-3733. doi: 10.1182/blood-2010-09-311076

Acarin, L., Vela, J. M., González, B., and Castellano, B. (1994). Demonstration of poly-N-acetyl lactosamine residues in ameboid and ramified microglial cells in rat brain by tomato lectin binding. J. Histochem. Cytochem. 42, 1033-1041. doi: 10.1177/42.8.8027523

Allen, B., Ingram, E., Takao, M., Smith, M. J., Jakes, R., Virdee, K., et al. (2002). Abundant tau filaments and nonapoptotic neurodegeneration in transgenic mice expressing human P301S tau protein. J. Neurosci. 22, 9340-9351.

Alsop, D. C., Dai, W., Grossman, M., and Detre, J. A. (2010). Arterial spin labeling blood flow MRI: its role in the early characterization of Alzheimer's disease. J. Alzheimer Dis. 20, 871-880. doi: 10.3233/JAD-2010-091699

Anderson, C. M., and Nedergaard, M. (2003). Astrocyte-mediated control of cerebral microcirculation. Trends Neurosci. 26, 340-344. doi: 10.1016/S01662236(03)00141-3

Arbel-Ornath, M., Hudry, E., Eikermann-Haerter, K., Hou, S., Gregory, J. L., Zhao, L., et al. (2013). Interstitial fluid drainage is impaired in ischemic stroke and Alzheimer's disease mouse models. Acta Neuropathol. 126, 353-364. doi: 10.1007/s00401-013-1145-2

Ayaz, M., Boikov, A. S., Haacke, E. M., Kido, D. K., and Kirsch, W. M. (2010). Imaging cerebral microbleeds using susceptibility weighted imaging: one step toward detecting vascular dementia. J. Magn. Reson. Imaging 31, 142-148. doi: 10.1002/jmri.22001

Badea, A., Gewalt, S., Avants, B. B., Cook, J. J., and Johnson, G. A. (2012). Quantitative mouse brain phenotyping based on single and multispectral MR protocols. Neuroimage 63, 1633-1645. doi: 10.1016/j.neuroimage.2012. 07.021

Baltes, C., Radzwill, N., Bosshard, S., Marek, D., and Rudin, M. (2009). Micro MRI of the mouse brain using a novel $400 \mathrm{MHz}$ cryogenic quadrature RF probe. NMR Biomed. 22, 834-842. doi: 10.1002/nbm.1396

Bard, F., Cannon, C., Barbour, R., Burke, R. L., Games, D., Grajeda, H., et al. (2000). Peripherally administered antibodies against amyloid $\mathrm{A} \beta$-peptide enter the central nervous system and reduce pathology in a mouse model of Alzheimer disease. Nat. Med. 6, 916-919. doi: 10.1038/78682

Bateman, R. J., Xiong, C., Benzinger, T. L., Fagan, A. M., Goate, A., Fox, N. C., et al. (2012). Clinical and biomarker changes in dominantly inherited Alzheimer's disease. N. Engl. J. Med. 367, 795-804. doi: 10.1056/NEJMoa1202753

Beach, T. G., Wilson, J. R., Sue, L. I., Newell, A., Poston, M., Cisneros, R., et al. (2007). Circle of Willis atherosclerosis: association with Alzheimer's disease, neuritic plaques and neurofibrillary tangles. Acta Neuropathol. 113, 13-21. doi: 10.1007/s00401-006-0136-y

Beckmann, N. (2000). High resolution magnetic resonance angiography non-invasively reveals mouse strain differences in the cerebrovascular anatomy in vivo. Magn. Reson. Med. 44, 252-258. doi: 10.1002/15222594(200008)44:2<252::AID-MRM12>3.0.CO;2-G

Beckmann, N. (2011). Probing cerebrovascular alterations in Alzheimer's disease using MRI: from transgenic models to patients. Curr. Med. Imag. Rev. 7, 51-61. doi: 10.2174/157340511794653531

Beckmann, N., Cannet, C., Babin, A. L., Blé, F. X., Zurbruegg, S., Kneuer, R., et al. (2009). In vivo visualization of macrophage infiltration and activity in 
inflammation using MRI. Wiley Interdiscip. Rev. Nanomed. Nanobiotechnol. 1, 272-298. doi: 10.1002/wnan.16

Beckmann, N., Gérard, C., Abramowski, D., Cannet, C., and Staufenbiel, M. (2011). Non-invasive MRI detection of cerebral amyloid angiopathy related microvascular alterations utilizing superparamagnetic iron oxide particles in APP transgenic mouse models of Alzheimer's disease: application to passive A $\beta$ immunotherapy. J. Neurosci. 31, 1023-1031. doi: 10.1523/JNEUROSCI.493610.2011

Beckmann, N., Schuler, A., Mueggler, T., Meyer, E. P., Wiederhold, K. H., Staufenbiel, M., et al. (2003). Age-dependent cerebrovascular abnormalities and blood flow disturbances in APP23 mice modeling Alzheimer's disease. J. Neurosci. 23, 8453-8459.

Beckmann, N., Stirnimann, R., and Bochelen, D. (1999). High resolution magnetic resonance angiography of the mouse brain: application to murine focal cerebral ischemia models. J. Magn. Reson. 140, 442-450. doi: 10.1006/jmre. 1999.1864

Bell, R. D., and Zlokovic, B. V. (2009). Neurovascular mechanisms and blood-brain barrier disorder in Alzheimer's disease. Acta Neuropathol. 118, 103-113. doi: 10.1007/s00401-009-0522-3

Biffi, A., and Greenberg, S. M. (2011). Cerebral amyloid angiopathy: a systematic review. J. Clin. Neurol. 7, 1-9. doi: 10.3988/jen.2011.7.1.1

Billings, L. M., Oddo, S., Green, K. N., McGaugh, J. L., and LaFerla, F. M. (2005). Intraneuronal abeta causes the onset of early Alzheimer's diseaserelated cognitive deficits in transgenic mice. Neuron 45, 675-688. doi: 10.1016/j.neuron.2005.01.040

Bittner, T., Fuhrmann, M., Burgold, S., Ochs, S. M., Hoffmann, N., Mitteregger, G., et al. (2010). Multiple events lead to dendritic spine loss in triple transgenic Alzheimer's disease mice. PLoS ONE 5:e15477. doi: 10.1371/journal.pone.0015477

Blanchard, V., Moussaoui, S., Czech, C., Touchet, N., Bonici, B., and Planche, M. (2003). Time sequence of maturation of dystrophic neurites associated with Ab deposits in APP/PS1 transgenic mice. Exp. Neurol. 184, 247-263. doi: 10.1016/S0014-4886(03)00252-8

Boche, D., Zotova, E., Weller, R. O., Love, S., Neal, J. W., and Pickering, R. M. (2008). Consequence of $\mathrm{A}\{$ beta $\}$ immunization on the vasculature of human Alzheimer's disease brain. Brain 131, 3299-3310. doi: 10.1093/brain/ awn261

Bornebroek, M., De Jonghe, C., Haan, J., Kumar-Singh, S., Younkin, S., Roos, R., et al. (2003). Hereditary cerebral hemorrhage with amyloidosis Dutch type (AbetaPP 693): decreased plasma amyloid-beta 42 concentration. Neurobiol. Dis. 14, 619-623. doi: 10.1016/j.nbd.2003.08.019

Bosshard, S. C., Baltes, C., Wyss, M. T., Mueggler, T., Weber, B., and Rudin, M. (2010). Assessment of brain responses to innocuous and noxious electrical forepaw stimulation in mice using BOLD fMRI. Pain 151, 655-663. doi: 10.1016/j.pain.2010.08.025

Boucsein, C., Kettenmann, H., and Nolte, C. (2000). Electrophysiological properties of microglial cells in normal and pathologic rat brain slices. Eur. J. Neurosci. 12, 2049-2058. doi: 10.1046/j.1460-9568.2000.00100.x

Braakman, N., Matysik, J., van Duinen, S. G., Verbeek, F., Schliebs, R., de Groot, H. J., et al. (2006). Longitudinal assessment of Alzheimer's beta-amyloid plaque development in transgenic mice monitored by in vivo magnetic resonance microimaging. J. Magn. Reson. Imaging 24, 530-536. doi: 10.1002/jmri. 20675

Buee, L., Hof, P. R., Bouras, C., Delacourte, A., Perl, D. P., and Morrison, J. H. (1994). Pathological alterations of the cerebral microvasculature in Alzheimer's disease and related dementing disorders. Acta Neuropathol. 87, 469-480. doi: 10.1007/BF00294173

Burgold, S., Bittner, T., Dorostkar, M. M., Kieser, D., Fuhrmann, M., Mitteregger, G., et al. (2011). In vivo multiphoton imaging reveals gradual growth of newborn amyloid plaques over weeks. Acta Neuropathol. 121, 327-335. doi: 10.1007/s00401-010-0787-6

Busche, M. A., Chen, X., Henning, H. A., Reichwald, J., Staufenbiel, M., Sakmann, B., et al. (2012). Critical role of soluble amyloid- $\beta$ for early hippocampal hyperactivity in a mouse model of Alzheimer's disease. Proc. Natl. Acad. Sci. U.S.A. 109, 8740-8745. doi: 10.1073/pnas.1206171109

Busche, M. A., Eichhoff, G., Adelsberger, H., Abramowski, D., Wiederhold, K. H., and Haass, C. (2008). Clusters of hyperactive neurons near amyloid plaques in a mouse model of Alzheimer's disease. Science 321, 1686-1689. doi: 10.1126/science. 1162844
Calcinaghi, N., Wyss, M. T., Jolivet, R., Singh, A., Keller, A. L., Winnik, S., et al. (2013). Multimodal imaging in rats reveals impaired neurovascular coupling in sustained hypertension. Stroke 44, 1957-1964. doi: 10.1161/STROKEAHA.111.000185

Calhoun, M. E., Wiederhold, K. H., Abramowski, D., Phinney, A. L., Probst, A., Sturchler-Pierrat, C., et al. (1998). Neuron loss in APP transgenic mice. Nature 395, 755-756. doi: 10.1038/27351

Calhoun, M. E., Burgermeister, P., Phinney, A. L., Stalder, M., Tolnay, M., Wiederhold, K. H., et al. (1999). Neuronal overexpression of mutant amyloid precursor protein results in prominent deposition of cerebrovascular amyloid. Proc. Natl. Acad. Sci. U.S.A. 96, 14088-14093. doi: 10.1073/pnas.96.24.1 4088

Casas, C., Sergeant, N., Itier, J. M., Blanchard, V., Wirths, O., van der Kolk, N., et al. (2004). Massive CA1/2 neuronal loss with intraneuronal and N-terminal truncated Abeta42 accumulation in a novel Alzheimer transgenic model. Am. J. Pathol. 165, 1289-1300. doi: 10.1016/S0002-9440(10)63388-3

Caserta, M. T., Caccioppo, D., Lapin, G. D., Ragin, A., and Groothuis, D. R. (1998). Blood-brain barrier integrity in Alzheimer's disease patients and elderly control subjects. J. Neuropsychiatry Clin. Neurosci. 10, 78-84.

Chao, L. L., Buckleys, S. T., Kornak, J., Schuff, N., Madison, C., Yaffe, K., et al. (2010). ASL, perfusion MRI predicts cognitive decline and conversion from MCI to dementia. Alzheimer Dis. Assoc. Disord. 24, 19-27. doi: 10.1097/WAD.0b013e3181b4f736

Chen, G., Chen, K. S., Knox, J., Inglis, J., Bernard, A., Martin, S. J., et al. (2000). A learning deficit related to age and beta-amyloid plaques in a mouse model of Alzheimer's disease. Nature 408, 975-979. doi: 10.1038/35046031

Chen, J. J., Rosas, H. D., and Salat, D. H. (2011a). Age-associated reductions in cerebral blood flow are independent from regional atrophy. Neuroimage 55, 468-478. doi: 10.1016/j.neuroimage.2010.12.032

Chen, Y., Wolk, D. A., Reddin, J. S., Korczykowski, M., Martinez, P. M., and Musiek, E. S. (2011b). Voxel-level comparison of arterial spin-labeled perfusion MRI and FDG-PET in Alzheimer disease. Neurology 77, 1977-1185. doi: 10.1212/WNL.0b013e31823a0ef7

Chishti, M. A., Yang, D. S., Janus, C., Phinney, A. L., Horne, P., Pearson, J., et al. (2001). Early-onset amyloid deposition and cognitive deficits in transgenic mice expressing a double mutant form of amyloid precursor protein 695. J. Biol. Chem. 276, 21562-21570. doi: 10.1074/jbc.M100710200

Cirrito, J. R., May, P. C., O’Dell, M. A., Taylor, J. W., Parsadanian, M., Cramer, J. W., et al. (2003). In vivo assessment of brain interstitial fluid with microdialysis reveals plaque-associated changes in amyloid- $\beta$ metabolism and half-life. J. Neurosci. 23, 8844-8853.

Cohen, R. M., Rezai-Zadeh, K., Weitz, T. M., Rentsendorj, A., Gate, D., Spivak, I., et al. (2013). A transgenic Alzheimer rat with plaques, tau pathology, behavioral impairment, oligomeric a $\beta$, and frank neuronal loss. J. Neurosci. 33, 6245-6256. doi: 10.1523/JNEUROSCI.3672-12.2013

Cordonnier, C., and van der Flier, W. M. (2011). Brain microbleeds and Alzheimer's disease: innocent observation or key player? Brain 134, 335-344. doi: 10.1093/brain/awq321

Cortes-Canteli, M., Paul, J., Norris, E. H., Bronstein, R., Ahn, H. J., Zamolodchikov, D., et al. (2010). Fibrinogen and betaamyloid association alters thrombosis and fibrinolysis: a possible contributing factor to Alzheimer's disease. Neuron 66, 695-709. doi: 10.1016/j.neuron.2010.05.014

Daumas, S., Sandin, J., Chen, K. S., Kobayashi, D., Tulloch, J., Martin, S. J., et al. (2008). Faster forgetting contributes to impaired spatial memory in the PDAPP mouse: deficit in memory retrieval associated with increased sensitivity to interference? Learn. Mem. 15, 625-632. doi: 10.1101/lm.9 90208

Davis, J., Xu, F., Deane, R., Romanov, G., Previti, M. L., Zeigler, K., et al. (2004). Early-onset and robust cerebral microvascular accumulation of amyloid beta-protein in transgenic mice expressing low levels of a vasculotropic Dutch/Iowa mutant form of amyloid beta-protein precursor. J. Biol. Chem. 279, 20296-20306. doi: 10.1074/jbc.M312946200

Deane, R., Sagare, A., and Zlokovic, B. V. (2008). The role of the cell surface LRP and soluble LRP in blood- brain barrier Abeta clearance in Alzheimer's disease. Curr. Pharm. Des. 14, 1601-1605. doi: 10.2174/138161208784705487

Deane, R., Wu, Z., and Zlokovic, B. V. (2004). RAGE (yin) versus LRP (yang) balance regulates Alzheimer amyloid beta-peptide clearance through transport across the blood- brain barrier. Stroke 35 (11 Suppl. 1), 2628-2631. doi: 10.1161/01.STR.0000143452.85382.d1 
Dewachter, I., Van Dorpe, J., Smeijers, L., Gilis, M., Kuipéri, C., Laenen, I., et al. (2000). Aging increased amyloid peptide and caused amyloid plaques in brain of old APP/V717I transgenic mice by a different mechanism than mutant presenilin1. J. Neurosci. 20, 6452-6458.

Dodart, J. C., Meziane, H., Mathis, C., Bales, K. R., Paul, S. M., and Ungerer, A. (1999). Behavioral disturbances in transgenic mice overexpressing the V717F beta-amyloid precursor protein. Behav. Neurosci. 113, 982-990. doi: 10.1037/0735-7044.113.5.982

Domnitz, S. B., Robbins, E. M., Hoang, A. W., Garcia-Alloza, M., Hyman, B. T., Rebeck, G. W., et al. (2005). Progression of cerebral amyloid angiopathy in transgenic mouse models of Alzheimer disease. J. Neuropathol. Exp. Neurol. 64, 588-594. doi: 10.1097/01.jnen.0000171644.00180.fc

Dorr, A., Sahota, B., Chinta, L. V., Brown, M. E., Lai, A. Y., Ma, K., et al. (2012). Amyloid- $\beta$-dependent compromise of microvascular structure and function in a model of Alzheimer's disease. Brain 135, 3039-3050. doi: 10.1093/brain/aws243

Doyle, L. A., and Ross, D. D. (2003). Multidrug resistance mediated by the breast cancer resistance protein BCRP (ABCG2). Oncogene 22, 7340-7358. doi: 10.1038/sj.onc. 1206938

Duff, K., Knight, H., Refolo, L. M., Sanders, S., Yu, X., Picciano, M., et al. (2000).Characterization of pathology in transgenic mice over-expressing human genomic and cDNA tau transgenes. Neurobiol. Dis. 7, 87-98. doi: 10.1006/nbdi.1999.0279

El Tannir El Tayara, N., Delatour, B., Volk, A., and Dhenain, M. (2010). Detection of vascular alterations by in vivo magnetic resonance angiography and histology in APP/PS1 mouse model of Alzheimer's disease. MAGMA 23, 53-64. doi: 10.1007/s10334-009-0194-y

El Tayara Nel, T., Volk, A., Dhenain, M., and Delatour, B. (2007). Transverse relaxation time reflects brain amyloidosis in young APP/PS1 transgenic mice. Magn. Reson. Med. 58, 179-184. doi: 10.1002/mrm.21266

Faure, A., Verret, L., Bozon, B., El Tannir El Tayara, N., Ly, M., Kober, F., et al. (2011). Impaired neurogenesis, neuronal loss, and brain functional deficits in the APPxPS1-Ki mouse model of Alzheimer's disease. Neurobiol. Aging 32, 407-418. doi: 10.1016/j.neurobiolaging.2009.03.009

Fleisher, A. S., Chen, K., Quiroz, Y. T., Jakimovich, L. J., Gutierrez-Gomez, M., Langoi, C. M., et al. (2012). Florbetapir PET analysis of amyloid-b deposition in the presenilin $1 \mathrm{E} 280 \mathrm{~A}$ autosomal dominant Alzheimer's disease kindred: a cross sectional study. Lancet Neurol. 11, 1057-1065. doi: 10.1016/S14744422(12)70227-2

Frohman, E. M., Frohman, T. C., Gupta, S., de Fougerolles, A., and van den Noort, S. (1991). Expression of intercellular adhesion molecule 1 (ICAM1) in Alzheimer's disease. J. Neurol. Sci. 106, 105-111. doi: 10.1016/0022510X(91)90202-I

Fryer, J. D., Taylor, J. W., Demattos, R. B., Bales, K. R., Paul, S. M., Parsadanian, M., et al. (2003). Apolipoprotein E markedly facilitates age-dependent cerebral amyloid angiopathy and spontaneous hemorrhage in amyloid precursor protein transgenic mice. J. Neurosci. 23, 7889-7896.

Fuhrmann, M., Bittner, T., Jung, C. K., Burgold, S., Page, R. M., Mitteregger, G., et al. (2010). Microglial Cx3crl knockout prevents neuron loss in a mouse model of Alzheimer's disease. Nat. Neurosci. 13, 411-413. doi: 10.1038/nn.2511

Games, D., Adams, D., Alessandrini, R., Barbour, R., Berthelette, P., Blackwell, C., et al. (1995). Alzheimer-type neuropathology in transgenic mice overexpressing V717F beta-amyloid precursor protein. Nature 373, 523-527. doi: $10.1038 / 373523 \mathrm{a} 0$

Garcia-Alloza, M., Prada, C., Lattarulo, C., Fine, S., Borrelli, L. A., Betensky, R., et al. (2009). Matrix metalloproteinase inhibition reduces oxidative stress associated with cerebral amyloid angiopathy in vivo in transgenic mice. J. Neurochem. 109, 1636-1647. doi: 10.1111/j.1471-4159.2009.06096.x

Garcia-Alloza, M., Robbins, E. M., Zhang-Nunes, S. X., Purcell, S. M., Betensky, R. A., Raju, S., et al. (2006). Characterization of amyloid deposition in the APPswe/PS1dE9 mouse model of Alzheimer disease. Neurobiol. Dis. 24, 516-524. doi: 10.1016/j.nbd.2006.08.017

Giesel, F. L., Mehndiratta, A., and Essig, M. (2010). High-relaxivity contrastenhanced magnetic resonance neuroimaging: a review. Eur. Radiol. 20, 2461-2474. doi: 10.1007/s00330-010-1805-8

Gotz, J., Probst, A., Spillantini, M. G., Schafer, T., Jakes, R., Burki, K., et al. (1995). Somatodendritic localization and hyperphosphorylation of tau protein in transgenic mice expressing the longest human brain tau isoform. EMBO J. 14, 1304-1313.
Gregory, J. L., Prada, C. M., Fine, S. J., Garcia-Alloza, M., Betensky, R. A., Arbel-Ornath, M., et al., 2012. Reducing available soluble $\beta$-amyloid prevents progression of cerebral amyloid angiopathy in transgenic mice. J. Neuropathol. Exp. Neurol. 71, 1009-1017. doi: 10.1097/NEN.0b013e3182729845

Grienberger, C., Rochefort, N. L., Adelsberger, H., Henning, H. A., Hill, D. N., Reichwald, J., et al. (2012). Staged decline of neuronal function in vivo in an animal model of Alzheimer's disease. Nat. Commun. 3, 774. doi: $10.1038 /$ ncomms 1783

Hajjar, I., Brown, L., Mack, W. J., and Chui, H. (2012). Impact of angiotensin receptor blockers on Alzheimer's disease pathology in a large brain autopsy series. Arch. Neurol. 69, 1632-1638. doi: 10.1001/archneurol.2012.1010

Han, B. H., Zhou, M. L., Abousaleh, F., Brendza, R. P., Dietrich, H. H., Koenigsknecht-Talboo, J., et al. (2008). Cerebrovascular dysfunction in amyloid precursor protein transgenic mice: contribution of soluble and insoluble amyloid- $\beta$ peptide, partial restoration via $\gamma$-secretase inhibition. J. Neurosci. 28 , 13542-13550. doi: 10.1523/JNEUROSCI.4686-08.2008

Han, B. H., Zhou, M. L., Vellimana, A. K., Milner, E., Kim, D. H., Greenberg, J. K., et al. (2011). Resorufin analogs preferentially bind cerebrovascular amyloid: potential use as imaging ligands for cerebral amyloid angiopathy. Mol. Neurodegener. 6, 86. doi: 10.1186/1750-1326-6-86

Hardy, J., and Selkoe, D. J. (2002). The amyloid hypothesis of Alzheimer's disease: progress and problems on the road to therapeutics. Science 297, 353-356. doi: $10.1126 /$ science. 1072994

Harmsen, M. M., and De Haard, H. J. (2007). Properties, production, and applications of camelid single-domain antibody fragments. Appl. Microbiol. Biotechnol. 77, 13-22. doi: 10.1007/s00253-007-1142-2

Hartman, R. E., Izumi, Y., Bales, K. R., Paul, S. M., Wozniak, D. F., and Holtzman, D. M. (2005). Treatment with an amyloid-beta antibody ameliorates plaque load, learning deficits, and hippocampal long-term potentiation in a mouse model of Alzheimer's disease. J. Neurosci. 25, 6213-6220. doi: 10.1523/JNEUROSCI.0664-05.2005

Havas, D., Hutter-Paier, B., Ubhi, K., Rockenstein, E., Crailsheim, K., Masliah, E., et al. (2011). A longitudinal study of behavioral deficits in an A $\beta P P$ transgenic mouse model of Alzheimer's disease. J. Alzheimers Dis. 25, 231-243. doi: 10.3233/JAD-2011-101866

Hébert, F., Grand'maison, M., Ho, M. K., Lerch, J. P., Hamel, E., and Bedell, B. J. (2013). Cortical atrophy and hypoperfusion in a transgenic mouse model of Alzheimer's disease. Neurobiol. Aging 34, 1644-1652. doi: 10.1016/j.neurobiolaging.2012.11.022

Hefendehl, J. K., Wegenast-Braun, B. M., Liebig, C., Eicke, D., Milford, D. and Calhoun, M. E. (2011). Long-term in vivo imaging of beta-amyloid plaque appearance and growth in a mouse model of cerebral beta-amyloidosis. J. Neurosci. 31, 624-629. doi: 10.1523/JNEUROSCI.5147-10.2011

Helm, P. J., Ottersen, O. P., and Nase, G. (2009). Analysis of optical properties of the mouse cranium - implications for in vivo multiphoton laser scanning microscopy. J. Neurosci. Methods 178, 316-322. doi: 10.1016/j.jneumeth.2008.12.032

Herzig, M. C., Paganetti, P., Staufenbiel, M., and Jucker, M. (2007). BACE1 and mutated presenilin-1 differently modulate $A \beta 40$ and $A \beta 42$ levels and cerebral amyloidosis in APP dutch transgenic mice. Neurodegener. Dis. 4, 127-135. doi: $10.1159 / 000101837$

Herzig, M. C., Eisele, Y. S., Staufenbiel, M., and Jucker, M. (2009). E22Qmutant Abeta peptide (AbetaDutch) increases vascular but reduces parenchymal Abeta deposition. Am. J. Pathol. 174, 722-726. doi: 10.2353/ajpath.2009.0 80790

Herzig, M. C., van Nostrand, W. E., and Jucker, M. (2006). Mechanism of cerebral $\beta$-amyloid angiopathy: murine and cellular models. Brain Pathol. 16, 40-54. doi: 10.1111/j.1750-3639.2006.tb00560.x

Herzig, M. C., Winkler, D. T., Burgermeister, P., Pfeifer, M., Kohler, E., Schmidt, S. D., et al. (2004). Abeta is targeted to the vasculature in a mouse model of hereditary cerebral hemorrhage with amyloidosis. Nat. Neurosci. 7, 954-960. doi: $10.1038 / \mathrm{nn} 1302$

Higuchi, M. (2009). Visualization of brain amyloid and microglial activation in mouse models of Alzheimer's disease. Curr. Alzheimer Res. 6, 137-143. doi: 10.2174/156720509787602906

Hintersteiner, M., Enz, A., Frey, P., Jaton, A. L., Kinzy, W., Kneuer, R., et al. (2005). In vivo detection of amyloid-ßdeposits by near-infrared imaging using an oxazine-derivative probe. Nat. Biotechnol. 23, 577-583. doi: 10.1038/ nbt1085 
Holcomb, L., Gordon, M. N., McGowan, E., Yu, X., Benkovic, S., Jantzen, P., et al. (1998). Accelerated Alzheimer-type phenotype in transgenic mice carrying both mutant amyloid precursor protein and presenilin 1 transgenes. Nat. Med. 4, 97-100. doi: 10.1038/nm0198-097

Holtmaat, A., Bonhoeffer, T., Chow, D. K., Chuckowree, J., De Paola, V., Hofer, S. B., et al. (2009). Long-term, high resolution imaging in the mouse neocortex through a chronic cranial window. Nat. Protoc. 4, 1128-1144. doi: 10.1038/nprot.2009.89

Hooijmans, C. R., Graven, C., Dederen, P. J., Tanila, H., van Groen, T., and Kiliaan, A. J. (2007b). Amyloid beta deposition is related to decreased glucose transporter-1 levels and hippocampal atrophy in brains of aged APP/PS1 mice. Brain Res. 1181, 93-103. doi: 10.1016/j.brainres.2007.08.063

Hooijmans, C. R., Rutters, F., Dederen, P. J., Gambarota, G., Veltien, A., and van Groen, T. (2007a). Changes in cerebral blood volume and amyloid pathology in aged Alzheimer's APP/PS1 mice on a docosahexaenoic acid (DHA) diet or cholesterol enriched Typical Western Diet (TWD). Neurobiol. Dis. 28, 16-29. doi: 10.1016/j.nbd.2007.06.007

Hsiao, K., Chapman, P., Nilsen, S., Eckman, C., Harigaya, Y., Younkin, S., et al. (1996). Correlative memory deficits, Abeta elevation, and amyloid plaques in transgenic mice. Science 274, 99-102. doi: 10.1126/science.274.5284.99

Hu, S., Yan, P., Maslov, K., Lee, J. M., and Wang, L. V. (2009). Intravital imaging of amyloid plaques in a transgenic mouse model using optical-resolution photoacoustic microscopy. Opt. Lett. 34, 3899-3901. doi: 10.1364/OL.34.0 03899

Hyde, D., de Kleine, R., MacLaurin, S. A., Miller, E., Brooks, D. H., Krucker, T., et al. (2009). Hybrid FMT-CT imaging of amyloid-beta plaques in a murine Alzheimer's disease model. Neuroimage 44, 1304-1311. doi: 10.1016/j.neuroimage.2008.10.038

Iadecola, C., Zhang, F., Niwa, K., Eckman, C., Turner, S. K., Fischer, E., et al. (1999). SOD1 rescues cerebral endothelial dysfunction in mice overexpressing amyloid precursor protein. Nat. Neurosci. 2, 157-161. doi: 10.1038/5715

Jankowsky, J. L., Slunt, H. H., Ratovitski, T., Jenkins, N. A., Copeland, N. G., and Borchelt, D. R. (2001). Co-expression of multiple transgenes in mouse CNS: a comparison of strategies. Biomol. Eng. 17, 157-165. doi: 10.1016/S13890344(01)00067-3

Jankowsky, J. L., Slunt, H. H., Gonzales, V., Savonenko, A. V., Wen, J. C., and Jenkins, N. A. (2005). Persistent amyloidosis following suppression of A $\beta$ production in a transgenic model of Alzheimer disease. PLoS Med 2:e355. doi 10.1371/journal.pmed.0020355

Jantaratnotai, N., Schwab, C., Ryu, J. K., McGeer, P. L., and McLarnon, J. G. (2010). Converging perturbed microvasculature and microglial clusters characterize Alzheimer disease brain. Curr. Alzheimer Res. 7, 625-636. doi: 10.2174/156720510793499039

Jarrett, J. T., Berger, E. P., and Lansbury, P. T. Jr. (1993). The carboxy terminus of the beta amyloid protein is critical for the seeding of the amyloid formation: implications for the pathogenesis of Alzheimer's diseases. Biochemistry 32, 4693-4697. doi: 10.1021/bi00069a001

Jawhara, S., Trawickaa, A., Jenneckensa, C., Bayera, T. A., and Wirths, O. (2012). Motor deficits, neuron loss, and reduced anxiety coinciding with axonal degeneration and intraneuronal A $\beta$ aggregation in the 5XFAD mouse model of Alzheimer's disease. Neurobiol. Aging 33, 196.e29-196.e40. doi: 10.1016/j.neurobiolaging.2010.05.027

Jellinger, K. A. (2002). Alzheimer disease and cerebrovascular pathology: an update. J. Neural Transm. 109, 813-836. doi: 10.1007/s007020200068

Jensen, J. H., and Chandra, R. (2000). MR imaging of microvasculature. Magn. Reson. Med. 44, 224-230. doi: 10.1002/1522-2594(200008)44:2<224::AIDMRM9>3.0.CO;2-M

Jick, H., Zornberg, G. L., Jick, S. S., Seshadri, S., and Drachman, D. A. (2000). Statins and the risk of dementia. Lancet 356, 1627-1631. doi: 10.1016/S01406736(00)03155-X

Johnson, G., Wetzel, S. G., Cha, S., Babb, J., and Tofts, P. S. (2004). Measuring blood volume and vascular transfer constant from dynamic, $\mathrm{T}(2)^{*}$-weighted contrastenhanced MRI. Magn. Res. Med. 51, 961-968. doi: 10.1002/mrm.20049

Johnson, K. A., Gregas, M., Becker, J. A., Kinnecom, C., Salat, D. H., Moran, E. K., et al. (2007). Imaging of amyloid burden and distribution in cerebral amyloid angiopathy. Ann. Neurol. 62, 229-234. doi: 10.1002/ana.21164

Johnson, N. A., Jahng, G. H., Weiner, M. W., Miller, B. L., Chui, H. C., Jagust, W. J., et al. (2005). Pattern of cerebral hypoperfusion in Alzheimer disease and mild cognitive impairment measured with arterial spin-labeling MR imaging: initial experience. Radiology 234, 851-859. doi: 10.1148/radiol.2343040197

Jonckers, E., Van Audekerke, J., De Visscher, G., Van der Linden, A., and Verhoye, M. (2011). Functional connectivity fMRI of the rodent brain: comparison of functional connectivity networks in rat and mouse PLOS ONE 6:e18876. doi: 10.1371/journal.pone.0018876

Kalaria, R. N., Akinyemi, R., and Ihara, M. (2012). Does vascular pathology contribute to Alzheimer changes? J. Neurol. Sci. 322, 141-147. doi: 10.1016/j.jns.2012.07.032

Kara, F., Dongen, E. S., Schliebs, R., Buchem, M. A., Groot, H. J., and Alia, A. (2012). Monitoring blood flow alterations in the Tg2576 mouse model of Alzheimer's disease by in vivo magnetic resonance angiography at $17.6 \mathrm{~T}$. Neuroimage 60, 958-966. doi: 10.1016/j.neuroimage.2011.12.055

Kassner, A., Roberts, T., Taylor, K., Silver, F., and Mikulis, D. (2005). Prediction of hemorrhage in acute ischemic stroke using permeability MR imaging. AJNR Am. J. Neuroradiol. 26, 2213-2217.

Kastyak-Ibrahim, M. Z., Di Curzio, D. L., Buist, R., Herrera, S. L., Albensi, B. C., Del Bigio, M. R., et al. (2013). Neurofibrillary tangles and plaques are not accompanied by white matter pathology in aged triple transgenic-Alzheimer disease mice. Magn. Reson. Imaging 31, 1515-1521. doi: 10.1016/j.mri.2013.06.013

Kim, J., Onstead, L., Randle, S., Price, R., Smithson, L., Zwizinski, C., et al. (2007). Abeta40 inhibits amyloid deposition in vivo. J. Neurosci. 27, 627-633. doi: 10.1523/JNEUROSCI.4849-06.2007

Kimura, R., and Ohno, M. (2009). Impairments in remote memory stabilization precede hippocampal synaptic and cognitive failures in 5XFAD Alzheimer mouse model. Neurobiol. Dis. 33, 229-235. doi: 10.1016/j.nbd.2008.10.006

Klohs, J., Baltes, C., Princz-Kranz, F., Ratering, D., Nitsch, R. M., Knuesel, I., et al. (2012). Contrast-enhanced magnetic resonance microangiography reveals remodeling of the cerebral microvasculature in transgenic ArcA $\beta$ mice. J. Neurosci. 32, 1705-1713. doi: 10.1523/JNEUROSCI.5626-11.2012

Klohs, J., Deistung, A., Schweser, F., Grandjean, J., Dominietto, M., Waschkies, C., et al. (2011). Detection of cerebral microbleeds with quantitative susceptibility mapping in the ArcAbeta mouse model of cerebral amyloidosis. J. Cereb. Blood Flow. Metab. 31, 2282-2292. doi: 10.1038/jcbfm.2011.118

Klohs, J., Politano, I. W., Deistung, A., Grandjean, J., Drewek, A., Dominietto, M., et al. (2013). Longitudinal assessment of amyloid pathology in transgenic ArcA $\beta$ mice using multi-parametric magnetic resonance imaging. PLoS ONE 8:e66097. doi: 10.1371/journal.pone.0066097

Klohs, J., and Rudin, M. (2011). Unveiling molecular events in the brain by noninvasive imaging. Neuroscientist 17, 539-559. doi: 10.1177/1073858410383433

Klunk, W. E., Lopresti, B. J., Ikonomovic, M. D., Lefterov, I. M., Koldamova, R. P., Abrahamson, E. E., et al. (2005). Binding of the positron emission tomography tracer Pittsburgh compound-B reflects the amount of amyloid-beta in Alzheimer's disease brain but not in transgenic mouse brain. J. Neurosci. 25, 10598-10606. doi: 10.1523/JNEUROSCI.2990-05.2005

Knobloch, M., Konietzko, U., Krebs, D. C., and Nitsch, R. M. (2007). Intracellular Abeta and cognitive deficits precede beta-amyloid deposition in transgenic arcAbeta mice. Neurobiol. Aging 28, 1297-1306. doi: 10.1016/j.neurobiolaging.2006.06.019

Koenigsknecht-Talboo, J., Meyer-Luehmann, M., Parsadanian, M., Garcia-Alloza, M., Finn, M. B., Hyman, B. T., et al. (2008). Rapid microglial response around amyloid pathology after systemic anti-Abeta antibody administration in PDAPP mice. J. Neurosci. 28, 14156-14164. doi: 10.1523/JNEUROSCI.4147-0 8.2008

Koutnetsova, E., Klinger, M., Sorger, D., Sabri, O., Grossmann, U., Steinbach, J., et al. (2006). Developmental and amyloid plaque-related changes in cerebral cortical capillaries in transgenic Tg2576 Alzheimer mice. Int. J. Dev. Neurosci. 24, 187-193. doi: 10.1016/j.ijdevneu.2005.11.011

Krstic, D., and Knuesel, I. (2013). Deciphering the mechanism underlying lateonset Alzheimer disease. Nat. Rev. Neurol. 9, 25-34. doi: 10.1038/nrneurol.2012.236

Krucker, T., Schuler, A., Meyer, E. P., Staufenbiel, M., and Beckmann, N. (2004). Magnetic resonance angiography and vascular corrosion casting as tools in biomedical research: application to transgenic mice modeling Alzheimer's disease. Neurol. Res. 26, 507-516. doi: 10.1179/016164104225016281

Kuhnke, D., Jedlitschky, G., Grube, M., Krohn, M., Jucker, M., Mosyagin, I., et al. (2007). MDR1-P-glycoprotein (ABCB1) mediates transport of Alzheimer's amyloid-beta peptides-implications for the mechanisms of Abeta clearance 
at the blood-brain barrier. Brain Pathol. 17, 347-353. doi: 10.1111/j.17503639.2007.00075.x

Kulic, L., McAfoose, J., Welt, T., Tackenberg, C., Spani, C., Wirth, F., et al. (2012). Early accumulation of intracellular fibrillar oligomers and late congophilic amyloid angiopathy in mice expressing the Osaka intra-Abeta APP mutation. Transl. Psychiatry 2, e183. doi: 10.1038/tp.2012.109

Kumar-Singh, S. (2009). Hereditary and sporadic forms of A $\beta$-cerebrovascular amyloidosis and relevant transgenic mouse models. Int. J. Mol. Sci. 10, 1872-1895. doi: 10.3390/ijms10041872

Kumar-Singh, S., Pirici, D., McGowan, E., Serneels, S., Ceuterick, C., Hardy, J., et al. (2005). Dense-core plaques in Tg2576 and PSAPP mouse models of Alzheimer's disease are centered on vessel walls. Am. J. Pathol. 167, 527-543. doi: 10.1016/S0002-9440(10)62995-1

Lau, J. C., Lerch, J. P., Sled, J. G., Henkelman, R. M., Evans, A. C., and Bedell, B. J. (2008). Longitudinal neuroanatomical changes determined by deformationbased morphometry in a mouse model of Alzheimer's disease. Neuroimage 42, 19-27. doi: 10.1016/j.neuroimage.2008.04.252

Li, N. C., Lee, A., Whitmer, R. A., Kivipelto, M., Lawler, E., Kazis, L. E., et al. (2010). Use of angiotensin receptor blockers and risk of dementia in a predominantly male population: prospective cohort analysis. BMJ 340, b5465. doi: 10.1136/bmj.b5465

Li, X. G., Autio, A., Ahtinen, H., Helariutta, K., Liljenbäck, H., and Jalkanen, S. (2013). Translating the concept of peptide labeling with 5-deoxy-5[18F] fluororibose into preclinical practice: $18 \mathrm{~F}-$ labeling of Siglec-9 peptide for PET imaging of inflammation. Chem. Commun. (Camb.) 49, 3682-3684. doi: $10.1039 / \mathrm{c} 3 \mathrm{cc} 40738 \mathrm{a}$

Lin, W., Abendschein, D. R., Celik, A., Dolan, R. P., Lauffer, R. B., Walovitch, R. C., et al. (1997). Intravascular contrast agent improves magnetic resonance angiography of carotid areries in minipigs. J. Magn. Reson. Imaging 7, 963-971. doi: 10.1002/jmri.1880070605

Lobatto, M. E., Fuster, V., Fayad, Z. A., and Mulder, W. J. (2011). Perspectives and opportunities for nanomedicine in the management of atherosclerosis. Nat. Rev. Drug. Discov. 10, 835-852. doi: 10.1038/nrd3578

Logothetis, N. K., Pauls, J., Augath, M., Trinath, T., and Oeltermann, A. (2001). Neurophysiological investigation of the basis of the fMRI signal. Nature 412, 150-157. doi: 10.1038/35084005

Lord, A., Kalimo, H., Eckman, C., Zhang, X. Q., Lannfelt, L., and Nilsson, L. N. (2006). The Arctic Alzheimer mutation facilitates early intraneuronal Abeta aggregation and senile plaque formation in transgenic mice. Neurobiol. Aging 27, 67-77. doi: 10.1016/j.neurobiolaging.2004.12.007

Lovasic, L., Bauschke, H., and Janus, C. (2005). Working memory impairment in a transgenic amyloid precursor protein TgCRND8 mouse model of Alzheimer's disease. Genes Brain Behav. 4, 197-208. doi: 10.1111/j.1601-183X.2004. 00104.x

Luo, F., Rustay, N. R., Ebert, U., Hradil, V. P., Cole, T. B., Llano, D. A., et al. (2012). Characterization of 7- and 19-month-old Tg2576 mice using multimodal in vivo imaging: limitations as a translatable model of Alzheimer's disease. Neurobiol. Aging 33, 933-944. doi: 10.1016/j.neurobiolaging.2010.08.005

Luo, F., Rustay, N. R., Seifert, T., Roesner, B., Hradil, V., Hillen, H., et al. (2010). Magnetic resonance imaging detection and time course of cerebral microhemorrhages during passive immunotherapy in living amyloid precursor protein transgenic ice. J. Pharmacol. Exp. Ther. 335, 580-588. doi: 10.1124/jpet.110.172932

Luo, F., Seifert, T. R., Edalji, R., Loebbert, R. W., Hradil, V. P., Harlan, J., et al. (2008). Non-invasive characterization of beta-amyloid(1-40) vasoactivity by functional magnetic resonance imaging in mice. Neuroscience 155, 263-269. doi: 10.1016/j.neuroscience.2008.04.021

Maat-Schieman, M. L., van Duinen, S. G., Rozemuller, A. J., Haan, J., and Roos, R. A. (1997). Association of vascular amyloid beta and cells of the mononuclear phagocyte system in hereditary cerebral hemorrhage with amyloidosis (Dutch) and Alzheimer disease. J. Neuropathol. Exp. Neurol. 56, 273-284. doi: 10.1097/00005072-199703000-00006

Maeda, J., Ji, B., Irie, T., Tomiyama, T., Maruyama, M., Okauchi, T., et al. (2007). Longitudinal, quantitative assessment of amyloid, neuroinflammation, and anti-amyloid treatment in a living mouse model of Alzheimer's disease enabled by positron emission tomography. J. Neurosci. 27, 10957-10968. doi: 10.1523/JNEUROSCI.0673-07.2007

Maeda, J., Zhang, M. R., Okauchi, T., Ji, B., Ono, M., Hattori, S., et al. (2011). In vivo positron emission tomographic imaging of glial responses to amyloid-beta and tau pathologies in mouse models of Alzheimer's disease and related disorders. J. Neurosci. 31, 4720-4730. doi: 10.1523/JNEUROSCI.307610.2011

Maruyama, M., Shimada, H., Suhara, T., Shinotoh, H., Ji, B., Maeda, J., et al. (2013). Imaging of tau pathology in a tauopathy mouse model and in Alzheimer patients compared to normal controls. Neuron 79, 1094-1108. doi: 10.1016/j.neuron.2013.07.037

Masamoto, K., and Kanno, I. (2012). Anesthesia and the quantitative evaluation of neurovascular coupling. J. Cereb. Blood Flow. Metab. 32, 1233-1247. doi: 10.1038/jcbfm.2012.50

Massaad, C. A., Amin, S. K., Hu, L., Mei, Y., Klann, E., and Pautler, R. G. (2010). Mitochondrial superoxide contributes to blood flow and axonal transport deficits in the Tg2576 mouse model of Alzheimer's disease. PLoS ONE 5:e10561. doi: 10.1371/journal.pone.0010561

Matsuoka, Y., Saito, M., LaFrancois, J., Saito, M., Gaynor, K., Olm, V., et al. (2003). Novel therapeutic approach for the treatment of Alzheimer's disease by peripheral administration of agents with an affinity to beta-amyloid. J. Neurosci. 23, 29-33.

McGowan, E., Pickford, F., Kim, J., Onstead, L., Eriksen, J., Yu, C., et al. (2005). Abeta42 is essential for parenchymal and vascular amyloid deposition in mice. Neuron 47, 191-199. doi: 10.1016/j.neuron.2005.06.030

McLaurin, J., Kierstead, M. E., Brown, M. E., Hawkes, C. A., Lambermon, M. H., Phinney, A. L., et al. (2006). Cyclohexanehexol inhibitors of Abeta aggregation prevent and reverse Alzheimer phenotype in a mouse model. Nat. Med. 12, 801-808. doi: 10.1038/nm1423

McLean, D., Cooke, M. J., Albay, R. 3rd., Glabe, C., and Shoichet, M. S. (2013). Positron emission tomography imaging of fibrillar parenchymal and vascular amyloid- $\beta$ in TgCRND8 mice. ACS Chem. Neurosci. 4, 613-623. doi: $10.1021 / \mathrm{cn} 300226 \mathrm{q}$

Mellin, A. F., Cofer, G. P., Smith, B. R., Suddarth, S. A., Hedlund, L. W., and Johnson, G. A. (1994). Three dimensional magnetic resonance microangiography of rat neurovasculature. Mag. Res. Med. 32, 199-205. doi: 10.1002/mrm. 1910320208

Melnikova, T., Fromholt, S., Kim, H., Lee, D., Xu, G., Price, A., et al. (2013). Reversible pathologic and cognitive phenotypes in an inducible model of Alzheimer-amyloidosis. J. Neurosci. 33, 3765-3779. doi: 10.1523/JNEUROSCI.4251-12.2013

Merlini, M., Meyer, E. P., Ulmann-Schuler, A., and Nitsch, R. M. (2011). Vascular $\beta$-amyloid and early astroctye alterations impair cerebrovascular function and cerebral metabolism in transgenic arcA $\beta$ mice. Acta Neuropathol. 122, 293-311. doi: 10.1007/s00401-011-0834-y

Meyer, E. P., Ulmann-Schuler, A., Staufenbiel, M., and Krucker, T. (2008). Altered morphology and $3 \mathrm{D}$ architecture of brain vasculature in a mouse model for Alzheimer's disease. Proc. Natl. Acad. Sci. U.S.A. 105, 3587-3592. doi: 10.1073/pnas.0709788105

Miao, J., Xu, F., Davis, J., Otte-Holler, I., Verbeek, M. M., and van Nostrand, W. E. (2005). Cerebral microvascular amyloid beta protein deposition induces vascular degeneration and neuroinflammation in transgenic mice expressing human vasculotropic mutant amyloid beta precursor protein. Am. J. Pathol. 167, 505-515. doi: 10.1016/S0002-9440(10)62993-8

Moechars, D., Dewachter, I., Lorent, K., Reversé, D., Baekelandt, V., Naidu, A., et al. (1999). Early phenotypic changes in transgenic mice that overexpress different mutants of amyloid precursor protein in brain. J. Biol. Chem. 274, 6483-6492. doi: 10.1074/jbc.274.10.6483

Montagne, A., Gauberti, M., Macrez, R., Jullienne, A., Briens, A., Raynaud, J. S., et al. (2012). Ultra-sensitive molecular MRI of cerebrovascular cell activation enables early detection of chronic central nervous system disorders. Neuroimage 63, 760-770. doi: 10.1016/j.neuroimage.2012.07.018

Mucke, L., Masliah, E., Yu, G. Q., Mallory, M., Rockenstein, E. M., Tatsuno, G., et al. (2000). High-level neuronal expression of abeta 1-42 in wild-type human amyloid protein precursor transgenic mice: synaptotoxicity without plaque formation. J. Neurosci. 20, 4050-4058.

Mueggler, T., Baumann, D., Rausch, M., Staufenbiel, M., and Rudin, M. (2003). Age-dependent impairment of somatosensory response in the amyloid precursor protein 23 transgenic mouse model of Alzheimer's disease. J. Neurosci. 23, 8231-8236

Mueggler, T., Sturchler-Pierrat, C., Baumann, D., Rausch, M., Staufenbiel, M., and Rudin, M. (2002). Compromized hemodynamic response in amyloid precursor protein transgenic mice. J. Neurosci. 22, 7218-7224. 
Nabuurs, R. J., Rutgers, K. S., Welling, M. M., Metaxas, A., de Backer, M. E., Rotman, M., et al. (2012). In vivo detection of amyloid-b deposits using heavy chain antibody fragments in a transgenic mouse model for Alzheimer's disease. PLoS ONE 7:e38284. doi: 10.1371/journal.pone.0038284

Nagata, K., Maruya, H., Yuya, H., Terashi, H., Mito, Y., Kato, H., et al. (2000). Can PET data differentiate Alzheimer's disease from vascular dementia? Ann. N.Y. Acad. Sci. 903, 252-261. doi: 10.1111/j.1749-6632.2000. tb06375.x

Nilsson, L. N., Arendash, G. W., Leighty, R. E., Costa, D. A., Low, M. A., Garcia, M. F., et al. (2004). Cognitive impairment in PDAPP mice depends on ApoE and ACT-catalyzed amyloid formation. Neurobiol. Aging 25, 1153-1167. doi: 10.1016/j.neurobiolaging.2003.12.011

Niwa, K., Kazama, K., Younkin, L., Younkin, S. G., Carlson, G. A., and Iadecola, C. (2002). Cerebrovascular autoregulation is profoundly impaired in mice overexpressing amyloid precursor protein. Am. J. Physiol. Heart Circ. Physiol. 283, H315-H323. doi: 10.1152/ajpheart.00022.2002

Niwa, K., Porter, V. A., Kazama, K., Cornfield, D., Carlson, G. A., and Iadecola, C. (2001). Abeta-peptides enhance vasoconstriction in cerebral circulation. Am. J. Physiol. Heart Circ. Physiol. 281, H2417-H2424.

Oakley, H., Cole, S. L., Logan, S., Maus, E., Shao, P., Craft, J., et al. (2006). Intraneuronal $\beta$-amyloid aggregates, neurodegeneration, and neuron loss in transgenic mice with five familial Alzheimer's disease mutations: potential factors in amyloid plaque formation. J. Neurosci. 26, 10129-10140. doi: 10.1523/JNEUROSCI.1202-06.2006

Oberg, J., Spenger, C., Wang, F. H., Andersson, A., Westman, E., Skoglund, P., et al. (2008). Age related changes in brain metabolites observed by H-1 MRS in APP/PS1 mice. Neurobiol. Aging 29, 1423-1433. doi: 10.1016/j.neurobiolaging.2007.03.002

Oddo, S., Caccamo, A., Kitazawa, M., Tseng, B. P., and LaFerla, F. M. (2003a). Amyloid deposition precedes tangle formation in a triple transgenic model of Alzheimer's disease. Neurobiol. Aging 24, 1063-1070. doi: 10.1016/j.neurobiolaging.2003.08.012

Oddo, S., Caccamo, A., Shepherd, J. D., Murphy, M. P., Golde, T. E., and Kayed, R. (2003b). Triple-transgenic model of Alzheimer's disease with plaques and tangles: intracellular Abeta and synaptic dysfunction. Neuron 39, 409-421. doi: 10.1016/S0896-6273(03)00434-3

Ogawa, S., Tank, D. W., Menon, R., Ellermann, J. M., Kim, S. G., and Merkle, H. (1992). Intrinsic signal changes accompanying sensory stimulation: functional brain mapping with magnetic resonance imaging. Proc. Nat. Acad. Sci. U.S.A. 89, 5951-5955. doi: 10.1073/pnas.89.13.5951

Okamoto, Y., Yamamoto, T., Kalaria, R. N., Senzaki, H., Maki, T., Hase, Y., et al. (2012). Cerebral hypoperfusion accelaretes cerebral amyloid angiopathy and promotes cortical microinfarcts. Acta Neuropathol. 123, 381-394. doi: 10.1007/s00401-011-0925-9

Okamura, N., Furumoto, S., Harada, R., Tago, T., Yoshikawa, T., Fodero-Tavoletti, M., et al. (2012). Novel 18F-labeled arylquinoline derivatives for noninvasive imaging of tau pathology in Alzheimer disease. J. Nucl. Med. 54, 1420-1427. doi: 10.2967/jnumed.112.117341

Okamura, N., Suemoto, T., Shiomitsu, T., Suzuki, M., Shimadzu, H., Akatsu, H., et al. (2004). A novel imaging probe for in vivo detection of neuritic and diffuse amyloid plaques in the brain. J. Mol. Neurosci. 24, 247-255. doi: $10.1385 / J M N: 24: 2: 247$

O'Leary, T. P., and Brown, R. E. (2009). Visuo-spatial learning and memory deficits on the Barnes maze in the 16-month-old APPswe/PS1dE9 mouse model of Alzheimer's disease. Behav. Brain Res. 201, 120-127. doi: 10.1016/j.bbr.2009.01.039

Owen, D. R., Lindsay, A. C., Choudhury, R. P., and Fayad, Z. A. (2011). Imaging of atherosclerosis. Annu. Rev. Med. 62, 25-40. doi: 10.1146/annurev-med-041709133809

Paris, D., Humphrey, J., Quadros, A., Patel, N., Crescentini, R., Crawford, F., et al. (2003). Vasoactive effects of A beta in isolated human cerebrovessels and in a transgenic mouse model of Alzheimer's disease: role of inflammation. Neurol. Res. 25, 642-651. doi: 10.1179/016164103101201940

Paris, D., Town, T., Mori, T., Parker, T. A., Humphrey, J., and Mullan, M. (2000). Soluble beta-amyloid peptides mediate vasoactivity via activation of a pro-inflammatory pathway. Neurobiol. Aging 21, 183-197. doi: 10.1016/S01974580(00)82162-4

Park, L., Zhou, P., Koizumi, K., El Jamal, S. E., Previti, M. L., van Nostrand, W. E., et al. (2013). Brain and circulating levels of A 1-40 differentially contribute to vasomotor dysfunction in the mouse brain. Stroke 44, 198-204. doi: 10.1161/STROKEAHA.112.670976

Park, L., Zhou, P., Pistick, R., Capone, C., Anrather, J., Norris, E. H., et al. (2008). Nox2-derived radicals contribute to neurovascular and behavioral dysfunction in mice overexpressing the amyloid precursor protein. Proc. Natl. Acad. Sci. U.S.A. 105, 1347-1352. doi: 10.1073/pnas.0711568105

Paul, J., Strickland, S., and Melchor, J. P. (2007). Fibrin deposition accelerates neurovascular damage and neuroinflammation in mouse models of Alzheimer's disease. J. Exp. Med. 204, 1999-2008. doi: 10.1084/jem.20070304

Perez-Cruz, C., Nolte, M. W., van Gaalen, M. M., Rustay, N. R., Termont, A., Tanghe, A., et al. (2011). Reduced spine density in specific regions of CA1 pyramidal neurons in two transgenic mouse models of Alzheimer's disease. J. Neurosci. 31, 3926-3934. doi: 10.1523/JNEUROSCI.614210.2011

Perez-Torres, C. J., Reynolds, J. O., and Pautler, R. G. (2014). Use of magnetization transfer contrast MRI to detect early molecular pathology in Alzheimer's disease. Magn. Reson. Med. 71, 333-338. doi: 10.1002/mrm.24665

Pettersen, J. A., Sathiyamoorthy, G., Gao, F. Q., Szilagyi, G., Nadkarni, N. K., St. George-Hyslop, P., et al. (2008). Microbleed topography, leukoaraiosis, and cognition in probable Alzheimer disease from the Sunnybrook Dementia study. Arch. Neurol. 65, 790-795. doi: 10.1001/archneur.65.6.790

Pfeifer, M., Boncristiano, S., Bondolfi, L., Stalder, A., Deller, T., Staufenbiel, M., et al. (2002). Cerebral hemorrhage after passive anti-Abeta immunotherapy. Science 298, 1379. doi: 10.1126/science.1078259

Poduslo, J. F., Hultman, K. L., Curran, G. L., Preboske, G. M., Chamberlain, R., Marjañska, M., et al. (2011). Targeting vascular amyloid in arterioles of Alzheimer disease transgenic mice with amyloid $\beta$ protein antibody-coated nanoparticles. J. Neuropathol. Exp. Neurol. 70, 653-661. doi: 10.1097/NEN.0b013e318225038c

Poisnel, G., Herard, A. S., El Tannir El Tayara, N., Bourrin, E., Vol, A., Kober, F., et al. (2012). Increased regional cerebral glucose uptake in an APP/PS1 model of Alzheimer's disease. Neurobiol. Aging 33, 1995-2005. doi: 10.1016/j.neurobiolaging.2011.09.026

Prada, C. M., Garcia-Alloza, M., Betensky, R. A., Zhang-Nunes, S. X., Greenberg, S. M., Bacskai, B. J., et al. (2007). Antibody-mediated clearance of amyloidbeta peptide from cerebral amyloid angiopathy revealed by quantitative in vivo imaging. J. Neurosci. 27, 1973-1980. doi: 10.1523/JNEUROSCI.542606.2007

Princz-Kranz, F. L., Mueggler, T., Knobloch, M., Nitsch, R. M., and Rudin, M. (2010). Vascular response to acetazolamide decreases as a function of age in the arcA beta mouse model of cerebral amyloidosis. Neurobiol. Dis. 40, 284-292. doi: 10.1016/j.nbd.2010.06.002

Radde, R., Bolmont, T., Kaeser, S. A., Coomaraswamy, J., Lindau, D., Stoltze, L., et al. (2006). Abeta42-driven cerebral amyloidosis in transgenic mice reveals early and robust pathology. EMBO Rep. 7, 940-946. doi: 10.1038/sj.embor.7400784

Rausch, M., Scheffler, K., Rudin, M., and Radü, E. W. (2000). Analysis of input functions from different arterial branches with gamma variate functions and cluster analysis for quantitative blood volume measurements. Magn. Reson. Imaging 18, 1235-1243. doi: 10.1016/S0730-725X(00)00219-8

Redwine, J. M., Kosofsky, B., Jacobs, R. E., Games, D., Reilly, J. F., Morrison, J. H., et al. (2003). Dentate gyrus volume is reduced before onset of plaque formation in PDAPP mice: a magnetic resonance microscopy and stereologic analysis. Proc. Natl. Acad. Sci. U.S.A. 100, 1381-1386. doi: 10.1073/pnas.2427 46599

Reese, T., Bochelen, D., Sauter, A., Beckmann, N., and Rudin, M. (1999). Magnetic resonance angiography of the rat cerebrovascular system without the use of contrast agents. NMR Biomed. 12, 189-196.

Reiman, E. M., Quiroz, Y. T., Fleisher, A. S., Chen, K., Velez-Pardo, C., JimenezDel-Rio, M., et al. (2012). Brain imaging and fluid biomarker analysis in young adults at genetic risk for autosomal dominant Alzheimer's disease in the presenilin 1 E280A kindred: a case-control study. Lancet Neurol. 11, 1048-1056. doi: 10.1016/S1474-4422(12)70228-4

Richards, J. G., Higgins, G. A., Ouagazzal, A. M., Ozmen, L., Kew, J. N., Bohrmann, B., et al. (2003). PS2APP transgenic mice, coexpressing hPS2mut and hAPPswe, show age-related cognitive deficits associated with discrete brain amyloid deposition and inflammation. J. Neurosci. 23, 8989-9003.

Robbins, E. M., Betensky, R. A., Domnitz, S. B., Purcell, S. M., Garcia-Alloza, M., Greenberg, C., et al. (2006). Kinetics of cerebral amyloid angiopathy progression 
in a transgenic mouse model of Alzheimer disease. J. Neurosci. 26, 365-371. doi: 10.1523/JNEUROSCI.3854-05.2006

Rockenstein, E., Mallory, M., Mante, M., Sisk, A., and Masliaha, E. (2001). Early formation of mature amyloid-beta protein deposits in a mutant APP transgenic model depends on levels of Abeta(1-42). J. Neurosci. Res. 66, 573-582. doi: 10.1002/jnr.1247

Roher, A. E., Esh, C., Kokjohn, T. A., Kalback, W., Luehrs, D. C., Seward, J. D., et al. (2003). Circle of willis atherosclerosis is a risk factor for sporadic Alzheimer's disease. Arterioscler. Thromb. Vasc. Biol. 23, 2055-2062. doi: 10.1161/01.ATV.0000095973.42032.44

Rojas, S., Herance, J. R., Gispert, J. D., Abad, S., Torrent, E., Jiménez, X., et al. (2013). In vivo evaluation of amyloid deposition and brain glucose metabolism of 5xFAD mice using positron emission tomography. Neurobiol. Aging 34, 1790-1798. doi: 10.1016/j.neurobiolaging.2012.12.027

Rönnbäck, A., Sagelius, H., Bergstedt, K. D., Näslund, J., Westermark, G. T., Winblad, B., et al. (2012). Amyloid neuropathology in the single Arctic APP transgenic model affects interconnected brain regions. Neurobiol. Aging 33, 831.e11-831.e19. doi: 10.1016/j.neurobiolaging.2011.07.012

Rönnbäck, A., Zhu, S., Dillner, K., Aoki, M., Lilius, L., Näslund, J., et al. (2011). Progressive neuropathology and cognitive decline in a single Arctic APP transgenic mouse model. Neurobiol. Aging 32, 280-292. doi: 10.1016/j.neurobiolaging.2009.02.021

Rupp, N. J., Wegenast-Braun, B. M., Radde, R., Calhoun, M. E., and Jucker, M. (2011). Early onset amyloid lesions lead to severe neuritic abnormalities and local, but not global neuron loss in APPPS1 transgenic mice. Neurobiol. Aging 32, 2324.e2321-2324.e2326. doi: 10.1016/j.neurobiolaging.2010.0 8.014

Rutgers, K. S., van Remoortere, A., van Buchem, M. A., Verrips, C. T., Greenberg, S. M., and Bacskai, B. J. (2009). Differential recognition of vascular and parenchymal beta amyloid deposition. Neurobiol. Aging 32, 1774-1783. doi: 10.1016/j.neurobiolaging.2009.11.012

Sadowski, M., Pankiewicz, J., Scholtzova, H., Yong, J., Quartermain, D., Jensen, C. H., et al. (2004). Amyloid-beta deposition is associated with decreased hippocampal glucose metabolism and spatial memory impairment in APP/PS1 mice. J. Neuropathol. Exp. Neurol. 63, 418-428.

Sanganahalli, B. G., Herman, P., Behar, K. L., Blumenfeld, H., Rothman, D. L., and Hyder, F. (2013). Functional MRI and neural responses in a rat model of Alzheimer's disease. Neuroimage 79, 404-411. doi: 10.1016/j.neuroimage.2013.04.099

SantaCruz, K., Lewis, J., Spires, T., Paulson, J., Kotilinek, L., Ingelsson, M., et al. (2005). Tau suppression in a neurodegenerative mouse model improves memory function. Science 309, 476-481. doi: 10.1126/science.1113694

Savonenko, A., Xu, G. M., Melnikova, T., Morton, J. L., Gonzales, V., Wong, M. P., et al. (2005). Episodic-like memory deficits in the APPswe/PS1dE9 mouse model of Alzheimer's disease: relationships to beta-amyloid deposition and neurotransmitter abnormalities. Neurobiol. Dis. 18, 602-617. doi: 10.1016/j.nbd.2004.10.022

Schmitz, C., Rutten, B. P., Pielen, A., Schäfer, S., Wirths, O., Tremp, G., et al. (2004). Hippocampal neuron loss exceeds amyloid plaque load in a transgenic mouse model of Alzheimer's disease. Am. J. Pathol. 164, 1495-1502. doi: 10.1016/S0002-9440(10)63235-X

Schroeter, S., Khan, K., Barbour, R., Doan, M., Chen, M., Guido, T., et al. (2008). Immunotherapy reduces vascular amyloid-beta in PDAPP mice. J. Neurosci. 28, 6787-6793. doi: 10.1523/JNEUROSCI.2377-07.2008

Schulz, K., Sydekum, E., Krueppel, R., Engelbrecht, C. J., Schlegel, F., Schröter, A., et al. (2012). Simultaneous BOLD fMRI and fiber-optic calcium recording in rat neocortex. Nat. Methods 9, 597-602. doi: 10.1038/nmeth.2013

Schwendele, B., Brawek, B., Hermes, M., and Garaschuk, O. (2012). Highresolution in vivo imaging of microglia using a versatile nongenetically encoded marker. Eur. J. Immunol. 42, 2187-2196. doi: 10.1002/eji.201 242436

Shibata, M., Ohtani, R., Ihara, M., and Tomimoto, H. (2004). White matter lesions and glial activation in a novel mouse model of chronic cerebral hypoperfusion. Stroke 35, 2598-2603. doi: 10.1161/01.STR.0000143725.19053.60

Smith, K. D., Kallhoff, V., Zheng, H., and Pautler, R. G. (2007). In vivo axonal transport rates decrease in a mouse model of Alzheimer's disease. Neuroimage 35, 1401-1408. doi: 10.1016/j.neuroimage.2007.01.046

Snellman, A., Lopez-Picon, F. R., Rokka, J., Salmona, M., Forloni, G., Scheinin, M., et al. (2013). Longitudinal amyloid imaging in mouse brain with 11C-PIB: comparison of APP23, Tg2576, and APPswe-PS1dE9 mouse models of Alzheimer disease. J. Nucl. Med. 54, 1434-1441. doi: 10.2967/jnumed.112.110163

Snowdon, D. A. (2003). Nun study, healthy aging and dementia: findings from the Nun study. Ann. Intern. Med. 139(5 Pt 2), 450-454. doi: 10.7326/0003-4819139-5_Part_2-200309021-00014

Song, S. K., Kim, J. H., Lin, S. J., Brendza, R. P., and Holtzman, D. M. (2004). Diffusion tensor imaging detects age-dependent white matter changes in a transgenic mouse model with amyloid deposition. Neurobiol. Dis. 15, 640-647. doi: 10.1016/j.nbd.2003.12.003

Sparks, D. L., Sabbagh, M., Connor, D., Soares, H., Lopez, J., Stankovic, G., et al. (2006). Statin therapy in Alzheimer's disease. Acta Neurol. Scand. Suppl. 185, 78-86. doi: 10.1111/j.1600-0404.2006.00689.x

Spencer, N. G., Bridges, L. R., Elderfield, K., Amir, K., Austen, B., and Howe, F. A. (2013). Quantitative evaluation of MRI and histological characteristics of the 5xFAD Alzheimer mouse brain. Neuroimage 76, 108-115. doi: 10.1016/j.neuroimage.2013.02.071

Sperling, R. A., Jack, C. R. Jr., Black, S. E., Frosch, M. P., Greenberg, S. M., Hyman, B. T., et al. (2011). Amyloid-related imaging abnormalities in amyloid-modifying therapeutic trials: recommendations from the Alzheimer's Association Research Roundtable Workgroup. Alzheimers Dement. 7, 367-385. doi: 10.1016/j.jalz.2011.05.2351

Spilman, P., Podlutskaya, N., Hart, M. J., Debnath, J., Gorostiza, O., Bredesen, D., et al. (2010). Inhibition of mTOR by rapamycin abolishes cognitive deficits and reduces amyloid-beta levels in a mouse model of Alzheimer's disease. PLoS ONE 5:e9979. doi: 10.1371/journal.pone.0009979

Starmans, L. W., van Duijnhoven, S. M., Rossin, R., Aime, S., Daemen, M. J., Nicolay, K., et al. (2013). SPECT imaging of fibrin using fibrin-binding peptides. Contrast Media Mol. Imaging 8, 229-237. doi: 10.1002/cmmi.1521

Starr, J. M., Farrall, A. J., Armitage, P., McGurn, B., and Wardlaw, J. (2009). Bloodbrain barrier permeability in Alzheimer's disease: a case-control MRI study. Psychiatry Res. 171, 232-241. doi: 10.1016/j.pscychresns.2008.04.003

Stover, K. R., and Brown, R. E. (2012). Age-related changes in visual acuity, learning and memory in the APPswe/PS1dE9 mouse model of Alzheimer's disease. Behav. Brain Res. 231, 75-85. doi: 10.1016/j.bbr. 2012.02.044

Sturchler-Pierrat, C., Abramowski, D., Duke, M., Wiederhold, K. H., Mistl, C., Rothacher, S., et al. (1997). Two amyloid precursor protein transgenic mouse models with Alzheimer disease-like pathology. Proc. Natl. Acad. Sci. U.S.A. 94, 13287-13292. doi: 10.1073/pnas.94.24.13287

Sun, S. W., Song, S. K., Harms, M. P., Lin, S. J., Holtzman, D. M., Merchant, K. M., et al. (2005). Detection of age-dependent brain injury in a mouse model of brain amyloidosis associated with Alzheimer's disease using magnetic resonance diffusion tensor imaging. Exp. Neurol. 191, 77-85. doi: 10.1016/j.expneurol.2004.09.006

Takano, T., Han, X., Deane, R., Zlokovic, B., and Nedergaard, M. (2007). Twophoton imaging of astrocytic $\mathrm{Ca} 2+$ signaling and the microvasculature in experimental mice models of Alzheimer's disease. Ann. N.Y. Acad. Sci. 1097, 40-50. doi: 10.1196/annals.1379.004

Takano, T., Tian, G. F., Peng, W., Lou, N., Libionka, W., and Han, X. (2006). Astrocyte-mediated control of cerebral blood flow. Nat. Neurosci. 9, 260-267. doi: $10.1038 / \mathrm{nn} 1623$

Takeda, S., Sato, N., Takeuchi, D., Kurinami, H., Shinohara, M., Niisato, K., et al. (2009). Angiotensin receptor blocker prevented beta-amyloid-induced cognitive impairment associated with recovery of neurovascular coupling. Hypertension 54, 1345-1352. doi: 10.1161/HYPERTENSIONAHA.109.138586

Talagala, S. L., Jungreis, C. A., Kanal, E., Meyers, S. P., Foo, T. K. F., Rubin, R. A., et al. (1995). Fast three-dimensional time-of-flight MR angiography of the intracranial vasculature. J. Magn. Reson. Imaging 5, 317-323. doi: 10.1002/jmri.1880050316

Tanghe, A., Termont, A., Merchiers, P., Schilling, S., Demuth, H. U., Scrocchi, L., et al. (2010). Pathological hallmarks, clinical parallels, and value for drug testing in Alzheimer's disease of the APP[V717I] London transgenic mouse model. Int. J. Alzheimers Dis. 2010:pii: 417314. doi: 10.4061/2010/417314

Thakker, D. R., Weatherspoon, M. R., Harrison, J., Keene, T. E., Lane, D. S., Kaemmerer, W. F., et al. (2009). Intracerebroventricular amyloid-beta antibodies reduce cerebral amyloid angiopathy and associated micro-hemorrhages in aged Tg2576 mice. Proc. Natl. Acad. Sci. U.S.A. 106, 4501-4506. doi: 10.1073/pnas.0813404106 
Thal, D. R., Capetillo-Zarate, E., Larionov, S., Staufenbiel, M., Zurbruegg, S., and Beckmann, N. (2009). Capillary cerebral amyloid angiopathy is associated with vessel occlusion and cerebral blood flow disturbances. Neurobiol. Aging 30, 1936-1948. doi: 10.1016/j.neurobiolaging.2008.01.017

Thal, D. R., Griffin, W. S., and Braak, H. (2008b). Parenchymal and vascular Abeta-deposition and its effects on the degeneration of neurons and cognition in Alzheimer's disease. J. Cell. Mol. Med. 12, 1848-1862. doi: 10.1111/j.15824934.2008.00411.x

Thal, D. R., Griffin, W. S., de Vos, R. A., and Ghebremedhin, E. (2008a). Cerebral amyloid angiopathy and its relationship to Alzheimer's disease. Acta Neuropathol. 115, 599-609. doi: 10.1007/s00401-008-0366-2

Thanopoulou, K., Fragkouli, A., Stylianopoulou, F., and Georgopoulos, S. (2010). Scavenger receptor class B type I (SR-BI) regulates perivascular macrophages and modifies amyloid pathology in an Alzheimer mouse model. Proc. Natl. Acad. Sci. U.S.A. 107, 20816-20821. doi: 10.1073/pnas.1005888107

Tofts, P. S., and Kernode, A. G. (1991). Measurement of the blood-brain barrier permeability and leakage space using dynamic MR imaging: 1. Fundamental concepts. Magn. Reson. Med. 17, 357-367. doi: 10.1002/mrm.1910170208

Tong, X. K., Lecrux, C., and Hamel, E. (2012). Age-dependent rescue by simvastatin of Alzheimer's disease cerebrovascular and memory deficits. J. Neurosci. 32, 4705-4715. doi: 10.1523/JNEUROSCI.0169-12.2012

Tong, X. K., Nicolakakis, N., Kocharyan,A., and Hamel, E. (2005). Vascular remodeling versus amyloid beta-induced oxidative stress in the cerebrovascular dysfunctions associated with Alzheimer's disease. J. Neurosci. 25, 11165-11174. doi: 10.1523/JNEUROSCI.4031-05.2005

Tropres, I., Grimault, S., Vaeth, A., Grillon, E., Julien, C., Payen, J. F., et al. (2001). Vessel size imaging. Magn. Reson. Med. 45, 397-408. doi: 10.1002/15222594(200103)45:3<397::AID-MRM1052>3.0.CO;2-3

van Assema, D. M., Lubberink, M., Bauer, M., van der Flier, W. M., Schuit, R. C., Windhorst, A. D., et al. (2012). Blood-brain barrier P-glycoprotein function in Alzheimer's disease. Brain 135(Pt 1), 181-189. doi: 10.1093/brain/awr298

van Dorpe, J., Smeijers, L., Dewachter, I., Nuyens, D., Spittaels, K., Van Den Haute, C., et al. (2000). Prominent cerebral amyloid angiopathy in transgenic mice overexpressing the London mutant of human APP in neurons. Am. J. Pathol. 157, 1283-1298. doi: 10.1016/S0002-9440(10)64644-5

Vanhoutte, G., Dewachter, I., Borghgraef, P., Van Leuven, F., and Van der Linden, A. (2005). Noninvasive in vivo MRI detection of neuritic plaques associated with iron in APP[V717I] transgenic mice, a model for Alzheimer's disease. Magn. Reson. Med. 53, 607-613. doi: 10.1002/mrm.20385

Venneti, S., Lopresti, B. J., Wang, G., Hamilton, R. L., Mathis, C. A., and Klunk, W. E. (2009). PK11195 labels activated microglia in Alzheimer's disease and in vivo in a mouse model using PET. Neurobiol. Aging 30, 1217-1226. doi: 10.1016/j.neurobiolaging.2007.11.005

Villringer, A., Rosen, B. R., Bellieau, J. W., Ackerman, J. L., Lauffer, R. B., Buxton, R. B., et al. (1998). Dynamic imaging with lanthanide chelates in normal brain contrast due to magnetic susceptibility effects. Magn. Res. Med. 6, 164-174. doi: 10.1002/mrm.1910060205

Vinters, H. V. (1987). Cerebral amyloid angiopathy. A critical review. Stroke 18, 311-324. doi: 10.1161/01.STR.18.2.311

Vinters, H. V., Natté, R., Maat-Schieman, M. L., van Duinen, S. G., HegemanKleinn, I., Welling-Graafland, C., et al. (1998). Secondary microvascular degeneration in amyloid angiopathy of patients with hereditary cerebral hemorrhage with amyloidosis, Dutch type (HCHWA-D). Acta Neuropathol. (Berl.) 95, 235-244. doi: 10.1007/s004010050793

Vom Berg, J., Prokop, S., Miller, K. R., Obst, J., Kalin, R. E., Lopategui-Cabezas, I., et al. (2012). Inhibition of IL-12/IL-23 signaling reduces Alzheimer's disease-like pathology and cognitive decline. Nat. Med. 18, 1812-1819. doi: 10.1038/nm.2965

Vromman, A., Trabelsi, N., Rouxel, C., Béréziat, G., Limon, I., and Blaise, R. (2013). $\beta$-Amyloid context intensifies vascular smooth muscle cells induced inflammatory response and de-differentiation. Aging Cell 12, 358-369. doi: 10.1111/acel.12056

Wang, F. H., Appelkvist, P., Klason, T., Gissberg, O., Bogstedt, A., Eliason, K., et al. (2012c). Decreased axonal transport rates in the Tg2576 APP transgenic mouse: improvement with the gamma-secretase inhibitor MRK-560 as detected by manganese-enhanced MRI. Eur. J. Neurosci. 36, 3165-3172. doi: 10.1111/j.1460-9568.2012.08258.x

Wang, H., He, J., Zhang, R., Zhu, S., Wang, J., Kong, L., et al. (2012a). Sensorimotor gating and memory deficits in an APP/PS1 double transgenic mouse model of Alzheimer's disease. Behav. Brain Res. 233, 237-243. doi: 10.1016/j.bbr.2012.05.007

Wang, J., Ho, L., Chen, L., Zhao, Z., Zhao, W., Qian, X., et al. (2007). Valsartan lowers brain b-amyloid protein levels and improves spatial learning in a mouse model of Alzheimer disease. J. Clin. Invest. 117, 3393-3402. doi: 10.1172/ JCI31547

Wang, M., Iliff, J. J., Liao, Y., Chen, M. J., Shinseki, M. S., Venkataraman, A., et al. (2012b). Cognitive deficits and delayed neuronal loss in a mouse model of multiple microinfarcts. J. Neurosci. 32, 17948-17960. doi: 10.1523/JNEUROSCI. 1860-12.2012

Washida, K., Ihara, M., Nishio, K., Fujita, Y., Maki, T., Yamada, M., et al. (2010). Nonhypotensive dose of telmisartan attenuates cognitive impairment partially due to peroxisome proliferator-activated receptor-gamma activation in mice with chronic cerebral hypoperfusion. Stroke 41, 1798-1806. doi: 10.1161/STROKEAHA.110.583948

Watts, J. C., Giles, K., Grillo, S. K., Lemus, A., DeArmond, S. J., and Prusiner, S. B. (2011). Bioluminescence imaging of Abeta deposition in bigenic mouse models of Alzheimer's disease. Proc. Natl. Acad. Sci. U.S.A. 108, 2528-2533. doi: 10.1073/pnas. 1019034108

Wegiel, J., Imaki, H., Wang, K. C., Wegiel, J., and Rubenstein, R. (2004). Cells of monocyte/microglial lineage are involved in both microvessel amyloidosis and fibrillar plaque formation in APPsw tg mice. Brain Res. 1022, 19-29. doi: 10.1016/j.brainres.2004.06.058

Weidensteiner, C., Metzger, F., Bruns, A., Bohrmann, B., Kuennecke, B., and von Kienlin, M. (2009). Cortical hypoperfusion in the B6.PS2APP mouse model for Alzheimer's disease: comprehensive phenotyping of vascular and tissular parameters by MRI. Magn. Reson. Med. 62, 35-45. doi: 10.1002/mrm.21985

Weiss, C., Venkatasubramanian, P. N., Aguado, A. S., Power, J. M., Tom, B. C., Li, L., et al. (2002). Impaired eyeblink conditioning and decreased hippocampal volume in PDAPP V717F mice. Neurobiol. Dis. 11, 425-433. doi: 10.1006/nbdi.2002.0555

Weissleder, R., Elizondo, G., Wittenberg, J., Rabito, C., Bengele, H., and Josephson, L. (1990). Ultrasmall superparamagnetic iron oxide: characterization of a new class of contrast agents for MR imaging. Radiology 175, 489-493.

Weller, R. O. (1998). Cerebral amyloid angiopathy: amyloid $\beta$ accumulates in putative interstitial fluid drainage pathways in Alzheimer's disease. Am. J. Pathol. 153, 725-733. doi: 10.1016/S0002-9440(10)65616-7

Weller, R. O., Boche, D., and Nicoll, J. A. (2009). Microvasculature changes and cerebral amyloid angiopathy in Alzheimer's disease and their potential impact on therapy. Acta Neuropathol. 118, 87-102. doi: 10.1007/s00401-0090498-z

Wilcock, D. M., Alamed, J., Gottschall, P. E., Grimm, J., Rosenthal, A., Pons, J., et al. (2006). Deglycosylated anti-amyloid- $\beta$ antibodies eliminate cognitive deficits and reduce parenchymal amyloid with minimal vascular consequences in aged amyloid precursor protein transgenic mice. J. Neurosci. 26, 5340-5346. doi: 10.1523/JNEUROSCI.0695-06.2006

Wilcock, D. M., Morgan, D., Gordon, M. N., Taylor, T. L., Ridnour, L. A., Wink, D. A., et al. (2011). Activation of matrix metalloproteinases following anti-A $\beta$ immunotherapy; implications for microhemorrhage occurrence. J. Neuroinflammation 8, 115. doi: 10.1186/1742-2094-8-115

Wilcock, D. M., Rojiani, A., Rosenthal, A., Levkowitz, G., Subbarao, S., and Alamed, J. (2004b). Passive amyloid immunotherapy clears amyloid and transiently activates microglia in a transgenic mouse model of amyloid deposition. J. Neurosci. 24, 6144-6151. doi: 10.1523/JNEUROSCI.1090-04.2004

Wilcock, D. M., Rojiani, A., Rosenthal, A., Subbarao, S., Freeman, M. J., Gordon, M. N., et al. (2004a). Passive immunotherapy against A $\beta$ in aged APP transgenic mice reverses cognitive deficits and depletes parenchymal amyloid deposits in spite of increased vascular amyloid and microhemorrhage. J. Neuroinflammation 1, 24. doi: 10.1186/1742-2094-1-24

Williams, D. S., Detre, J. A., Leigh, J. S., and Koretsky, A. P. (1992). Magnetic resonance imaging of perfusion using spin inversion of arterial water. Proc. Natl. Acad. Sci. U.S.A. 89, 212-216. doi: 10.1073/pnas.89.1.212

Winkler, D. T., Bondolfi, L., Herzig, M. C., Jann, L., Calhoun, M. E., Wiederhold, K. H., et al. (2001). Spontaneous hemorrhagic stroke in a mouse model of cerebral amyloid angiopathy. J. Neurosci. 21, 1619-1627.

Wolozin, B., Kellman, W., Ruosseau, P., Celesia, G. G., and Siegel, G. (2000). Decreased prevalence of Alzheimer disease associated with 3-hydroxy-3-methyglutaryl coenzyme A reductase inhibitors. Arch. Neurol. 57, 1439-1443. doi: 10.1001/archneur.57.10.1439 
Wong, D. F., Rosenberg, P. B., Zhou, Y., Kumar, A., Raymont, V., Ravert, H. T., et al. (2010). In vivo imaging of amyloid deposition in Alzheimer disease using the radioligand 18F-AV-45 (florbetapir [corrected] F 18). J. Nucl. Med. 51, 913-920. doi: 10.2967/jnumed.109.069088

Woolley, M. L., and Ballard, T. M. (2005). Age-related impairments in operant DMTP performance in the PS2APP mouse, a transgenic mouse model of Alzheimer's disease. Behav. Brain Res. 161, 220-228. doi: 10.1016/j.bbr.2005.02.007

Wright, A. L., Zinn, R., Hohensinn, B., Konen, L. M., Beynon, S. B., Tan, R. P., et al. (2013). Neuroinflammation and neuronal loss precede $A \beta$ plaque deposition in the hAPP-J20 mouse model of Alzheimer's disease. PLoS ONE 8:e59586. doi: 10.1371/journal.pone.0059586

Wu, E. X., Tang, H., Asai, T., and Yan, S. D. (2004). Regional cerebral blood volume reduction in transgenic mutant APP (V717F, K670N/M671L) mice. Neurosci. Lett. 365, 223-227. doi: 10.1016/j.neulet.2004.05.004

Wunder, A., and Klohs, J. (2008). Optical imaging of vascular pathophysiology. Basic Res. Cardiol. 103, 182-190. doi: 10.1007/s00395-008-0712-5

Wunder, A., Klohs, J., and Dirnagl, U. (2009). Non-invasive visualization of CNS inflammation with nuclear and optical imaging. Neuroscience 158, 1161-1173. doi: 10.1016/j.neuroscience.2008.10.005

Xiong, H., Callaghan, D., Jones, A., Bai, J., Rasquinha, I., Smith, C., et al. (2009). ABCG2 is upregulated in Alzheimer's brain with cerebral amyloid angiopathy and may act as a gatekeeper at the blood-brain barrier for Abeta(1-40) peptides. J. Neurosci. 29, 5463-5475. doi: 10.1523/JNEUROSCI.5103-08.2009

Xu, F., Grande, A. M., Robinson, J. K., Previti, M. L., Vasek, M., Davis, J., et al. (2007). Early-onset subicular microvascular amyloid and neuroinflammation correlate with behavioral deficits in vasculotropic mutant amyloid beta-protein precursor transgenic mice. Neuroscience 146, 98-107. doi: 10.1016/j.neuroscience.2007.01.043

Yang, J., Ji, Y., Mehta, P., Bates, K. A., Sun, Y., and Wisniewski, T. (2011). Blocking the ApolipoproteinE/Amyloid-b interaction reduces fibrillar vascular amyloid deposition and cerebral microhemorrhages in TgSwDI mice. J. Alzheimers Dis. 24, 269-285. doi: 10.3233/JAD-2011-101401

Yarchoan, M., Xie, S. X., Kling, M. A., Toledo, J. B., Wolk, D. A., Lee, E. B., et al. (2012). Cerebrovascular atherosclerosis correlates with Alzheimer pathology in neurodegenerative dementias. Brain 135, 3749-3756. doi: 10.1093/brain/aws271

Zha, Z., Choi, S. R., Ploessl, K., Lieberman, B. P., Qu, W., Hefti, F., et al. (2011). Multidentate (18)F-polypegylated styrylpyridines as imaging agents for $\mathrm{A} \beta$ plaques in cerebral amyloid angiopathy (CAA). J. Med. Chem. 54, 8085-8098. doi: $10.1021 / j \mathrm{~m} 2009106$

Zhang, W., Mojsilovic-Petrovic, J., Andrade, M. F., Zhang, H., Ball, M., and Stanimirovic, D. B. (2003). Expression and functional characterization of ABCG2 in brain endothelial cells and vessels. FASEB J. 17, 2085-2087. doi: 10.1096/fj.02-1131fje

Conflict of Interest Statement: Nicolau Beckmann and Derya R. Shimshek are employees of Novartis Pharma AG, Basel, Switzerland. The other authors declare that the research was conducted in the absence of any commercial or financial relationships that could be construed as a potential conflict of interest.

Received: 25 October 2013; accepted: 19 February 2014; published online: 13 March 2014.

Citation: Klohs J, Rudin M, Shimshek DR and Beckmann N (2014) Imaging of cerebrovascular pathology in animal models of Alzheimer's disease. Front. Aging Neurosci. 6:32. doi: 10.3389/fnagi.2014.00032

This article was submitted to the journal Frontiers in Aging Neuroscience.

Copyright (C) 2014 Klohs, Rudin, Shimshek and Beckmann. This is an open-access article distributed under the terms of the Creative Commons Attribution License (CC BY). The use, distribution or reproduction in other forums is permitted, provided the original author(s) or licensor are credited and that the original publication in this journal is cited, in accordance with accepted academic practice. No use, distribution or reproduction is permitted which does not comply with these terms. 